\title{
THE RELATIONSHIP BETWEEN TEACHER STRESS AND JOB SATISFACTION AS MODERATED BY COPING USING SINGLE-ITEM MEASURES
}

\begin{tabular}{l} 
A Dissertation presented to \\
the Faculty of the Graduate School \\
at the University of Missouri \\
\hline In Partial Fulfillment \\
of the Requirements for the Degree \\
Doctor of Education \\
by \\
Seth Woods \\
University of Missouri \\
Dr. James Sebastian, Dissertation Supervisor \\
JULY 2021
\end{tabular}


The undersigned, appointed by the Dean of the Graduate Faculty, have examined a dissertation entitled:

\section{THE RELATIONSHIP BETWEEN TEACHER STRESS AND JOB SATISFACTION AS MODERATED BY COPING USING SINGLE-ITEM MEASURES}

Presented by Seth Woods, a candidate for the degree of Doctor Of Education, and hereby certify that, in their opinion, it is worthy of acceptance.

Dr. James Sebastian

Dr. Lisa Dorner

Dr. Keith Herman

Dr. Beth Whitaker

Dr. Todd Whitaker 


\section{ACKNOWLEDGEMENTS}

I would like to begin by thanking my family. Jayne, my wife, and my two children, Brynn and Blake. I have nearly been an absentee husband and father for the last four years as I have pursued this degree, and the three of you are the biggest reason I made it to the end. Thank you for supporting me, inspiring me, listening to me, and for being so understanding when I spent late nights and weekends completing my work. I love you all and I am beyond lucky to have you.

I would also like to thank the member of my Columbia cohort. I learned from you and grew as a person, as a leader, and as a scholar because of my experiences learning with such awesome people. Best wishes to you all!

Thank you to my committee, Dr. Dorner, Dr. Herman, Dr. Beth Whitaker, and Dr. Todd Whitaker. I appreciate how much you helped me to push further into my research and to develop the best possible work that I could. Thank you for your time and your investment in me.

Finally, I would like to thank Dr. Sebastian. Thank you for making sure I did my work to the best of my ability. Thank you for knowing when I could do better work and expecting me to do so while also encouraging me when the work was done well. I cannot thank you enough for the work that you did to help me persevere and complete my work. 


\section{TABLE OF CONTENTS}

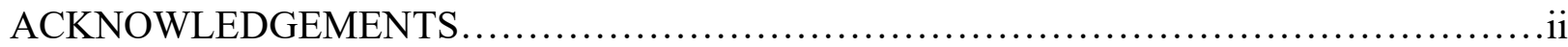

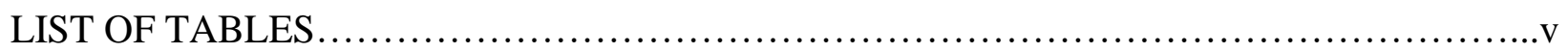

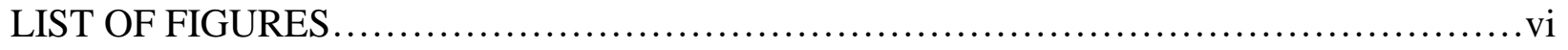

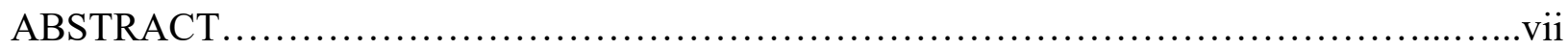

Section

1. INTRODUCTION TO THE DISSERTATION-IN-PRACTICE $\ldots \ldots \ldots \ldots \ldots \ldots \ldots \ldots \ldots \ldots$

Purpose of the Study .......................................................

Theoretical Frameworks................................................ 11

Research Question...................................................13

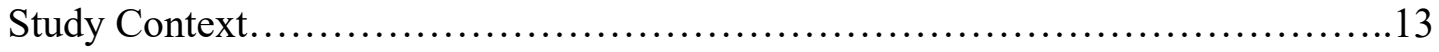

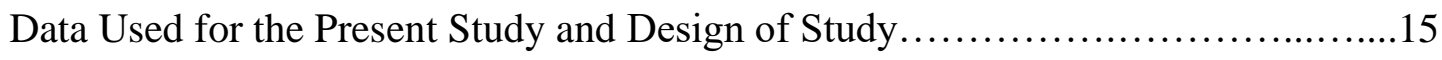

Significance of the Study ............................................. 21

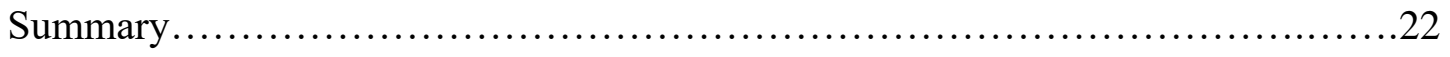

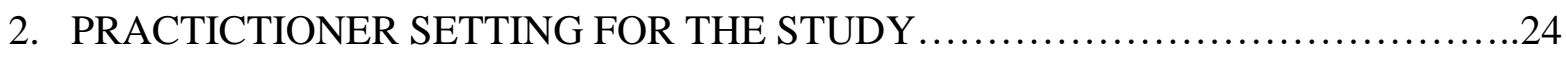

History of the Organization............................................. 28

Organizational Analysis...............................................29

Leadership Analysis................................................... 37

Implications for Research in the Practitioner Setting ..........................41

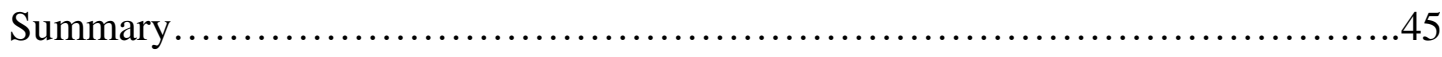

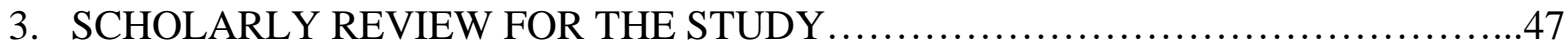

Introduction to the Problem............................................48

Review of Literature.................................................... 50 
Theoretical Framework................................................68

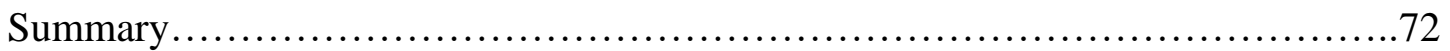

4. CONTRIBUTION TO PRACTICE......................................... 73

Article for Practitioner Journal..........................................75

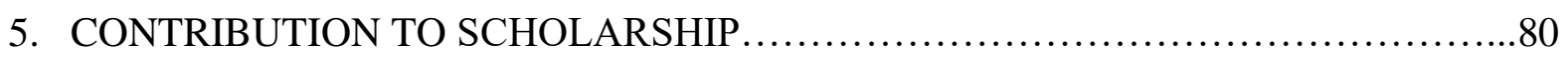

Article for Research Journal..........................................82

6. SCHOLARLY PRACTICTIONER REFLECTION ................................ 122

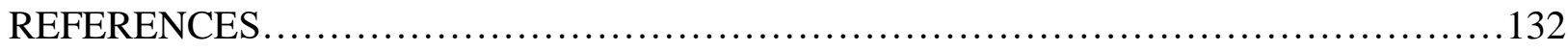

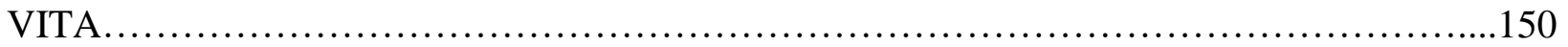




\section{LIST OF TABLES}

\section{TABLES}

1. Table 1. Percentage of teachers' responses to "I usually look forward to each working day." From the CPS Climate Survey, years 2016-2019.............................30

2. Table 2. Percentage of teachers' responses to "Generally speaking, I have the resources I need to do my job." From the CPS Climate Survey, years 2016-2019 .................35

3. Table 3. Descriptive Statistics................................................... 100

4. Table 4. Correlational Analysis....................................................

5. Table 5. Simple and Multiple Regression Analyses of the Relationship Between Stress

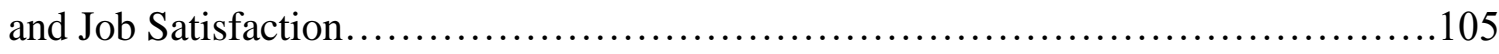

6. Table 6. Fixed Effects Regression Analysis of the Relationship Between Coping and Job Satisfaction.

7. Table 7. Fixed Effects Moderation Regression Analysis of the Relationship Between Stress, Coping and Job Satisfaction............................................ 110

8. Table 8. Simple Slopes Outputs of the Relationship Between Stress, Coping and Job Satisfaction. 


\section{LIST OF FIGURES}

\section{FIGURES}

1. Figure 1. Proposed conceptual model of stress based on the Job Demands-Resources

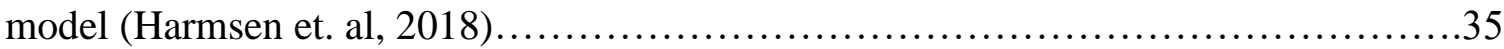

2. Figure 2. Lazarus and Folkman (1984) Transactional Model of Stress.................70

3. Figure 3. Teacher Ratings of Stress Using Single-Item Measure......................101

4. Figure 4. Teacher Ratings of Coping Using Single-Item Measure.....................101

5. Figure 5. Teacher Ratings of Job Satisfaction Using Single-Item Measure..............102

6. Figure 6. Simple Slopes Graphs of the Relationship Between Stress, Coping and Job Satisfaction 


\title{
THE RELATIONSHIP BETWEEN TEACHER STRESS AND JOB SATISFACTION AS MODERATED BY COPING USING SINGLE-ITEM MEASURES
}

\author{
Seth Timothy Woods
}

Dr. James Sebastian, Dissertation Supervisor

\begin{abstract}
Teacher stress has been studied for decades and the negative outcomes of too much stress are well known, such as burnout and lack of teacher retention. The present study focuses on the relationship between teacher stress and teacher job satisfaction. The Transactional Model of stress specifies that coping must be accounted for when considering a person's stress reaction, as a person's coping capacity or resources are what determines whether stress reaction will occur. The present study seeks to answer the question: Does coping moderate the relationship between teacher stress and job satisfaction? Moderation analysis was conducted using data from randomized trials examining a leadership training program. The results showed that coping moderated the relationship between stress and job satisfaction. Adding to the importance of this study for practitioners is that all three constructs (stress, coping, and job satisfaction) were measured using single items, making it easy for practitioners to measure among their staff.
\end{abstract}


SECTION ONE:

INTRODUCTION TO THE DISSERTATION-IN-PRACTICE 


\section{Importance of the Study}

Teacher retention continues to be a significant problem in K-12 education (Goldring, Taie, \& Riddles, 2014; Inman \& Marlow, 2004; Dunn, 2018; Chambers Mack, Johnson, JonesRincon, Tsatenawa, \& Howard, 2019). Many studies suggest that between 25 and 50\% of teachers do not continue to teach beyond their first 3 years of teaching (Blatt, 2016; Boe, Cook, \& Sunderland, 2008; Inman \& Marlow, 2004). The Missouri Department of Elementary and Secondary Education reports that 3-year and 5-year teacher retention rates are 63.4\% (in 20152016) and 34.6\% (in 2014-2015), respectively (Missouri Department of Elementary and Secondary Education, 2018). These figures not only represent a problem of maintaining continuity within school staff, but they also represent a significant financial burden for school systems. Borman and Dowling (2006) estimated that recruitment, hiring, and training new teachers is costing $\$ 2.2$ billion annually. In addition to the financial repercussions, schools that experience high levels of teacher turnover will also see this manifest in decreased student progress and achievement (Dolton \& Newson, 2003). Clearly teacher retention in the state of Missouri and nationwide has become a significant problem of practice for principals, teachers, and state-level education officials.

One important influencer of teacher retention is job satisfaction. Because of its importance, much research has been devoted to examining teacher job satisfaction, its causes, and its effects on teachers. Teachers' job satisfaction has been directly connected to teacher retention (Skaalvik \& Skaalvik, 2011), and it has also been tied to teachers' decisions about whether or not to stay in the teaching profession at all (Klassen \& Chiu, 2011; McCarthy, Lambert, Crowe, \& McCarthy, 2010). Adding to the importance of job satisfaction, research has shown that teachers who are satisfied tend to stay in their position. McCarthy, Lambert, and 
Reiser (2014) found that as job satisfaction increased, teacher plans to leave their current position decreased significantly. Job satisfaction also influences other aspects of teachers' work. It has been shown to have a positive effect on overall job performance (Wolomasi, Asaloei, \& Werang, 2019), effective use of classroom management (Kaya \& Selvitupo, 2019), teacher subjective well-being (Judge \& Watanabe, 1993), and teacher self-concept (Skaalvik \& Skaalvik, 2017). This research makes it clear that job satisfaction is an integral part of not only retaining teachers, but also in helping teachers be successful.

Unfortunately, there is evidence that teacher job satisfaction is dwindling. A 2012 Met Life survey discovered that only $39 \%$ of teachers reported themselves as very satisfied, the lowest proportion in 25 years (Metlife, 2012). However, the 2018 Teaching and Learning International Survey (TALIS) by the Organisation for Economic Co-operation and Development (OECD) found that 90\% of United States teachers in grades 7-9 are satisfied with their job, though 36\% believe they are undervalued by society (Schleicher, 2018). Regardless of which study is most accurate, it is still imperative that practitioners understand the factors that influence job satisfaction among their teachers. In Herzberg's (1966) work regarding job satisfaction, he identified stress as an influencer of lower job satisfaction. There were also specific factors that prevent dissatisfaction, such as peer relationships, salary, organizational policies, and supervision. Herzberg's (1966) prevention factors, unfortunately, are also closely aligned with known stressors for teachers. Those stressors include classroom management difficulties, time pressure and workload concerns, adjusting to change, teacher evaluation, peer relationships, selfesteem and status, working with administration, role conflict/ambiguity, and poor working conditions (Kyriacou, 2001; Travers \& Cooper, 1996). Many of these sources of stress are also on the list of factors that could prevent dissatisfaction (Herzberg, 1966) if they were not stressors 
for teachers. Unfortunately, all those sources of stress could be creating more dissatisfaction according to Herzberg (1966).

In general, stress among teachers is commonplace and is becoming an increasingly significant problem. Of course, there can also be positive effects from stress. Eustress is defined as "the positive psychological response to a stressor, indicated by the presence of positive psychological states." (Hargrove, Nelson, \& Cooper, 2013, p. 61) Eustress is experienced by those workers who are fully immersed in their task and derive satisfaction from it (Hargrove, Nelson, \& Cooper, 2013). One helpful explanation of this distinction comes from the Challenge Hindrance Framework (CHF) put forth by Cavanaugh, Boswell, Roehling, and Boudreau (2000). CHF explains that challenge stressors are those that help accomplish job tasks and promote the development of the individual facing these challenge stressors. These challenge stressors generally promote positive attitudes and positive outcomes for the organization, such as motivation to learn, commitment to the organization, and increased job satisfaction. On the other hand, hindrance stressors are those that are deemed as impediments to accomplishing job tasks or personal development (Hargrove, Nelson, \& Cooper, 2013).

Unfortunately, many of the stressors faced by teachers would fall in the hindrance stressor category. Demands on time, increasing class sizes, student behavior problems, conflict with other staff, and inadequate resources (both materials and buildings) can all be contributors to teacher stress (Wiley, 2000). All of these would be examples of hindrance stressors because they are impediments to accomplishing job tasks (Hargrove, Nelson, \& Cooper, 2013). The stress levels experienced by teachers are similar to those levels experienced by ambulance workers, police, and prison officers (Johnson et al., 2005). Stress and burnout among teachers are negatively related to job satisfaction (Avanzi et al., 2017; Ingersoll, 2001; Liu \& Ramsey, 2008; 
Richards, 2012; Watson, Harper, Ratliff, and Singleton, 2010) and teacher turnover intention (Hultell, Melin, \& Gustavsson, 2013; Kyriacou, 2001; Skaalvik \& Skaalvik, 2015; Skaalvik \& Skaalvik, 2010). This makes stress a serious threat to both job satisfaction and teacher retention. Stress for teachers can come from a multitude of sources. Demands on time, increasing class sizes, student behavior problems, conflict with other staff, and inadequate resources (both materials and buildings) can all be contributors to teacher stress (Wiley, 2000). Other potential stressors for teachers, such as working conditions, staff collegiality, and administrative support, all can have a significant effect on job satisfaction (or dissatisfaction) (Shen, Leslie, Spybrook, \& Ma, 2012). These sources of stress closely align with Herzberg's (1966) list of factors that are influencers of job dissatisfaction and with hindrance stressors. If these factors are influencing people negatively, then Herzberg (1966) contends that job dissatisfaction will increase and CHF (2000) would contend that these could cause more negative outcomes for both the individual teacher and their organization.

The question, then, is what do teachers do about stress? The way teachers manage their stress is called coping. Coping is defined as "all of the cognitive and behavioral efforts, constantly changing, expended (by one person) to manage the internal and/or external demands perceived as consuming or exceeding his resources" (Lazarus \& Folkman, 1984, p. 141). One teacher may have high stress, but also high coping strength, while another teacher may also have high stress but inadequate coping strength. These two teachers will likely experience very different outcomes because of the differences in their coping capacity (Herman, Hickman Rosa, \& Reinke, 2018; Richards, 2012).

Many studies have examined the combined effects of teacher stress and coping and generally conclude that stress is part of every teacher's job. They also contend that stress 
influences a variety of outcomes and that coping can play a role in how stress influences those outcomes. For example, outcomes that were specifically examined were student achievement, student behavior issues (Herman et al., 2018), burnout (Antoniou, Ploumpi, \& Ntalla; 2013), job satisfaction and intention to leave the profession (Klassen \& Chiu, 2011), and physical symptoms (Skaalvik \& Skaalvik, 2015). These outcomes can be influenced by the teacher's coping capacity or style (Antoniou, Ploumpi, \& Ntalla, 2013; Herman, et al., 2018; Laugaa, Rascale, Bruchon-Schweitzer, 2008). However, few studies have examined all three of stress, coping, and job satisfaction among teachers. Among the studies that have, McCarthy, Lambert, and Reiser (2014) and McCarthy, Lambert, Crowe, and McCarthy (2010) utilized a measurement scale called the Classroom Appraisal of Demands and Resources (CARD) as a way to measure demands and resources. The authors described the CARD as "a measure of teacher stress that is grounded in transactional models of stress and coping in that it measures teacher's perceptions of both classroom resources and demands." (McCarthy et al., 2010, p. 311) The CARD measured teacher perceptions of their demands and resources to classify the teachers into three groups (demands equal to resources, demands exceeding resources, and demands less than resources). Those in the under-resourced group experienced more burnout symptoms and statistically significantly lower job satisfaction scores than those teachers in the other two groups. In addition, the CARD has been described by McCarthy et al. (2015) as an appraisal of whether a teacher will experience stress based upon the demands the teacher experiences and the resources they can use to deal with those demands. Also, the CARD represents a finite list of potential demands/stressors and resources/coping resources instead of a more wholistic measure of overall stress and coping, and therefore may be unintentionally leaving out relevant stressors or coping 
resources, while single-item measures of stress and coping could be more all-encompassing (Scarpello \& Campbell, 1983).

While coping has been examined in many studies examining teacher stress, it has not always played the role of a moderator for job satisfaction. Using coping as a moderator when examining the impact of stress on other outcomes has been supported by studies for outcomes such as academic achievement, disruptive behaviors (Herman, et al., 2018) and teacher burnout (Antoniou, Ploumpi, \& Ntalla, 2013; Laugaa, Rascale, Bruchon-Schweitzer, 2008). Herman et al. (2018) found that teachers who were highly stressed and had low coping resources had the highest rates of student behavior problems and the lowest academic achievement. Antoniou, Ploumpi, and Ntalla (2013) found that positive coping strategies were positive predictors of lower levels of burnout characteristics, a finding that was echoed by Laugaa, Rascale, and Bruchon-Schweitzer (2008). Using coping as a moderator when examining its relationship to stress and other outcomes also has theoretical support, as it is seen as a moderator in the transactional model of stress put forth by Lazarus and Folkman (1984). This model suggests that any time an individual encounters a life demand, a cognitive process is begun in which the individual weighs the demands of the task against his or her perceived ability to cope with the demand. However, the theory does not employ coping as a moderator to specifically examine job satisfaction. The present literature is lacking in studies that have examined coping as a moderator in the relationship between overall stress and job satisfaction. The McCarthy, Lambert, \& Reiser (2014) study concluded that the CARD score (which they called the appraisal index) and job satisfaction were significantly and positively correlated. The McCarthy et al. (2010) study found that increased resources were positively associated with job satisfaction and increased demands were negatively associated with job satisfaction, but it did not specifically measure overall stress 
and utilize overall coping as a moderator. In brief, although there is support in literature and theoretical support for coping moderating the effects of stress, there are few empirical studies that examine the effect of coping on the relationship between stress and job satisfaction. Some studies have examined the relationship between stress and job satisfaction, but do not include coping at all such as Klassen and Chiu (2010) who found that teachers with $10 \%$ greater teaching stress had approximately $2 \%$ lower job satisfaction. What did this literature find. What about studies that have looked at only coping and satisfaction. Studies connecting coping and job satisfaction among teachers are few in number. McCarthy, Lambert, Crowe, and McCarthy (2010) conducted one such study. They found when teachers have lower levels of personal resources for stress prevention that they tend to experience a decrease in job satisfaction. It has also been shown that, among university employees, positive coping strategies (direct action techniques) are positively correlated with job satisfaction, while negative coping strategies (palliative techniques) are negatively correlated with job satisfaction (Mark \& Smith, 2012). A study of employees across 75 different jobs found that higher coping resources were predictive of lower strain and higher job satisfaction (Decker \& Borgen, 1993). In a study of medical interns, Vinothkumar et al. (2016) explained that physicians who utilize positive coping strategies tend to have higher levels of job satisfaction. Srivistava and Tang (2018) reached a similar finding among sales professionals, finding that problem-focused coping had a positive and significant relationship with job satisfaction. While not all of the research connecting coping and job satisfaction is focused on teachers, it is clear that coping has an influence on the job satisfaction by workers in general.

The researcher was unable to find studies focus on the relationship between stress and job satisfaction while utilizing coping as a moderator, other than the Skaalvik and Skaalvik (2015), 
which was qualitative in nature. This represents a critical gap in research considering the importance of job satisfaction for teacher retention and the close relationship between stress and coping. Further, those studies that did focus on the relationship between stress, coping, and job satisfaction (McCarthy, Lambert, \& Reiser, 2014; McCarthy et al., 2010) utilized a variety of measurement tools to measure stress, coping, and job satisfaction that required participants to complete surveys consisting of dozens of items in total. The present study utilized single-item measures. Shortening surveys can improve response rates and minimize non-response bias (Rogelberg \& Stanton, 2007; Stanton, Sinar, Balzer, \& Smith, 2002), making single-item measures particularly advantageous. The use of single-item measures can also help facilitate the use of more frequent surveying because of the reduced load on participants (Fisher, Matthews, \& Gibbons, 2016). In addition, Scarpello and Campbell (1983) explained that the use of multi-item scales may not be ideal because they can either include items that are not relevant to the construct being measured or they could omit items that are relevant. This means single-item measures may be more inclusive than scales (Scarpello \& Campbell, 1983).

\section{Purpose of the Study}

The present study will further the line of research that examines the relationship between stress and job satisfaction of teachers by including coping as a moderator. Even though there are studies that examine stress, coping, and job satisfaction together, no study has examined empirically how coping moderates the relationship between stress and job satisfaction. Skaalvik and Skaalvik (2015) did a qualitative study related to stress, coping, and job satisfaction, but they stopped short of saying coping was moderating the relationship between stress and satisfaction. Instead, they focused on teachers at different stages of their careers and how they recovered from the stress of their jobs, such as taking vacations, using sick leave, reduction in work time, leaving 
the profession, or taking a disability pension. The present study can also be considered a replication study examining the relationship between stress and satisfaction. Replication studies have long been considered an integral part of research design (Fisher, 1935). Polio and Gass (1997) identified two types of replication studies: exact and conceptual. Exact replication is intended to exactly duplicate every detail of a prior study to test that original study's findings. Conceptual replication, though, may have methodological variations from the original study, but still can test the generalizability of the original study's hypothesis (Polio \& Gass, 1997). The present study would be considered somewhat of a conceptual replication study of the work of McCarthy, Lambert, and Rieser (2014) and McCarthy et al. (2010) because of differences in methodology and measurement. However, McCarthy et al. (2015) described the CARD as an appraisal of whether a teacher will experience stress based upon the demands the teacher experiences and the resources they can use to deal with those demands, so the present study is not a true replication.

Prior research that has measured stress, coping, and job satisfaction utilized scales with multiple (sometimes many dozens of) items (Antoniou, Ploumpi, \& Ntalla, 2013; Foley \& Murphy, 2015; Laugaa, Rascle, \& Bruchon-Schweitzer, 2008; McCarthy, Lambert, \& Reiser, 2014; McCarthy, Lambert, Crowe, \& McCarthy, 2010; Salkovsky, Romi, \& Lewis, 2015; Smetackova et al., 2019). The present study will use single-item measures. Further, none of the prior studies utilized coping as a moderator to empirically measure the relationship between stress and job satisfaction. Above adding to the literature on connecting stress and job satisfaction, this study will also add to the literature that utilizes single-item measures. Several studies have utilized single-item measures of stress (see for example..Boyle, Berg, Falzon, \& Baglioni, 1995; Chaplain, 2008; Klassen \& Chiu, 2010). Eddy, Herman, \& Reinke (2019) 
examined the concurrent and predictive validity of using single-item measures for both stress and coping. Wanous, Reichers, and Hudy (1997) explored the reliability of single-item measures of job satisfaction and found that the minimum estimated reliability of such measures to be approximately .70. Further supporting the use of a single-item measure of job satisfaction, Scarpello and Campbell (1983) found that the singe-item measure of job satisfaction may be preferable, explaining "Low correlations between sum of many facet scores and the global measures are probably not due to unreliability of the global measures. Rather, they may be related to failure to measure the range of variables that influence job satisfaction.” (p. 597)

The Herman et al. (2018) study that utilized single-item measures of stress and coping used them to develop four classes of teachers within their sample based upon their stress and coping levels (High stress/low coping, high stress/medium coping, high stress/high coping, and low stress/high coping). They then examined various student outcomes (concentration, disruptive behavior, prosocial behavior, and achievement) for each class of teachers; job satisfaction was not included as an outcome in this study. No study to date has examined the moderating effect of coping on the relationship between stress and job satisfaction. The present study also used single-item measures for stress, coping, and satisfaction. The use of single item measures makes surveying teachers significantly more expeditious and would provide schools a way to quickly measure the stress, coping, and job satisfaction levels of their teachers. In summary, the present study will further the line of research utilizing single-item measures of stress, coping, and job satisfaction by using them to test for a relationship between stress and job satisfaction using coping as a moderator. These plans make this study more than a just a replication study, although there are aspects of conceptual replication.

\section{Theoretical Frameworks}


To better understand the effects and mechanisms of stress, it is important to examine theories that explain it. The primary framework that supports this study (and many of the studies reviewed thus far) are the transactional model of stress (Lazarus \& Folkman, 1984). In addition, McClusky's (1963) Theory of Margin also helps to support this study. Both frameworks center their attention on the amount of stress individuals are experiencing as compared to their ability to adapt to that stress. Lazarus and Folkman (1984) put forth a theory of stress called the transactional model. The transactional model of stress indicates that any time an individual encounters a life demand, a cognitive process is begun in which the individual weighs the demands of the task against his or her perceived ability to cope with the demand. This demand is appraised in two phases, primary and secondary. The primary appraisal consists of a determination of whether the individual believes the event affects his or her well-being (Lazarus \& Folkman, 1987). The secondary appraisal is when the individual decides whether or not they have sufficient coping resources to deal with the event (Lazarus \& Folkman, 1987). If the demands of the tasks are perceived to be greater than the ability to deal with the demand, the stress response is triggered. If the individual believes his or her ability to deal with the event will resolve the issue at hand, then stress is absent or lessened (Lazarus \& Folkman, 1987).

In addition to the transactional model of stress, McClusky's (1963) Theory of Margin (Power-Load-Margin Theory) provides another theory that could help explain why teachers may experience lower job satisfaction. Margin in Life is a ratio of a person's load and power and it measures an adult's potential or readiness to learn or change (Hanpachern, et al., 1998). Load consists of those aspects of a person's life that are considered stressors when someone engages with them either mentally, emotionally, or physically. Power is made up of the resources (such as family support, money, employer support, etc.) that help an individual deal with their load 
(Hanpachern, et al., 1998; Merriam \& Bierema, 2014). Power can also come from a teacher's own personal coping capacity. Coping are those behaviors or thoughts a person uses to manage the demands of their load (Herman, Hickmon-Rosa, \& Reinke, 2018). Margin in Life supports the structure of this study in that it accounts for more than just stress in gauging an individual's outcomes.

Based upon these theoretical models, it is reasonable to suspect that coping may moderate the relationship between stress and job satisfaction. Teachers with higher coping levels would have weaker relationships between stress and job satisfaction and teachers with lower coping levels would have stronger relationships between stress and job satisfaction. Therefore, the hypothesis for the present study is that for teachers with higher coping levels, the relationship between stress and job satisfaction will be relatively weak, whereas among teachers with lower coping levels, the relationship between stress and job satisfaction will be stronger.

\section{Research Question}

Research Question 1: Is there a relationship between teacher stress and job satisfaction?

Research Question 2: Is there a relationship between teacher coping and job satisfaction?

Research Question 3: Does coping moderate the relationship between teacher stress and job satisfaction?

\section{Study Context}

The data for this study was pulled from two larger studies conducted the Missouri Prevention Science Institute (Herman et al., 2010). One study is the Safe and Civil Schools Leadership (SCSL), which is a grant-funded randomized control trial funded by the Institute of Education Sciences (IES). The program focuses on training school principals to use data-driven decision-making tools to promote school safety and climate. The main goals of the SCSL study 
are to implement the Safe and Civil Schools training with principals and determine the training's effects on leadership skills, safety, school climate, and student achievement using a randomized control design (Missouri Prevention Science Institute, n.d.). For the SCSL study, cohort 1 included a total of 21 elementary, middle and high schools from four school districts in the Kansas City, Missouri area. Cohort 2 consisted of 16 elementary, middle, and high schools from three school districts in the same area.

The other study is also a randomized control trial called START, which utilized the START on Time program for school principals to teach them skills to foster a safe and positive learning environment for students (Missouri Prevention Science Institute, n.d.). This study also incorporates training in SCSL and is funded by a grant from the National Institute of Justice (NIJ) and is a randomized control design. START is the Principal and School Climate project and is funded by the National Institute of Justice in schools in Oklahoma. This study also incorporates training in Safe and Civil Schools and is a randomized control design. For the START study, cohort 1 included 10 middle schools and high schools from nine school districts in Oklahoma. Cohort 2 consisted of 4 middle and high schools from 4 school districts and Cohort 3 consisted of 9 middle and high schools from 6 school districts, also in Oklahoma. Both the SCSL and START studies consist of multiple cohorts spaced two years apart. Both studies are still ongoing and so far there are four cohorts in each study. Each cohort was surveyed 3 times per year.

\section{Setting}

For the SCSL study, cohort 1 included a total of 21 elementary, middle and high schools from four school districts in the Kansas City, Missouri area. Cohort 2 consisted of 16 elementary, middle, and high schools from three school districts in the same area. For the 
START study, cohort 1 included 10 middle schools and high schools from nine school districts in Oklahoma. Cohort 2 consisted of 4 middle and high schools from 4 school districts and Cohort 3 consisted of 9 middle and high schools from 6 school districts, also in Oklahoma.

\section{Data Used for the Present Study and Design of the Study}

\section{Participants}

The participants for this study are teachers who were part of cohorts 1 and 2 of the SCSL study and teachers in cohorts 1 through 3 in the START study, for a grand total of 1,777 teachers from 59 schools. Because of recoding of some of the survey data response categories, between the first and second round of data collection in cohort 1 of the START study, the present study will only focus on data collected during Time 2 in each cohort of each study. For the SCSL study, the Time 2 data was collected in May 2018 for cohort 1 and for cohort 2 in May 2019. For the START study, the Time 2 data was collected from cohort 1 in November and December 2017, from cohort 2 in November and December 2018, and from cohort 3 in November and December 2019. In the SCSL study, the response rate for cohort 1 at time 2 was $71 \%$ (628 out of 887 eligible teachers). For cohort 2, the response rate at time 2 was $84 \%$ (512 out of 609 eligible teachers). In the START study, the response rate for cohort 1 at time 2 was $80 \%$ (370 out of 463 eligible teachers). For cohort 2, the response rate at time 2 was $93 \%$ (65 out of 70 eligible teachers). For cohort 3, the response rate at time 2 was $85 \%$ (192 out of 226 eligible teachers).

\section{Data Collection Tools}

The study used surveys to collect data from participants. These surveys utilized single item measures of stress, coping, and job satisfaction. The single item for stress read, "How stressful is your job?" and participants responded on a 10-point Likert scale with a rating of 1 meaning "Not Stressful" and a rating of 10 meaning "Very stressful." The single item for coping 
read, "How well are you coping with the stress of your job?" and participants responded on a 10point Likert scale. The single item for job satisfaction reads "Overall, how satisfied with your job at this school?" This question utilized a 6-point Likert scale with 1 representing "Very Dissatisfied," and 6 representing "Very Satisfied." Responses 2 through 5 represented a continuum of satisfaction, with these descriptors (in order from 2 to 5): Dissatisfied, Slightly Dissatisfied, Slightly Satisfied, and Satisfied.

\section{Data Analysis}

To begin, a correlational analysis between stress levels and job satisfaction levels was conducted. This was done to determine whether there is a significant relationship between stress and job satisfaction for the data set, as prior research has indicated (McCarthy, Lambert, \& Reiser, 2014; McCarthy et al., 2010). To answer research question one, both a simple and multiple regressions were conducted using stress as the independent variable and job satisfaction as the dependent variable. The simple regression included no covariates and then there were three multiple regressions conducted, introducing a few covariates at a time until all were included (see the section below for information regarding covariates). To answer research question 2, the same process was followed using coping as the independent variable and job satisfaction as the dependent variable.

Because the existing literature base and theoretical models indicate that coping has a moderating effect on the relationship between stress and job satisfaction, a moderation analysis was then conducted in order to answer research question three. Moderation analysis is designed to determine whether a moderating variable (coping in this study) affects the strength and/or direction of the relationship between an independent variable (stress) and dependent variable (job satisfaction) (Field, 2018). 
This moderation analysis was conducted using the procedure set forth by Baron and Kenny (1986) and used regression that included several participant-level covariates with school fixed-effects. This approach controls for non-observed school level characteristics using dummy variables for each school included in the studies. All outcome variables were treated as continuous for this process. Johnson \& Creech (1983) showed the treatment of this Likert-style data as continuous is supported when scales contains greater than five response categories. Norman (2010), Sullivan and Artino (2013), and Zumbo and Zimmerman (1993) have all reached similar conclusions about it being acceptable to utilize parametric tests (such as regression) with Likert-style variable when they contain at least five response categories. Prior to performing the moderation regression, the predictor variables (stress and coping) were centered. Centering is necessary in moderation analysis because it ensures that the slopes for stress and coping in this particular analysis represent the effect of each when the other predictor is at its mean value (which is zero because of the centering), and the intercept would then represent the job satisfaction rating when both stress and coping are at their means (Field, 2018). The following regression equation will be used for the moderation analysis:

$Y_{i}=\beta_{0}+\beta_{1}($ Stress_Centered $)+\beta_{2}($ Coping_Centered $)+\beta_{3}($ Stress*Coping $)+b_{x} \mathbf{X}_{i}+r_{i j}$

In formula (3), $Y_{i}$ denotes the job satisfaction outcome variable for teacher $i$. The slope $\beta_{1}$ represents the average expected change in job satisfaction when the stress score increases by one unit and coping is at its average value. The slope $\beta_{2}$ represents the average expected change in job satisfaction when the coping score is increased by one unit and stress is at its average value. The variable Stress*Coping is the interaction term. The slope $\beta_{3}$ represents the expected change in job satisfaction when the moderator score is increased by one unit. If the regression from (3) shows the effect of stress and coping as insignificant while the effect of the interaction term 
(Stress*Coping) is significant, then this would be considered complete moderation (Baron \& Kenny, 1986). It is also possible that one or both of stress and coping will show significance in addition to the interaction term, which would indicate that those terms still have a significant effect on job satisfaction even when considering the interaction term (Baron \& Kenny, 1986). $\mathbf{X} \boldsymbol{i j}$ represents a vector of the teacher level covariates which include experience, gender, grade level taught, White or non-White race, treatment condition, and school identification number. The PROCESS plugin for SPSS by Andrew F. Hayes was will be utilized to conduct the moderation analysis. The PROCESS plugin quickly conducts the moderation analysis and displays results that provide the needed regression data and simple slopes data to better aid with visual representations of the results of the moderation analysis.

\section{Control Variables}

Some studies suggest that stress varies across different points in a teacher's career (Harmsen, Helms-Lorenz, Maulana, \& van Veen, 2019; Hubermann, 1993; Ingersoll, 2001; Lauermann \& Konig, 2016; Prillentensky, Neff, and Bessell, 2016). Some research has shown that stress levels vary by grade levels the teacher teaches (Antoniou, Ploumpi, \& Ntalla, 2013), so this will be included as a covariate, as well. In addition, Antoniou, Polychroni, and Vlachakis (2006) found that females experience more occupational stress than their male counterparts. Therefore the following variables were included as covariates in the study: years of teaching experience, grade level taught, gender, and White or non-White race. Any school-level factors are controlled for by using the School ID as a covariate. Grade level taught spanned Pre-K through $12^{\text {th }}$ grade, with each category being its own variable that was dummy coded. Similarly, years of teaching experience was dummy coded into four categories, with categories for 1 to 2 years of experience, 3 to 5 years, 6 to 10 years, and greater than 10 years. Race was dummy 
coded into a single variable in which each participant was identified as either White or nonWhite. While the survey collected race data for many races, the number of responses in each of the race categories was so small that they were not having a significant influence on the model results. This study utilized listwise deletion of any responses that did not contain all the needed data, so any teacher who did not respond to all the questions of interest (stress, coping, job satisfaction, and all covariates) was not included in the analysis.

\section{Limitations}

The present study has some limitations. This study did not measure specific coping techniques employed by teachers. Research makes it clear that the type of coping (whether it is problem-focused or avoidant, also called direct action or palliative) utilized has a significant effect on the outcomes (Austin, Shah, \& Muncer, 2005; Marroquin et al., 2010; Shin et al., 2014), but the single item measure of coping used in this study was not sensitive to those differences. Further research could attempt to look at job satisfaction outcomes for teachers who employ differing coping strategies. Another limitation is that the items that measured stress, coping, and job satisfaction were pulled from survey tools that consisted of many dozens of items. Such long surveys could have affected response rates (Crawford, Couper, \& Lamias, 2001; Woods \& Hampton, 2005), so the participants in the study may not be a complete representation of all segments of the teaching profession. Finally, this study did not determine what courses of action to utilize to support teachers who may be experiencing high stress, low coping, or low job satisfaction. This would be an opportunity for further research in which a treatment for coping could be applied to struggling teachers and measures of stress, coping, and job satisfaction could be taken both before and after the treatment.

\section{Definitions of Key Terms}




\section{- Independent variable}

- Stress in this study will utilize the definition provided by Lazarus and Folkman (1984). They defined stress as "a particular transaction between the individual and the environment in which the situation is evaluated as exceeding his resources or threatening his well-being.” (p. 19)

\section{- Dependent variable}

○ Job satisfaction is the extent to which people like or dislike their job (Spector, 1997).

- A moderator is a variable that changes the size and/or the direction of the relationship between two other variables (Field, 2018).

○ Coping is defined by Lazarus and Folkman (1984) as "all of the cognitive and behavioral efforts, constantly changing, expended (by one person) to manage the internal and/or external demands perceived as consuming or exceeding his resources.” (Lazarus \& Folkman, 1984, p. 141)

- Teacher retention in this study refers to the rate at which teachers stay in their present position with their school.

- Teacher attrition in this study refers to the rate at which teachers leave their present position either for another teaching position outside the present school or if the teacher leaves the profession of teaching altogether.

- Load consists of those aspects of a person's life that are considered stressors when someone engages with them either mentally, emotionally, or physically (Hanpachern, et al., 1998; Merriam \& Bierema, 2014). 
- Power is made up of the resources (such as family support, money, employer support, etc.) that help an individual deal with their load (Hanpachern, et al., 1998; Merriam \& Bierema, 2014).

- Margin is a ratio of a person's load and power and it measures an adult's potential or readiness to learn or change (Hanpachern, et al., 1998).

- Primary appraisal consists of a determination of whether an individual believes an event affects his or her well-being (Lazarus \& Folkman, 1987).

- Secondary appraisal is when an individual decides whether or not they have sufficient coping resources to deal with an event (Lazarus \& Folkman, 1987).

\section{Significance of the Study}

\section{Scholarship}

The present study's contribution to scholarship takes a few forms. First, it adds to the existing literature by directly testing for a relationship between stress and job satisfaction using coping as a moderator. While many studies have examined stress and coping, stress and job satisfaction, or coping and job satisfaction, the researcher was unable to find any that have made the connections between stress, coping, and satisfaction that this study will examine. Next, the present study will further the research base that utilizes single-item measures to measure stress, coping, and job satisfaction. Multiple studies have shown that the perceived survey burden can cause lower response rates (Crawford, Couper, \& Lamias, 2001; Woods \& Hampton, 2005). On the other hand, shortening surveys can improve response rates and minimize non-response bias (Rogelberg \& Stanton, 2007; Stanton, Sinar, Balzer, \& Smith, 2002), making single-item measures particularly advantageous. The use of single-item measures can also help facilitate the use of more frequent surveying because of the reduced load on participants (Fisher, Matthews, \& 
Gibbons, 2016). This study will potentially be the first to test for a relationship between stress and job satisfaction using coping as a moderator while using single-item measures for all three of those constructs.

\section{Practice}

Teachers continue to leave the profession at an alarming rate. The present study could provide school leaders with an expeditious method for measuring their teachers' stress and coping levels utilizing single-item measures. In addition to speed, the use of single-item measures can also help facilitate the use of more frequent surveying because of the reduced load on participants (Fisher, Matthews, \& Gibbons, 2016). Houdmont et al. (2019) noted the utility of single-item measures, explaining that they reduce survey fatigue and could be given frequently to allow for early identification of stress problems or to monitor the effectiveness of a stress reduction intervention, which could be immensely valuable for school leadership. Ultimately, the results of this study could give school leaders a clear idea of whether their teaching staff is struggling with stress and/or coping and whether that will have an impact on those teachers' job satisfaction. This knowledge will help school leaders know whether support is needed to help teachers reduce stress and/or increase coping skills. Research has shown that reduced job satisfaction has been shown to have an effect on overall job performance (Wolomasi, Asaloei, \& Werang, 2019), effective use of classroom management (Kaya \& Selvitupo, 2019), teacher subjective well-being (Judge \& Watanabe, 1993), and teacher self-concept (Skaalvik \& Skaalvik, 2017). This knowledge of teacher needs regarding stress and coping could allow leaders to target support where it is needed and, hopefully, improve job satisfaction. This could in turn have a positive effect on teacher attrition and other important teacher outcomes.

\section{Summary}


Teacher attrition has remained a persistent problem for schools (Goldring, Taie, \& Riddles, 2014; Inman \& Marlow, 2004; Dunn, 2018; Chambers Mack, Johnson, Jones-Rincon, Tsatenawa, \& Howard, 2019). Job satisfaction is an important influencer of teacher retention, as teachers' job satisfaction has been directly connected to teacher retention (Skaalvik \& Skaalvik, 2011) and to teachers' decisions about whether or not to stay in the teaching profession at all (Klassen \& Chiu, 2011; McCarthy, Lambert, Crowe, \& McCarthy, 2010). Literature identifies stress as an influencer of lower job satisfaction among teachers, and, unfortunately, high ratings of stress are prevalent among teachers (Kyriacou, 2001). In order to deal with stress, teachers (and all people) utilize coping. Coping consists of those skills and methods that teachers use to deal with their stress (Lazarus \& Folkman, 1984). Many studies have examined the combined effects of teacher stress and coping and generally conclude that stress is part of every teacher's job and that the effect stress has on a host of outcomes, such as student achievement (Herman et al., 2018), job satisfaction, intention to leave the profession (McCarthy, Lambert, \& Reiser, 2014; McCarthy et al., 2010), and physical symptoms (Skaalvik \& Skaalvik, 2015), are related to the teacher's coping capacity or style. Much of the prior research measures stress, coping, and job satisfaction utilizing tools with dozens of items (Antoniou, Ploumpi, \& Ntalla, 2013; Foley \& Murphy, 2015; Laugaa, Rascle, \& Bruchon-Schweitzer, 2008; McCarthy, Lambert, \& Reiser, 2014; McCarthy, Lambert, Crowe, \& McCarthy, 2010; Salkovsky, Romi, \& Lewis, 2015; Smetackova et al., 2019), but there is significant research support for the use of and utility of single-item measures (Eddy, Herman, \& Reinke, 2019; Scarpello \& Campbell, 1993; Wanous, Reichers, \& Hudy,1997). The present study, then, aims to directly test the relationship between teacher stress and job satisfaction while utilizing coping as a moderator and while measuring those constructs with single-item measures. 
SECTION TWO:

PRACTITIONER SETTING FOR THE STUDY 


\section{Introduction}

Teacher stress levels have been studied for multiple decades (Kyriacou, 2001). Research began to mention the term "teacher stress" specifically in the late 1970s, although it was referred to in other ways prior to that (Kyriacou, 2001). Since then, a wealth of research regarding teacher stress and related outcomes has occurred. We now know that stress can lead to many negative outcomes for both teachers and students. Teacher stress has been shown to have a negative relationship with turnover intent (Ryan, et al., 2017; Klassen \& Chiu, 2011), burnout (Antoniou, Ploumpi, \& Ntalla, 2013; Laugaa, Rascle, Bruchon-Schweitzer, 2008; Schwarzer \& Hallum, 2008), absenteeism (Betoret, 2006), and job satisfaction (Kyriacou, 2001; McCarthy, Lambert, \& Reiser, 2014). Jepson and Forrest (2006) found that teachers with higher levels of work-related stress had lower job satisfaction, less commitment to the process of teaching, and greater intention to quit teaching. For students, teacher stress can lead to lowered academic achievement and increased struggles with behavior management (Herman, Hickmon-Rosa, \& Reinke, 2018; von der Embse et al., 2017).

Despite the research base regarding teacher stress and negative outcomes for both teachers and students, schools and policymakers continue to enact changes and policies that are causing more stress for teachers (Dunn, 2018). Evaluation practices, time pressure and workload, administration and management, and poor working conditions are all factors that teachers have identified as stressors (Kyriacou, 2001). One study found that test-based accountability practices significantly predicted higher rates of stress, burnout, and turnover intent (Ryan, et al., 2017).

A particularly disconcerting casualty of teacher stress is job satisfaction. Job satisfaction has been shown to be affected by predictors such as work conditions, staff collegiality, and 
administrative support, all of which are included as potential stressors for teachers (Shen, Leslie, Spybrook, \& Ma, 2012). Job satisfaction influences outcomes for teachers and their students in the ways one might expect. Wolomasi, Asaloei, and Werang (2019) demonstrated that overall job performance among elementary teachers was significantly and positively affected by job satisfaction. Higher job satisfaction has a positive effect on teachers' use of effective classroom management skills (Kaya \& Selvitupo, 2019), teacher subjective well-being (Judge \& Watanabe, 1993), and teacher self-concept (Skaalvik \& Skaalvik, 2017). McCarthy, Lambert, and Reiser (2014) found that as job satisfaction increased, teacher plans to leave their current position decreased significantly. Job satisfaction has been directly linked to teacher retention (Skaalvik \& Skaalvik, 2011), and job dissatisfaction has been directly linked to emotional exhaustion and decreased personal accomplishment (Skaalvik \& Skaalvik, 2009). The effect of stress on job satisfaction has a clear and significant influence on teachers, so it is important that practitioners and policymakers are aware of it. Stress and job satisfaction, though, do not completely capture the causes and outcomes of stress for teachers. Coping has been shown to be a moderator of the effects of stress for many outcomes, and it can either positively or negatively moderate depending upon the types of coping that are employed (Austin, Shah, \& Muncer, 2005; Kyriacou, 2001; Laugaa, Rascle, \& Bruchon-Schweitzer, 2008; Marroquin et al., 2010; Shin et al., 2014; Stoeber \& Rennert, 2008). In order to have a complete picture of how stress affects job satisfaction among teachers, one must include coping as a moderator in that process.

As both a former teacher and current building principal, I have watched teachers struggle greatly with the effects of stress on their career and personal lives. I have seen colleagues cry after a particularly difficult day, go through drastic and noticeable personality changes due to a traumatic event or after years of feeling worn down, and I have seen colleagues leave the 
profession after ultimately deciding they no longer could continue to do the work. In my experience, I have seen teachers avoid being assigned to particular classes or grade levels because of the added stress of high stakes testing that go with those assignments. I have had teachers crying in my office over negative or unsupportive relationships with teammates or other colleagues, parents, and/or students. Teachers have labored to meet the requirements of evaluation systems that, while the system may measure teaching practices effectively, have little or no proven effect at improving teaching, causing teachers to tell me they feel like it is just a "hoop to jump through." As discussed in Section 1, teachers (and all workers, typically) benefit from eustress, or those things that help them grow as educators and help them to feel as though they are making a positive difference in the education or lives of their students. However, in my experience, things like evaluation, high stakes testing, and conflict with colleagues, students, or parents do not cause eustress.

As a result of conducting this research, I can also see that stress had an impact on me at many points along my career path. There were many instances of policy changes (from both the state level and local levels) that did not seemed to be based on student needs or best practices. Frequently these policies made my colleagues and I feel as though changes were being done "to" us instead of "with" us. Multiple times I sought to find a new position in another district or in a private school setting and even new positions outside of education. While I may not have attributed the desire to change venues to these stressors directly, stress certainly influenced my sense of satisfaction with my job and, at those times, forced me to cope in new ways (which in that case was to seek other opportunities because I did not believe I could overcome the stressors I was facing). 
In addition to the observations of stressors among my colleagues over the last 18 years in education and my own experiences, it is important to add that learning positive and effective coping strategies has never been a focus or component of any teacher preparation program, teacher induction plan, or whole staff professional development program that I have been a part of or planned or heard of. I believe this to be a significant missed opportunity for practitioners that could benefit nearly every stakeholder in public education. Research already supports that coping can lessen the effects of stress (Antoniou, Ploumpi, \& Ntalla, 2013; Herman, et al., 2018; Laugaa, Rascle, \& Bruchon-Schweitzer, 2008), so an investment of time and resources to educate teachers about how to effectively cope with stressors seems like it could be important. Stress, coping, and job satisfaction among teachers is certainly a significant problem facing everyone involved with education. It is my hope that this study will help to further the discussion around those topics and help to guide myself and other school leaders to more effective ways to support our teachers when so many stressors are beyond our ability to control. In the next few sections, I will provide an overview of the history of my organization, an analysis of that organization, an analysis of my leadership, and implications my present study has for me as a practitioner.

\section{History of the Organization}

My personal context as a practitioner is as an elementary principal for Columbia Public Schools (CPS). Each year the district conducts a climate survey, which gathers response data from parents, students, and teachers about a large variety of topics. Of particular relevance to this study is the data from teachers about their jobs. Data for this survey is publicly available (https://public.tableau.com/profile/david.wilson1854\#!/vizhome/ClimateSurvey_2/AllSurveysDa ta). One statement in the teacher survey related to jobs is "I usually look forward to each working 
day." This statement has been included in the survey each year since 2016. The percentage of teachers that fell in each response category for this statement (they can choose agree, neutral, disagree, I don't know, or they can also choose not to respond) from 2016-2019 is listed below (Table 1). Unfortunately, the responses to this survey item for CPS are reflective of the nationwide educator community. Teacher job satisfaction is dwindling everywhere. A $2012 \mathrm{Met}$ Life survey discovered that only $39 \%$ of teachers reported themselves as very satisfied, the lowest proportion in 25 years (Metlife, 2012). The CPS data, though, is not reported the same way as the Met Life data, in that teachers can only agree, without distinguishing between satisfied or very satisfied. The CPS data, though, is closer to, though still less than, the 2018 Teaching and Learning International Survey (TALIS) by the OECD that found that $90 \%$ of United States teachers in grades 7-9 are satisfied with their job (Schleicher, 2018). This decrease in satisfaction can lead to negative outcomes for teachers and students, as decreased job satisfaction has been shown to have an effect on overall job performance (Wolomasi, Asaloei, \& Werang, 2019), effective use of classroom management (Kaya \& Selvitupo, 2019), teacher subjective well-being (Judge \& Watanabe, 1993), and teacher self-concept (Skaalvik \& Skaalvik, 2017). Job satisfaction has also been shown to influence teacher retention, with satisfied teachers wanting to stay in their position (McCarthy, Lambert, \& Reiser, 2014).

\section{Organizational Analysis}

The purpose of this section is to examine the elements of the organizations that are experiencing the negative outcomes associated with teacher stress. Of course, the organizations experiencing those negative effects would be every school district in the nation and across the world. So, the purpose of this section will be to examine the organizational elements of a typical school system, using CPS as an exemplar. In order to understand how teacher stress is having a 
negative impact, it is important to understand how schools operate from an organizational perspective and how that impacts stress levels. Teacher stress and its causes are known problems among practitioners (Skaalvik \& Skaalvik, 2015; Skaalvik \& Skaalvik, 2010; Wiley, 2000), but to appreciate why they persist as a problem, one must understand the organizational elements of typical schools. The human resource frame (Bolman \& Deal, 2013) focuses on "what organizations and people do to and for one another" (p. 113), and this helps to frame the problem of teacher stress and its causes.

Table 1

\begin{tabular}{ccccc}
\hline Year & Agree & Neutral & Disagree & $\begin{array}{c}\text { No Response or } \\
\text { Don't Know }\end{array}$ \\
\hline 2016 & $86 \%$ & $8.6 \%$ & $4.5 \%$ & $0.9 \%$ \\
2017 & $79.3 \%$ & $14.1 \%$ & $6.2 \%$ & $0.4 \%$ \\
2018 & $78 \%$ & $11.6 \%$ & $5.9 \%$ & $4.4 \%$ \\
\hline
\end{tabular}

Percentage of teachers' responses to "I usually look forward to each working day." From the CPS Climate Survey, years 2016-2019

(https://public.tableau.com/profile/david.wilson1854\#!/vizhome/ClimateSurvey_2/AllSurveysDat a)

Bolman and Deal (2013) contend that effective organizational problem solving is often prevented by shortcomings in the thinking of the problem solvers. They explain that leaders are only constrained by problems to the extent that their thinking is bound by an insufficient number of perspectives. Bolman and Deal (2013) propose that there are four frames: structural, human resource, political, and symbolic. These frames allow leaders to attack problems from a multitude of perspectives so they can find the best possible solutions. To address the problem of 
teacher stress and job satisfaction, the human resource frame seems to be the logical frame to examine.

\section{Human Resource Frame}

"Organizations exist to serve human needs rather than the converse" (Bolman \& Deal, 2013, p. 117). Examining the causes of teacher stress can make one openly wonder if schools, or those who exert control and influence over them, clearly understand that quote. The sources of stress discussed in section one seem to run counter to the ideas within the human resource frame that Bolman and Deal (2013) describe. One of the assumptions of the human resource frame is when the fit between the person and the organization is poor, then the person, organization, or both will suffer. Research has confirmed that both the person and the organization (and students) are suffering when it comes to teacher stress and schools. The human resource framework highlights the importance of the relationship between the employees and the organization. This relationship is more complicated than making sure employees get a paycheck and that the organization gets the services and work output of the employee. An organization must also strive to meet the human needs of its employees. A good fit between individuals and organizations means that individuals believe they are doing meaningful and satisfying work and the organization is getting talented, energetic workers. Pink's (2011) theory on motivation explains that there are three drivers of motivation. The first is autonomy and control of their work. The second is the drive for mastery and the human instinct to get better at what they do. The final driver of motivation is purpose, as it is also human nature to want to be a part of something bigger than just ourselves (Pink, 2011). Scholars have identified that the work of teaching and that achievement and enhancement are things that leads to satisfaction (Herzberg, 1966), so Pink's second two drivers are potentially satisfied in the work of teaching. However, autonomy 
and control of the work is one aspect of motivation that could be negatively affected by teacher stressors. Teachers have listed factors such as policies surrounding standardized testing and state standards (von der Embse, Ryan, Gibbs, \& Mankin, 2019), time pressure and workload concerns, and teacher evaluation systems (Kyriacou, 2001; Travers \& Cooper, 1996) as significant stressors and each of those could be eroding motivation because of the reduction of autonomy and control they represent.

Bolman and Deal (2013) explained that individuals within an organization are more motivated and ultimately more successful when all of their needs are met. Maslow (1943/2005) explained that people's basic human needs must be met before they can move up the hierarchy to more complex needs. While many schools are able to meet needs such as physiological and safety needs, some obviously begin to struggle farther up the hierarchy of needs. Many teachers report that social needs such as belonging and inclusion or even esteem needs such as respect and recognition are causes of stress (Kyriacou, 2001; Travers \& Cooper, 1996). The human resource framework contends that the employee is more important than the bottom line of an organization, and schools would be wise to identify and address needs that are concerns for their teachers.

Within CPS, there are steps that are taken to ensure teacher needs are met in a systematic way. One major step in meeting teacher needs and reducing teacher stressors is the use of a teacher induction program. Teacher induction programs are designed to support the needs of new teachers and consist of a series of programs designed to teach organizational culture, best classroom practices for behavior management and instruction, and professional development (Harmsen, Helms-Lorenz, Maulana, \& van Veen, 2019). Helms-Lorenz et al. (2012) showed that teachers who undergo an induction program tend to experience fewer causes of stress than those teachers who do not. In addition, Ingersoll and Smith (2004) found that beginning teachers who 
are provided with multiple supports are less likely to leave the profession after their first year. It is reasonable, then, to expect that induction programs can at least help in stress reduction and potentially help with job satisfaction.

At CPS, new teachers undergo a thorough induction program that spans the first two years of their career with the district. During a teacher's first two years with CPS, they are assigned a mentor. This mentor is someone who provides coaching, collaborative support, and conducts classroom observations for the new teacher. Mentors also help the new teacher develop a professional development plan for each of their first two years of teaching to help the new teacher focus professional learning on high-leverage skills. In addition to providing a mentor, the district has a series of new teacher induction meetings throughout the first two years of employment. In the first year, these meetings address expectations for new teachers, curriculum priorities, classroom management, restorative practices, resources for mental health needs, and creating a culture of equity. In the second year, the meetings focus more deeply on curriculum priorities, classroom management, and a culture of equity. These meetings are exclusively for beginning teachers and are facilitated by an assortment of curriculum coordinators, administrators, and experienced teaching staff. One potential improvement of these induction and mentoring programs for CPS, though, could be to directly take on the topics of stress and coping to help beginning teachers have an understanding of what stressors they will be facing and how they can effectively cope with them.

Bakker and Demerouti (2007) developed the Job Demands-Resources (JD-R) model that can explain some of the strain and supports that new teachers grapple with and how those factors lead to certain outcomes such as teacher quality, attrition, and stress responses. JD-R explains that teachers will undergo two main psychological processes: the health impairment process and 
the motivational process (Bakker \& Demerouti, 2007). The health impairment process accounts for the relationships between job resources and demands, strain on the teacher, and the resultant outcomes for the organization (Harmsen, Helms-Lorenz, Maulana, \& Van Veen, 2018). The motivational process explains that job resources have a motivational effect and lead teachers to higher work engagement and better overall performance (Harmsen et. al, 2018). Job resources are those aspects of a teacher's job that help stimulate growth in learning or reduce job demands (Bakker\& Demerouti, 2007). A quality teacher induction program, then, could be considered a job resource for beginning teachers that works to lessen job demands and provide professional growth.

Job demands are those aspects of the job that require physical or psychological effort (Bakker \& Demerouti, 2007). Not all job demands are negative, as demands are a part of any profession. For teachers, job demands could be things such as student misbehavior, planning instruction, or working with challenging parents or colleagues. These job demands could also be considered causes of teacher stress (Harmsen et. al, 2018). Harmsen et. al (2018) proposed a conceptual model of new teacher job demands and resources that shows the relationship between demands and resources for a new teacher and how those affect outcomes (see figure 1).

CPS climate survey data among teachers also measures whether teachers believe they have the resources they need to do their jobs, which is a survey item that fits well with the JD-R model. The statement in the survey is, "Generally speaking, I have the resources I need to do my job." The percentage of teachers that fell in each response category for this statement (they can choose agree, neutral, disagree, I don't know, or they can also choose not to respond) from 20162019 is listed below (Table 2). The data shows that the percentage of teachers agreeing with this 
statement is decreasing each year, creating the potential for added strain among teachers, according to the JD-R model.

Figure 1

Proposed conceptual model of stress based on the Job Demands-Resources model (Harmsen et. al, 2018).

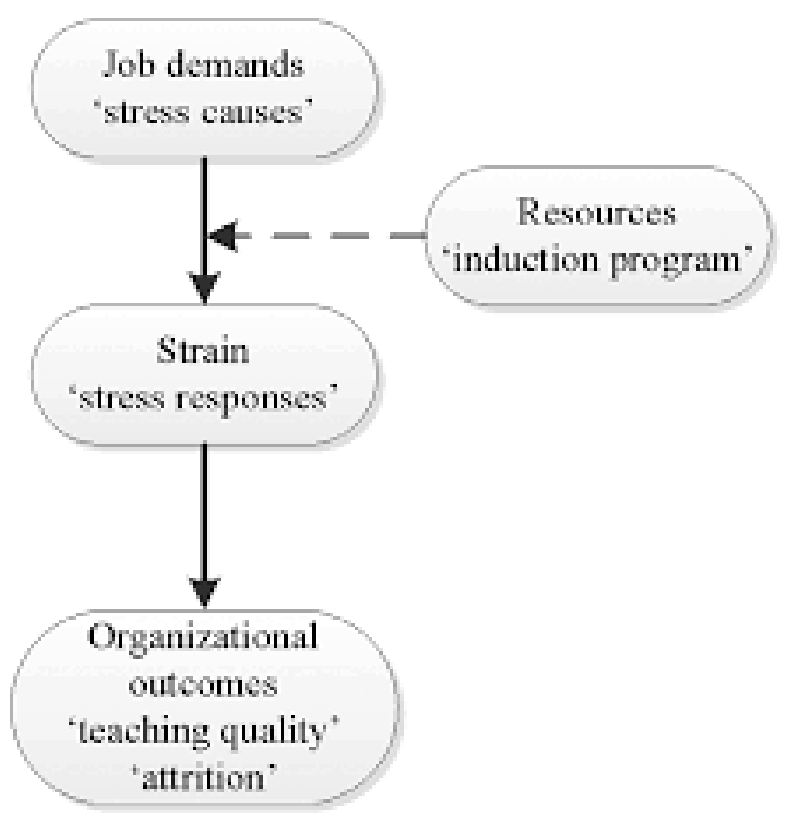

Table 2

Percentage of teachers' responses to "Generally speaking, I have the resources I need to do my job. ” From the CPS Climate Survey, years 2016-2019

(https://public.tableau.com/profile/david.wilson1854\#!/vizhome/ClimateSurvey_2/AllSurveysDat

a)

\begin{tabular}{ccccc}
\hline Year & Agree & Neutral & Disagree & $\begin{array}{c}\text { No Response or } \\
\text { Don't Know }\end{array}$ \\
\hline 2016 & $83.6 \%$ & $7.9 \%$ & $7.7 \%$ & $0.8 \%$ \\
2017 & $79.2 \%$ & $10 \%$ & $10.1 \%$ & $0.6 \%$ \\
2018 & $76.6 \%$ & $9.9 \%$ & $9.2 \%$ & $4.4 \%$ \\
\hline
\end{tabular}


In addition to the induction programs for new teachers, CPS also provides benefits designed to meet the more basic needs of their staff members. In addition to their yearly salary, teachers are provided health, vision, and dental insurance to help with costs associated with health needs. In addition to physical health, the district also offers access to the Employee Assistance Program (EAP). EAP is designed for teachers and their immediate families to be able to access counseling services when they are experiencing a variety of challenges or hardships. All teachers are part of the Missouri teacher retirement system in which teachers contribute $14.5 \%$ of their total compensation (salary and benefits) and that amount is matched by the local school board to ensure a secure retirement after the completion of their career. All of these structures can be viewed as meeting those basic needs (and perhaps some higher needs) on Maslow's (1943/2005) hierarchy.

These benefit and induction programs are in place for all teachers in CPS and represent a significant effort by the district to support their staff. However, these structures are not necessarily unique to CPS, as many districts provide either the same or similar benefits for their staffs. Because of the research on declining job satisfaction and increasing teacher attrition, these teacher support structures have not proven to be enough to maintain satisfaction and persistence. The research on causes of teacher stress makes it reasonable to assume that stress will persist throughout a teacher's career. From the perspective of the human resource frame, CPS (and other districts) should be seeking ways to continue to support teachers in coping with stress in order and they should also be looking for ways to adapt their own organizational practices with teacher stress in mind. In addition, CPS should begin collected data specifically related to the stress, coping, and job satisfaction of their employees so they can monitor that data and take any needed action. 


\section{Leadership Analysis}

Principals and district leaders are well aware that teachers are experiencing high levels of stress and most leaders could accurately describe many of the sources of those stressors. However, the power that any given school leader has to eliminate those stressors is difficult to quantify. Many stressors are a result of government mandates, such as standardized testing, teacher evaluation, or even discipline policies and decisions. It is unlikely that a building principal could change or ignore one of those mandates without risking their job. So, what is a school leader to do to overcome these stressors? Herzberg (1966) provided a theory regarding job satisfaction that identifies factors that prevent dissatisfaction, such as peer relationships, salary, organizational policies, supervision. Herzberg's (1966) theory also identified working conditions and factors that promote enhanced satisfaction, such as achievement, recognition, the work itself, responsibility, and advancement. When considering Herzberg's (1966) framework of job satisfaction, two theories of leadership stand out: emotional intelligence and servant leadership.

\section{Emotional Intelligence}

Understanding the tasks, mandates, interactions, or other stressors affecting teachers is an important skill for building principals. While there are mandates that principals cannot ignore, there are other initiatives that principals can enact with their teachers such as professional development focuses, procedural changes, scheduling adjustments, or meeting commitments. For me, this balancing act of implementing those mandates that are required and taking action on our specific building needs is a constant challenge. An understanding of how those initiatives will affect teachers (cause more stress, relieve stress, or neutral effects), could be an important key in reducing stress and/or increasing job satisfaction. Never has this fact been more evident than the 
last two school years that have been so significantly impacted by COVID-19. We have asked our teachers to reinvent the way they deliver instruction and doing so with elementary students has been tremendously challenging for my staff. In addition to reinventing instructional paradigms, we have also asked teachers to manage multiple health protocols in order to keep themselves and their students as safe as possible. Even in a "normal" school year, though, teachers in a system the size of CPS are consistently asked to implement district priorities (such as changes in grading practices or learning restorative practices) in addition to focusing on the needs of their individual buildings (such as the need to increase state assessment scores or reduce discipline referrals). As I try to balance these interests that compete for the finite personal resources my teachers can draw upon, one framework that helps guide me is that of emotional intelligence. Goleman (2011) identified emotional intelligence (EI) as a quality that all effective leaders share. Goleman (2011) explained that EI consists of a set of five skills that allow leaders to maximize both their own and their followers' performance. Those five skills include self-awareness, self-regulation, motivation, empathy, and social skill. EI fits under the larger umbrella of trait leadership because it is a specific trait of the leader and it does not depend upon characteristics of the followers (Northouse, 2016). A leader with high EI, would be able to accurately judge how their actions will affect their teachers.

In short, EI is about a leader recognizing both his or her own emotions and the emotions of his or her followers and being able to find ways to regulate or manage both sets of emotions (Goleman, 1996). When considering the stress levels and consequences of stress that teachers endure, it is imperative that school leaders at all levels have sufficient EI to recognize teacher stress and support teachers appropriately so they can assist in the development of enhanced job satisfaction and positive staff attitudes (Stein \& Book, 2001). Goleman (1996) explained that a 
leader's EI is an integral factor in fostering job satisfaction, and that the most successful organizations tend to have leaders with a high level of EI. Gardner and Stough (2002) concurred with Goleman, explaining that:

The ability of the leader to be able to identify and understand the emotions of others in the workplace, to be able to manage their own and others' positive and negative emotions, to be able to control emotions in the workplace effectively, to utilize emotional information when problem solving and to be able to express their feelings to others is integral to the leader being effective at creating appropriate levels of job satisfaction. (p. 76)

Singh (2013) studied the connection between EI and job satisfaction directly and found a significant correlation between employee job satisfaction and their leaders' EI. Additionally, Singh (2013) found that those employees who were dissatisfied with their work gave their leaders lower EI ratings.

In my own context as a school principal, I have seen firsthand how controlling one's emotions has a direct impact on the responses of others. Whether leading a staff meeting, talking one on one with a staff member, student, or parent, or being a participant in an IEP team meeting, my emotions and the way I read the emotions of those around me help guide the words and actions I choose to use and the problem solutions we choose to pursue. When discussing EI, Bolman and Deal (2013) asserted that, "Many improvement efforts fail not because managers' intentions are incorrect or insincere but because they are unable to handle the social challenges of change." (p. 171) When I was a curriculum director in another district, I failed to account for the stress our staff was already experiencing prior to rolling out an initiative related to use of new instructional practices. The initiative, while sound from an instructional standpoint, was largely 
unsuccessful in spreading these best practices because the staff saw it as another item on an already full plate. My failure to accurately understand how this would be received doomed the initiative almost before it began. I think this highlights the importance of being able to "read the room" and know what your team's current emotional state is before embarking on any project or change so you can be sure to provide work that is motivating and worthwhile instead of work that overwhelms or causes extra stress unnecessarily.

\section{Servant Leadership}

A leader who understands the needs and emotions of themselves and their followers are demonstrating EI (Goleman, 1996), but they are also demonstrating aspects of servant leadership. Northouse (2016) described a servant leader as someone who places the good of followers over their own and someone who seeks to develop their followers. Greenleaf (1970) explained that servant leaders are motivated by a desire to serve others over the desire to lead others. A key characteristic of a servant leader (among many others) is empathy (Northouse, 2016), which is also a key characteristic of EI (Goleman, 2011). The combined effect of all the stressors in the life of an educator require that school leaders support and serve their followers and beginning with empathy is a way to always lead with how actions affect followers in mind (Northouse, 2016). CPS has collectively adopted six values that guide the work of all within the district, and one of those values is empathy. Goleman (2011) explained that "Empathy means thoughtfully considering employees' feelings - along with other factors - in the process of making intelligent decisions." (p. 16) In order to be a servant leader to their followers, school leaders need to know what teachers are feeling and what their stressors are. As a principal, I have used my knowledge of the stressors my teachers are facing to advocate with central office administration about district-wide initiatives. As we have transitioned from traditional grading to 
standards-referenced grading practices, I have directly advocated for delays in the implementation of the new standards-referenced grade cards because I knew my teachers had not reached a point where they felt confident enough to begin using them. I then devoted time with my staff to address their questions and provide opportunities to collaborate with district curriculum coordinators and with each other to share strategies that had been successful so far in their transition. School leaders must actively take steps to help staff cope with their stressors so that the negative consequences of job stress can be minimized as best is possible. This is a key takeaway for practitioners. We should be asking our teachers to identify stressors so that we can provide appropriate supports or potentially even take away the emphasis on some of those stressors in order to lighten the load. Additionally, serving our teachers includes attempting to give them the tools to cope in positive ways to handle their stressors. To serve their teachers' needs, servant leaders need to develop their teachers' coping capacity and lessen or eliminate stressors as they are able. In addition, normalizing the need for and use of coping strategies could be an important component of these efforts. The need for coping should not be seen as a teacher's deficit, but rather something that all individuals need and utilize (Lazarus \& Folkman, 1987). School leaders' efforts to accomplish those two goals (develop coping and lessen/eliminate stressors) requires that they demonstrate both EI and servant leadership qualities.

\section{Implications for Research in the Practitioner Setting}

Teacher retention continues to be a significant problem in K-12 education (Goldring, Taie, \& Riddles, 2014; Inman \& Marlow, 2004; Dunn, 2018; Chambers Mack, Johnson, JonesRincon, Tsatenawa, \& Howard, 2019). In addition, job satisfaction has been tied to teachers' decisions about whether to stay in the profession (Klassen \& Chiu, 2011; McCarthy, Lambert, 
Crowe, \& McCarthy, 2010). Klassen and Chiu (2011) also found that commitment to the profession is influenced by job satisfaction. Teachers with greater work-related stress have lower job satisfaction (Jepson \& Forrest, 2006; McCarthy, Lambert, Crowe, \& McCarthy, 2010). It is no stretch then to state that stress is negatively influencing teacher job satisfaction and that could be a contributor to teachers' decisions to stay in the profession. There is hope, though, that the effect of stress on many outcomes could be positively influenced by teacher coping skills. Herman, et al. (2018) reported that coping skills and perceptions of self-efficacy have either a mitigating or exacerbating effect on the consequences related to stress. However, coping can have a positive or negative effect on outcomes of stress depending on the type(s) of coping a teacher utilizes (Kyriacou, 2001; Laugaa, Rascle, \& Bruchon-Schweitzer, 2008).

The present study could have multiple important implications for practice. First, if it is found that higher coping levels lead to a weaker or negative relationship between stress and job satisfaction, it will provide further evidence for practitioners to make an effort to determine their teachers' current coping capacity. Particularly in my context within CPS, we already survey our staff yearly, so the mechanism already exists to collect this data. In addition, the utility of singleitem measures of stress, coping, and job satisfaction makes measuring these factors on the yearly staff survey easy to do and does not greatly increase the survey burden on our staff members. As a building leader, even if the district does not commit to measuring these constructs, I can very easily incorporate these survey items into one of the surveys I conduct with my own staff. We already survey the staff at the beginning and end of the year about various needs and incorporating these items would be simple. In addition to the importance of taking action to build coping capacity among teachers, school leaders should be actively monitoring the stress, coping, and satisfaction levels of their staff. The work of Eddy et al. (2019) established the validity and 
reliability of single-item measures of both stress and coping. Wanous, Reichers, and Hudy (1997) have established the reliability of single-item measures of job satisfaction. The utility and ease of use of these single-item measures should make it easy for school leaders to survey their staffs with high response rates, particularly given the low survey burden (Rogelberg \& Stanton, 2007; Stanton, Sinar, Balzer, \& Smith, 2002).

Another implication for practitioners is if coping does moderate the relationship between stress and job satisfaction, it would be worthwhile for school leaders to make a concerted effort to develop and deliver professional development on positive coping skills for their teachers. More research may be desired to determine the best methods for increasing teacher coping, but there are studies that have already been conducted that have been shown to increase positive coping behaviors. One approach to doing so is utilization of a program such as Cultivating Awareness and Resilience in Education (CARE). CARE is a mindfulness-based program that is designed to help teachers reduce stress and improve their classroom outcomes (Jennings, Frank, Snowberg, Coccia, \& Greenberg, 2013). In a randomized control trial, those teachers that were in the CARE group saw improvements in well-being, self-efficacy, stress, and mindfulness. In addition, the teachers themselves believed the CARE program was effective (Jennings et al., 2013). There are other options that have been found to improve coping behaviors, as well. Online modules (Ansley et al., 2021), guided visualization techniques with musical accompaniment (Kaspereen, 2012), and meditation programs (Anderson, Levinson, Barker, \& Kiewra, 1999) are all potential options to equip teachers with beneficial strategies that can improve their use of coping. There are multiple opportunities for practitioners to implement interventions for improved coping. Preservice programs at colleges and universities could begin to lay the groundwork for this and make it an integral part of the student teaching experience. Districts 
would also be wise to incorporate such training into their teacher induction programs. Research has demonstrated that novice teachers report higher levels of stress than more experienced teachers (Antoniou, Polychroni, \& Vlachakis, 2006), so opportunities for learning about positive coping early in teachers' careers could be advantageous. At my building, we already have a regular meeting for staff who are new to our school and incorporating some time at those meetings to discuss positive coping seems to be a wise investment. It would be ideal to see our district also invest time in a district-wide way to teach positive coping skills. New teachers and teachers new to the district all participate in multiple induction meetings over the first few years with CPS, and hat provides ample opportunity to incorporate this learning.

One final implication for practitioners included in this study (but not unique to this study) is a clear demonstration of the need to devote more resources to educating teachers about effective coping mechanisms. If the present study does confirm that coping moderates the effect of stress on job satisfaction, that will provide more support and increased motivation for devoting time and resources to improving coping because of the many studies that support the importance of coping in determining important outcomes for teachers, students, and schools. Research has shown that reduced job satisfaction has been shown to have an effect on overall job performance (Wolomasi, Asaloei, \& Werang, 2019), effective use of classroom management (Kaya \& Selvitupo, 2019), teacher subjective well-being (Judge \& Watanabe, 1993), and teacher self-concept (Skaalvik \& Skaalvik, 2017). So, if leaders are able to take effective action to improve stressful conditions and/or improve teacher coping, many outcomes could improve for teachers and their schools. There are a couple of caveats to the importance of devoting time to coping interventions. As a practitioner in the time of COVID-19, I have seen the emotional toll the present reality has taken on my teaching staff. They are worn down and many of them feel 
overloaded already. I believe that to make an investment in coping successful, schools must be willing to take something off the plates of their teachers. CPS has provided some opportunities for voluntary mindfulness training, but I have heard teachers explain they do not want to participate in that training because, at the present time, it feels like yet another task for an already full plate. The other caveat is being mindful of how to appropriately frame professional learning about coping. Spending time learning about effective coping mechanisms should not be a judgement of whether teachers are capable copers, but rather a portion of a proactive method of addressing the realities of the teaching profession for all educators. Herman, Reinke, and Eddy (2020) posited the Coping-Competence-Context Theory of Teacher Stress (3C) wherein coping is just one of the components of a more holistic approach to addressing teacher stress that also involves competence in effective classroom practices and school and system practices (context) and how they all work together to contribute to teacher stress. The message to teachers should be clear that professional development in coping is an investment in outcomes for both the teacher and their students, and not a judgement on their professional abilities.

\section{Summary}

The setting for this study is one that is similar to so many districts and education systems throughout the nation. CPS teachers are experiencing a diminishment of their enthusiasm to come to work (Table 1) and a decreasing belief in the availability of resources (Table 2). School leaders will need to utilize emotional intelligence to successfully turn around these trends in the data. Singh (2013) explained there is a direct connection between employee job satisfaction and the organization's leadership EI. Stein and Book (2001) concurred and stressed that leaders need to have sufficient EI to recognize teacher stress and support teachers appropriately in order to assist in the development of enhanced job satisfaction and positive staff attitudes. 
In addition to EI and recognition of what teachers are experiencing, leaders will also need to be a servant to their teachers to help develop their capacity to cope with stress and also to remove those stressors that the leader can control. Beck (2014) explained that servant leaders are those that organizational stewards. This stewardship entails being responsible for the common interest of the organization and being a caretaker and a role model (Beck, 2014). Attending to the common interest of the organization would mean recognizing that teacher stress and coping can influence job satisfaction (McCarthy, Lambert, \& Reiser, 2014) and taking steps to ensure the organization is taking steps to positively influence those factors.

The present study aims to contribute to the understanding of the relationship between stress and job satisfaction using coping as a moderator. This study will also further the research base surrounding utilization of single item measures of stress, coping, and job satisfaction. In doing so, the results could further enable school leaders to be in touch with their teachers' stress, coping, and job satisfaction and give those leaders an expeditious way to determine present levels of those factors. Leaders could then turn this data into actionable steps in order to maintain or improve teacher stress and coping levels. 


\section{SECTION THREE:}

SCHOLARLY REVIEW FOR THE STUDY 


\section{Introduction to the problem}

Amy Benjamin, a teacher who contributes to Education Week, stated in a November 9, 2013 blog post, "It is said that stress equals the distance between what you have control over and what you are responsible for. Using that definition, teaching is a stressful job." (https://blogs.edweek.org/teachers/classroom_qa_with_larry_ferlazzo/2013/11/response_using_s elf-compassion_to_recover_from_a_bad_day.html) It is not evident if Ms. Benjamin spent time researching the theoretical underpinnings of stress, but she has captured what is perhaps the fundamental process of the stress response among all people, according to the transactional model of stress from Lazarus and Folkman (1987). Stress and its effects on teachers are significant problems of practice facing all education practitioners (Kyriacou, 2001), from teachers to administrators to policymakers. Included in the potential casualties resulting from teacher stress is job satisfaction. Job satisfaction among all workers has been shown to have a positive influence on job performance and commitment, and a negative relationship with turnover intention (Liu \& Ramsey, 2008). Stress and job satisfaction are typically negatively associated with one another, so knowing about teachers' stress levels and their ability to cope with them should be something that schools and policymakers consider for the overall health of their organization. Additionally, having a clear understanding of job satisfaction among teaching staff could be a key to helping retain more teachers.

Teaching has been shown to be a highly stressful profession, with stress levels on par with professions such as police officers and ambulance workers (Johnson, 2005). According to Kyriacou (2001), stress for teachers comes from a number of organizational factors, such as time pressures and workload, being evaluated by others, status, administration and management, and poor working conditions. Indeed, schools and policymakers have instituted many changes over 
the past couple of decades that have had a negative impact on teacher stress levels (Dunn, 2018). Examples of such changes include high stakes testing, changes to evaluation systems and the overall effect of the era of accountability (Ryan, et al., 2017). These changes have had a demonstrable impact on increasing both teacher stress and turnover intentions (Ryan, et al., 2017).

Teacher attrition has remained a persistent problem for schools (Goldring, Taie, \& Riddles, 2014; Inman \& Marlow, 2004; Dunn, 2018; Chambers Mack, Johnson, Jones-Rincon, Tsatenawa, \& Howard, 2019). Teachers' job satisfaction has been directly connected to teacher retention (Skaalvik \& Skaalvik, 2011), and it has also been tied to teachers' decisions about whether or not to stay in the teaching profession at all (Klassen \& Chiu, 2011; McCarthy, Lambert, Crowe, \& McCarthy, 2010). Literature identifies stress as an influencer of lower job satisfaction among teachers, and high ratings of stress are prevalent among teachers (Kyriacou, 2001). Coping consists of those skills and methods that teachers use to deal with their stress (Lazarus \& Folkman, 1984). Many studies have examined the combined effects of teacher stress and coping and generally conclude that stress is part of every teacher's job and that the effect stress has on outcomes (such as student achievement, intention to leave the profession, physical symptoms) are moderated by the teacher's coping capacity or style. The present study aims to directly test the relationship between teacher stress and job satisfaction while utilizing coping as a moderator.

This chapter will thoroughly review both foundational and current literature on stress among teachers, sources of teacher stress, consequences of that stress, and how stress influences teacher self-efficacy. Because stress is processed by all people using coping, a thorough review of teacher coping skills is also included in this chapter along with a review of current literature 
that examines teacher stress, coping, and job satisfaction. Because this study will also be utilizing single-item measures of stress, coping, and satisfaction, a thorough review of the use of single-item measures will be given. Additionally, the chapter will review the specific use of single-item measures of stress, coping, and job satisfaction. There is also theoretical support for the purpose of the current study in the Transactional Model of Stress (Lazarus \& Folkman, 1984) and the Theory of Margin (McCluskey, 1963), and those theories will be reviewed in depth.

\section{Review of Literature}

\section{Stress}

Kyriacou (2001) defined teacher stress "as the experience by a teacher of unpleasant, negative emotions, such as anger, anxiety, tension, frustration or depression, resulting from some aspect of their work as a teacher." (p. 28) Multiple studies have concluded that teaching is a highly stressful profession (Kyriacou, 2001; Johnson, 2005; von der Embse, Ryan, Gibbs, \& Mankin, 2019). Teacher stress can lead to negative influences on job satisfaction, burnout, absenteeism, and the decision to leave the profession altogether (Betoret, 2006; DarlingHammond, 2000; Jepson \& Forrest, 2006; McCarthy, Lambert, \& Reiser, 2014; Sass, Seal, \& Martin, 2011). Students can also feel the effects of teacher stress because teachers who are stressed can experience reduced effectiveness and lower student engagement (Wong, Ruble, Yu, \& McGrew, 2017). This section of the review of extant literature will focus on the sources and effects of stress on teachers.

\section{Sources of Teacher Stress}

Herman, Hickmon-Rosa, and Reinke (2018) found that a high percentage of teachers (93\% in their study) can be characterized as having high levels of stress. Johnson et. al (2005) found, that compared among a host of other occupations, teachers experienced stress levels at or 
above nearly all of them and similarly to professions such as ambulance workers, prison officers, and police. Demands on time, increasing class sizes, student behavior problems, conflict with other staff, and inadequate resources (both materials and buildings) can all be contributors to teacher stress (Wiley, 2000). One only needs to ask a teacher to hear that there are many stressors (and many rewarding experiences, as well) in their day-to-day work and in the overall goals for any student, class, or school during a year. There have also been a host of policy changes in the past decade that have added to the stress levels of teachers. Adoption of the Common Core State Standards (or something similar), updates to curriculum materials and instructional practices as a result of the standards changes, and changes to teacher evaluation systems that frequently include student standardized test scores are a few of these recent changes that have been linked increased stress for teachers (von der Embse, Ryan, Gibbs, \& Mankin, 2019). Teachers have identified many sources of stress within their day-to-day jobs. Those sources include classroom management difficulties, time pressure and workload concerns, adjusting to change, teacher evaluation, peer relationships, self-esteem and status, working with administration, role conflict/ambiguity, and poor working conditions (Kyriacou, 2001; Travers \& Cooper, 1996).

Novice teachers report higher levels of stress than more experienced teachers (Antoniou, Polychroni, \& Vlachakis, 2006). According to Helms-Lorenz and Maulana (2015), beginning teachers have a litany of stressors that stem from both their jobs and their personal lives. These can include a potentially overwhelming workload, insufficient support from principals and/or mentors, student motivation problems or behavior problems, or negative peer relationships. Indeed, other studies suggest that stress varies across different points in a teacher's career (Hubermann, 1993). Ingersoll (2001) found that teachers during the first five years of their career 
face competing professional and personal demands, such as learning their craft and potential life events such as marriage and starting a family. Prillentensky, Neff, and Bessell (2016) identified numerous stressors that teachers, particularly early career teachers, face such as isolation, inadequacy, anxiety, students, parents, colleagues, disempowering policies and practices. Hubermann (1995) found that the gap between pre-service teachers' perceptions of the job of teaching and the reality of the job can also lead to early attrition. One study that compared practicing educators and pre-service educators found that practicing educators reported overall higher levels of stress and higher levels of intention to quit than did pre-service educators (Klassen \& Chiu, 2011). The authors hypothesize that the pre-service teachers are not yet sufficiently exposed to the reality of teaching, and that lack of exposure could explain the lower levels of stress and intention to quit among pre-service teachers (Klassen \& Chiu, 2011).

Unfortunately, teacher stress can lead to a litany of negative outcomes for both the teacher and his or her students. While common sources of stress can be identified for teachers as a group, it is important to remember that these sources of stress can affect each individual teacher differently. There is an interplay between sources of stress and an individual's personal characteristics and circumstances that can determine how stress impacts that individual (Kyriacou, 2001). Griffith et al. (1999) found that social support and effective coping strategies can affect that teacher's perception of stress. This would indicate that teachers with varying levels of social support and/or effective coping strategies could experience what is objectively the same situation in quite different ways and that their perception of stress from those situations would vary from person to person (Kyriacou, 2001).

\section{Consequences of Teacher Stress}


Teachers who experience stress go through a stress response which leads to mental or emotional worry and/or decreased job satisfaction or commitment (Klassen \& Chiu, 2011). When these stress responses are experienced over a significant duration of time, teachers will then experience stress outcomes such as burnout (Helms-Lorenz \& Maulana, 2015). Wiley (2000), in a synthesis of research on teacher stress, explained that stress comes from one of four domains: extra-organizational, organizational, task-related, and individual. Teachers are dealing with stressors from all these domains at varying degrees and varying times. Further complicating these stressors and teachers' reaction to them is that each individual processes them in a different way. So, one stressor may be of no significant consequence to one teacher, while it makes another physically ill (Wiley, 2000). McCarthy, Lambert, Crowe, and McCarthy (2010) put it well when they explained,

...although there are aspects of teaching in any school that can cause teachers stress (i.e., large class sizes, high levels of instructional and noninstructional duties, lower salaries, etc.), it is important to understand that teachers' perceptions of their own demands and resources can be an important determinant of whether or not they experience stress. (p. 308)

Klassen and Chiu (2011) found a significant, positive correlation between overall stress and intention to quit and a significant, negative correlation between overall stress and occupational commitment. Teachers' stress can directly influence job satisfaction, burnout, absenteeism, and the decision to leave the profession altogether (Betoret, 2006; DarlingHammond, 2000; Jepson \& Forrest, 2006; McCarthy, Lambert, \& Reiser, 2014; Sass, Seal, \& Martin, 2011). Test-based accountability measures have a direct relationship with test-related 
stress, teacher burnout, and attrition (Ryan, et al., 2017). Teachers with high levels of stress are more likely to give more behavior referrals (Hastings \& Brown, 2002; Hastings \& Bham, 2003).

One of the potential outcomes of stress for the teacher is burnout. Burnout is defined as the collection of responses to prolonged stress in one's job (Herman, et al., 2018). The key consequences of burnout include emotional exhaustion, depersonalization of students and/or colleagues, a perceived lack of personal accomplishment (or low self-efficacy), lack of engagement, irritability, and work-related apathy (Lauermann \& Konig, 2016; Butler \& Constantine, 2005). Burnout and stress can lead teachers to increased intention to leave their job and increased absenteeism (Belcastro \& Gold, 1983). Clearly, burnout is not a desirable condition for teachers and stress is a contributor to it.

In addition to burnout, other consequences of teacher stress are also important to discuss. Skaalvik and Skaalvik (2015) found that stress resulted in several negative consequences, including exhaustion and physical symptoms, a reduced sense of accomplishment and selfefficacy, and a negative impact on self-esteem. Teachers in the Skaalvik and Skaalvik (2015) study reported that they experienced a reduced ability to prepare for teaching, reduction in the quality of friendships and social lives, neglect of family relationships, negative affect with their students, and a perceived loss of ability to manage their workload. These findings show a clear erosion of teacher self-efficacy as a result of stress. The negative affect with students was also found by Wentzel (2010), who found that stressed teachers tend to have poorer relationships with their students, which can lead to negative academic and behavioral outcomes for the students (Wentzel, 2010). Positive relationships between teachers and students is a goal that all educators should strive for, and stress can certainly be a barrier. Those teachers who believe their classroom demands exceed their resources report a host of negative outcomes: more burnout 
symptoms (McCarthy, Lambert, O’Donnell, \& Melendres, 2009), more students with negative behavior problems (Lambert, Kusherman, O'Donnell, \& McCarthy, 2006), and more students with learning disabilities (Lambert, McCarthy, O’Donnell, \& Melendres, 2006).

Another casualty of stress can be teacher self-efficacy. Self-efficacy for teachers consists of a teacher's belief in their ability to perform the necessary activities (such as planning, organizing, and carrying out learning activities) that are needed to achieve educational goals (Skaalvik \& Skaalvik, 2010). A teacher's self-efficacy can determine their persistence with a difficult situation, their overall effort expended, and their willingness to initiate a task (HelmsLorenz \& Maulana, 2015) and perceptions of self-efficacy have either a mitigating or exacerbating effect on the consequences related to stress (Herman et al., 2018). Current literature is somewhat unclear on whether stress begets lower feelings of self-efficacy (Skaalvik \& Skaalvik, 2015) or if concerns over self-efficacy beget job stress (Schwarzer \& Hallum, 2008). It may be that stress and perceptions of self-efficacy lead to each other regardless of which a teacher started with. What is clear, though, is that teacher stress and burnout have a clear link to teacher self-efficacy (Herman, et al., 2018; Avanzi et al., 2017; Lauermann \& Konig, 2016; Skaalvik \& Skaalvik, 2015; Hultell, Melin, \& Gustavsson, 2013; Schwarzer \& Hallum, 2008; Skaalvik \& Skaalvik, 2010). Schwarzer and Hallum (2008) found that teachers with either (or both) low teaching-specific self-efficacy or low general self-efficacy had a significant likelihood of experiencing job stress which then leads to burnout. Those teachers with low general selfefficacy were more likely to succumb to stress and burnout than those with just low teaching self-efficacy (Schwarzer \& Hallum, 2008).

On the opposite end of the self-efficacy spectrum, Herman et al. (2018) found that teachers with high levels of self-efficacy experience positive student outcomes in the classroom. 
In fact, this success serves as a positive feedback loop in which the teacher's self-efficacy is improved as a result of the positive classroom outcomes which makes it more likely that teachers will continue with best classroom practices (Herman et al., 2018). Those teachers with low selfefficacy, though, experience a negative feedback loop. The teachers who do not believe they can positively affect student behavior or academic outcomes will be less likely to continue to pursue improvement in those areas (Herman et al., 2018), creating a downward spiral over time that is detrimental for both the teacher and students. Teaching-specific self-efficacy and the general self-efficacy of teachers are so important to schools, teachers, and students and teacher stress is closely connected to both forms of efficacy.

Another clear consequence of teacher stress has to do with the financial ramifications for school districts across the nation. Berry (2010) found that teachers increase their effectiveness as they persist in their careers. If teachers are leaving the profession due to stress-related issues, then they are not reaching their maximum effectiveness. Additionally, schools are investing in training early career teachers, and if they do not remain in the profession, those dollars invested do not have a sufficient return on investment for school districts (Ryan, et al., 2017). The importance of retaining early career teachers is magnified even more by the fact that 200,000 fewer teachers entered teacher training programs in 2014 than in 2008 (U.S. Department of Education, Office of Postsecondary Education, 2015). If the nation is facing a shortage of teachers, remedying stress-related attrition could be one way to minimize the effects of the shortage. How teachers manage their stress can be an important factor in how or whether they will experience the outcomes described in this section. In the next section, we will describe coping and its role in the stress response.

\section{Coping}


It is evident that elevated stress levels are commonplace among teachers and there are many negative outcomes as a result of that stress. Schools would be wise to take a proactive approach to address stress with their staff. Herman, et al. (2018) reported that stress is not the only characteristic that needs to be taken into account, as coping skills and perceptions of selfefficacy have either a positive or negative effect on consequences related to stress. As mentioned above, stress is impacting teachers' self-efficacy beliefs, so finding a way to help identify teachers who are experiencing high levels of stress with lesser ability to cope would be advantageous for the teachers, students, and school leaders involved.

Coping is defined as "all of the cognitive and behavioral efforts, constantly changing, expended (by one person) to manage the internal and/or external demands perceived as consuming or exceeding his resources" (Lazarus \& Folkman, 1984, p. 141). Coping, then, could be a range of strategies that include both productive outcomes and negative outcomes. Kyriacou (2001) claims that individual coping strategies fall into two main categories: direct action techniques and palliative techniques. Direct action techniques are those things a teacher does to eliminate the source of stress (such as learning a new teaching technique, speaking directly to a person who is a source of stress, or better management of his or her time) (Kyriacou, 2001). Palliative techniques are those things a teacher does to lessen the feeling of stress. These could include mental approaches such as reframing a problem to change their appraisal of it or physical approaches that help the teacher feel more relaxed (Kyriacou, 2001).

Positive coping strategies were found to be used more often by experienced teachers than by novice teachers (Laugaa, Rascle, \& Bruchon-Schweitzer, 2008). Laugaa, Rascle, and Bruchon-Schweitzer (2008) found that coping centered on the problem was found to have a direct negative effect on all three facets of burnout (emotional exhaustion, professional 
nonaccomplishment, and depersonalization), while traditional teaching had a positive effect on all three facets and avoidance coping has a positive effect on two of the three (professional nonaccomplishment and depersonalization). Foley and Murphy (2015) also explained that coping strategies can be either problem focused (working to directly resolve the stressor) or emotion focused (working to change the meaning of the stressor or challenge), but there are coping strategies that put one's health at risk (such as substance abuse). Multiple studies have demonstrated that the use of negative or ineffective coping strategies only serve to increase teacher burnout levels (Austin, Shah, \& Muncer, 2005; Marroquin et al., 2010; Shin et al., 2014), while Austin, Shah, and Muncer (2005) showed that teachers that use problem centered coping strategies experience lower levels of burnout. Research by Smetackova et al. (2019) also demonstrated that the use of positive coping skills had a significant negative correlation (-0.259) with burnout and the use of negative coping skills had a significant positive correlation (0.553) with burnout. Smetackova et al. (2019) also found a significant positive correlation (0.354) between positive coping and self-efficacy and a significant negative correlation $(-0.214)$ between negative coping and self-efficacy. Still another study divided coping into two types, active and avoidant (Stoeber \& Rennert, 2008), with active coping having more positive outcomes than avoidant. The types of coping employed can have a significant impact on how successful a teacher is in dealing with any stressor and whether a teacher ultimately ends up experiencing burnout or even whether they are confident in their professional abilities.

\section{Stress and Coping}

Herman et al. (2018) further established the importance of examining both stress and coping for teachers by classifying teachers into four categories: stressed/low coping, stressed/moderate coping, stressed/high scoping, and well adjusted. The stressed/low coping 
group (which comprised 3\% of the teachers they surveyed) saw lower student achievement and increased disruptive behaviors (Herman et al., 2018). Kyriacou (2001) pointed out that one of the major problems facing the teaching profession is the number of teachers leaving the profession after just a few years and also those teachers who stay but become disaffected. Hubermann's (1993) findings supported this concern in that many teachers face a mid-career crisis and have to reassess their career choice. The key then, and one of the goals of this study, is to determine a way to identify which teachers may be experiencing more stress than they can effectively cope with so they can receive the needed resources to deal with their stress and protect their sense of self-efficacy. Having a holistic understanding of teachers' stress and coping levels can help districts target support services or spur them to implement more universal supports to lessen stress and to teach productive coping skills.

One key point about the interplay between stress and coping is that prolonged exposure to stress can cause teachers to engage in emotional rumination, in which they spend excessive time focusing on the source of stress and prolong the negative feelings association with a stressor (Roger \& Hudson, 1995). Antoniou, Ploumpi, and Ntalla (2013) also found that teachers who engage in avoidance coping experience higher levels of burnout. The type of coping utilized by teachers, then, can have an important impact on the outcomes experienced due to stress. Another study found that teachers coped with stress using four main strategies: need to communicate, coping centered on the problem, avoidance coping, and adopting a traditional style of teaching (Laugaa, Rascle, \& Bruchon-Schweitzer, 2008). The two former strategies led to positive outcomes, while the latter two strategies led to negative outcomes for both the teacher and students. Zurlo, Pes, and Capasso (2016) found that coping strategies focused on problem solving and strategies focused on hobbies and pastimes have a buffering effect on stressors. They 
also found that strategies based on not confronting the situation were not adequate in aiding teachers to deal with stressors. The reason coping can be so important for teachers is that those teachers that employ effective coping strategies experience lower degrees of burnout and better overall health than those teachers who use palliative techniques (Van Dick \& Wagner, 2001). Those teachers that are experiencing high levels of stress are more likely to employ palliative coping strategies (Austin, Saklofske, \& Egan, 2005), which further increases the importance of giving teachers help in engaging in effective coping mechanisms.

In addition to determining teacher stress levels and their ability to cope, some research has indicated that stress levels vary throughout a teacher's career (Harmsen, Helms-Lorenz, Maulana, \& van Veen, 2019; Lauermann \& Konig, 2016; Huberman, 1993), so it is important to pay attention to the stress levels of all teachers, not just those early in their careers. Therefore, the present study aims to measure stress levels across bands of experience to see if there are some experience levels that are characterized by more stress than others.

Many studies have examined the combined effects of teacher stress and coping and generally conclude that stress is part of every teacher's job and that the effect stress has on outcomes (such as student achievement, job satisfaction, intention to leave the profession, physical symptoms) are moderated by the teacher's coping capacity or style (Antoniou, Ploumpi, \& Ntalla, 2013; Herman, et al., 2018; Laugaa, Rascale, Bruchon-Schweitzer, 2008). Using coping as a moderator when examining the impact of stress on other outcomes has been supported by many studies for outcomes such as academic achievement, disruptive behaviors (Herman, et al., 2018) and teacher burnout (Antoniou, Ploumpi, \& Ntalla, 2013; Laugaa, Rascale, Bruchon-Schweitzer, 2008). Using coping as a moderator also has theoretical support, as it is seen as a moderator in the transactional model of stress put forth by Lazarus and Folkman (1984), though the theory does 
not employ coping as a moderator to specifically examine satisfaction. The present literature, though, is lacking in direct connections between overall stress and job satisfaction while using coping as a moderator, so this study aims to fill in that gap.

\section{Job Satisfaction}

As noted earlier among the many effects of stress, a critically important effect relates to job satisfaction. Job satisfaction has been tied to teachers' decisions about whether to stay in the profession (Klassen \& Chiu, 2011; McCarthy, Lambert, Crowe, \& McCarthy, 2010). Job satisfaction is defined as the extent to which people like or dislike their job (Spector, 1997). Klassen and Chiu (2011) also explained that commitment to the profession is influenced by job satisfaction. Herzberg (1966) noted that job satisfaction is influenced by factors that prevent dissatisfaction, such as peer relationships, salary, organizational policies, supervision. Herzberg (1966) also identified working conditions and factors that promote enhanced satisfaction, such as achievement, recognition, the work itself, responsibility, and advancement. While there are studies that include job satisfaction as a variable, many use it as an input variable in determining other student or teacher outcomes (Antoniou, Ploumpi, \& Ntalla, 2013; Herman, et al., 2018; Laugaa, Rascale, Bruchon-Schweitzer, 2008; McCarthy, Lambert, Crowe, \& McCarthy, 2010; McCarthy, Lambert, \& Reiser, 2014; Skaalvik \& Skaalvik, 2015). There are also studies that examine job satisfaction as an output variable, utilizing factors such as self-efficacy (Klassen \& Chiu, 2010), or workload and working conditions (Liu \& Ramsey, 2008) as inputs instead of utilizing stress as an input, although workload and working conditions could be causes of stress, as previously described. Overall, job satisfaction is extraordinarily important for workers, and it has been tied to outcomes such as performance, mental health, and career decisions (Caprara et al., 2003, 2006; Fritzsche and Parrish, 2005; Judge et al., 2001; Skaalvik and Skaalvik, 2009). 


\section{Stress and Job Satisfaction}

Teachers with greater work-related stress have lower job satisfaction (Jepson \& Forrest, 2006; McCarthy, Lambert, Crowe, \& McCarthy, 2010). Stress and job satisfaction are typically related in opposite ways to important outcomes. An example would be relationships with students. When teachers have negative student relationships, they have greater stress (Jennings \& Greenberg, 2009), while teachers who have positive student relationships have increased job satisfaction (Veldman, van Tartwijk, Brekelmans, \& Wubbels, 2013). Zurlo, Pes, and Capasso (2016), though, found that job satisfaction has a protective effect in teachers who are dealing with stressful teaching situations. Ouellette, Frazier, Shernoff, Capella, Mehta, Marinez-Lora, Cua, and Atkins (2018) proposed a model in which there are three contextual levels that influence teacher stress and job satisfaction: organizational health, student functioning and behaviors, and teacher self-efficacy. These three contextual considerations capture nearly all the sources of stress earlier, and research presented above would support each of these contextual levels as being influencers of stress. Ouellette, et al. (2018) were able to demonstrate the organizational health was strongly and negatively associated with teacher stress and that organizational health was positively associated with job satisfaction.

The connections between stress and job satisfaction have been studied by multiple scholars. Liu and Ramsey (2008) found that stress from poor working conditions had a significant negative impact on job satisfaction. Reilly, Dhingra, and Boduzsek (2014) found a moderate negative correlation between stress and job satisfaction and that perceived stress was the only significant predictor of job satisfaction $(\beta=-0.35)$ among host of other potential predictors. Skaalvik and Skaalvik (2015) explained that factors such as supportive school environments, positive relationships with colleagues and administration, and teacher autonomy 
are all positively related to job satisfaction, but all those factors can also be sources of stress when environments are not supportive, relationships are not positive, and autonomy is diminished as explained earlier in the sources of stress section. In fact, Skaalvik and Skaalvik's (2015) work in this study showed that lack of autonomy, value conflicts, and teamwork were sources of stress for teachers. Karabatak and Alanoglu (2019) also found stress was a significant and negative predictor $(\beta=-0.65, \mathrm{p}<.01)$ of job satisfaction. Overall, the research base is clear that increased stress is negatively related to job satisfaction.

\section{Coping and Job Satisfaction}

Studies connecting coping and job satisfaction among teachers are few in number. McCarthy, Lambert, Crowe, and McCarthy (2010) conducted one such study. They found when teachers have lower levels of personal resources for stress prevention that they tend to experience a decrease in job satisfaction. It has also been shown that, among university employees, positive coping strategies (direct action techniques) are positively correlated with job satisfaction, while negative coping strategies (palliative techniques) are negatively correlated with job satisfaction (Mark \& Smith, 2012). A study of employees across 75 different jobs found that higher coping resources were predictive of lower strain and higher job satisfaction (Decker \& Borgen, 1993). In a study of medical interns, Vinothkumar et al. (2016) explained that physicians who utilize positive coping strategies tend to have higher levels of job satisfaction. Srivistava and Tang (2018) reached a similar finding among sales professionals, finding that problem-focused coping had a positive and significant relationship with job satisfaction. While not all of the research connecting coping and job satisfaction is focused on teachers, it is clear that coping has an influence on the job satisfaction by workers in general.

\section{Job Satisfaction, Stress, and Coping}


There is a wide research base of studies that examine stress, coping, and job satisfaction, though none examine this combination in a moderation analysis using coping as a moderator, and some do not examine the interplay between these three constructs. In addition, many studies relating all three constructs are in professions other than K-12 education. Those studies do provide some clues about the way stress, coping, and job satisfaction are related, though. In a study of operating room nurses, several connections between stress, coping, and job satisfaction were made. First, the authors found that all the dimensions of stress they measured were positively correlated with destructive coping strategies, but some of those stressors were also positively correlated with positive coping strategies (Chen, Lin, Wang, \& Hou, 2009). Chen et al. (2009) found that the job stressors they measured were all negatively correlated with four of their five measured job satisfaction domains and that three of the five job satisfaction scores were inversely related to destructive coping strategies. In a 1996 study of university academic staff, Abouserie found approximately $84 \%$ of those staff members were at least moderately stressed and that job stress was negatively and significantly related to job satisfaction. Abouserie (1996) also went on to identify different coping methods employed by those university staff, but the study did not attempt to include coping in the relationship between stress and job satisfaction. A study of full-time employed individuals found that stress and strain were the most significant factors influencing job satisfaction and that coping did not make a significant contribution to job satisfaction (Fogarty et al., 1999).

The most relevant study addressing these three constructs among K-12 educators was conducted by McCarthy, Lambert, and Reiser (2014). The authors utilized the Classroom Appraisal of Demands and Resources (CARD) to sort teachers into three categories: demand group (demands exceed resources), balanced group (demands and resources balanced), and 
resource group (resources exceed demands). Statistically significant differences among those groups were found across a variety of categories. Among those differences was job satisfaction in which there was a large difference with an effect size of 1.5 between the demand and resource groups (McCarthy, Lambert, \& Reiser, 2014). The demand group also had significant amount more intention to leave their current job than both the resource and balanced groups. Additionally, the study found that as job satisfaction increased, teacher plans to leave their current position decreased significantly (McCarthy, Lambert, \& Reiser, 2014). This study indicates that job satisfaction is not only significantly intertwined with demands (stress) and resources (coping), but also that job satisfaction directly affects a teacher's plans to remain in their current position making it an important consideration for all schools. This study, though, did not measure overall stress and coping, but rather consisted of teacher ratings of a finite list of descriptors of demands and resources that could be considered sources of stress and coping, repsectively.

\section{Single Item Measures of Stress and Coping}

One challenge in measuring stress, coping, or job satisfaction (and many other items) can be survey fatigue (also called survey burden). The use of single-item measures of is not new, and, thus, their use comes with criticisms and benefits. Multiple studies have shown that the perceived survey burden can cause lower response rates (Crawford, Couper, \& Lamias, 2001; Woods \& Hampton, 2005). On the other hand, shortening surveys can improve response rates and minimize non-response bias (Rogelberg \& Stanton, 2007; Stanton, Sinar, Balzer, \& Smith, 2002), making single-item measures particularly advantageous. The use of single-item measures can also help facilitate the use of more frequent surveying because of the reduced load on participants (Fisher, Matthews, \& Gibbons, 2016). In addition, Scarpello and Campbell (1983) 
explained that the use of multi-item scales for job satisfaction may not be ideal because they can either include items that are not relevant to the construct being measured or they could omit items that are relevant. This means single-item measures may be more inclusive than scales (Scarpello \& Campbell, 1983). Of course, there are also criticisms of the use of single-item measures. In contrast to the findings of Scarpello and Campbell (1983), some say that singleitem measures may be deficient in measuring some constructs because they do not sufficiently represent the content domain of that construct (Cronbach \& Meehl, 1955; Nunnally \& Bernstein, 1978; Schriesheim et al., 1991). Others may say that the reliability and/or validity of single-item measures cannot be calculated, particularly for single-item measures that were utilized on an adhoc basis (Fisher, Matthews, \& Gibbons, 2016). Fisher, Matthews, and Gibbons (2016) provided a useful conclusion on the utilizing single-item measures:

The use of single-item measures, if done systematically using concrete and validated items, should not be viewed as a fatal flaw within a study; whether single- or multipleitem measures are used, the study as a whole must be examined in terms of the contribution it makes in advancing the field. (pp. 21)

It follows from the research presented above, that close examination of single-item measures for stress, coping, and job satisfaction would be important. Kyriacou (2001) explained that teacher stress is typically measured using self-report questionnaires. Many studies have used a single item measure of stress, such as "I find teaching to be stressful" (Boyle, Borg, Falzon, \& Baglioni, 1995; Chaplain, 2008; Klassen, Usher, \& Bong, 2010; Kyriacou, 2001; Manthei, Gilmore, Tuck, \& Adair, 1996). Houdmont et al. (2019) conducted a qualitative study examining sources of stress for a sample of 55 adults who were employed full time. Their study also included a single-item measure of general stress. The authors concluded that a single-item 
measure of stress represented a good preliminary assessment of which workers were or were not in need of a further risk assessment for stress consequences (Houdmont et al., 2019). In addition, Houdmont et al. (2019) noted the utility of single-item measures, explaining that they reduce survey fatigue and could be given frequently to allow for early identification of stress problems or to monitor the effectiveness of a stress reduction intervention.

Eddy, Herman, and Reinke (2019) conducted a study to test the concurrent and predictive validity and sensitivity to change of single-item teacher stress and coping measures. This study explains that single-item measures can give a more global account of factors related to stress or coping than multi-item measures that are limited to just the specific stressors or coping strategies that were asked about in the survey. In addition, Eddy, Herman, and Reinke (2019) found that the single-item stress measure was positively associated with emotional exhaustion and negatively associated with personal accomplishment while the single-item coping measure was negatively associated with emotional exhaustion, negatively associated with depersonalization, and positively associated with personal accomplishment. The coping item was also a significant predictor of end of the year emotional exhaustion and positively associated with self-efficacy (Eddy, Herman, \& Reinke, 2019). Wanous, Reichers, and Hudy (1997) explored the reliability of single-item measures of job satisfaction and found that the minimum estimated reliability of such measures to be close to .70 . In addition, the authors asserted that single-item measures are acceptable for use when the situation is such that scales would not be effective to use (Wanous, Reichers, \& Hudy, 1997). Further supporting the use of a single-item measure of job satisfaction, Scarpello and Campbell (1983) found that the single-item measure of job satisfaction was preferable over a scale based on the sum of job facets. It is clear that these single-item measures of stress, coping, and job satisfaction could be powerful, expeditious, and reliable in helping 
teachers and school leaders get a clear picture of whether staff members may or may not be on the path to negative outcomes, and, thus far, there is no research that utilizes these single-item measures to examine relationships between these quantities.

\section{Theoretical Framework}

The wealth of literature examining stress and coping and their relationships with many outcomes have theoretical support for connecting the concepts. The primary frameworks that support this study (and many of the studies reviewed thus far) are the transactional model of stress (Lazarus \& Folkman, 1984) and McClusky’s (1963) Theory of Margin. Both frameworks center their attention on the amount of stress individuals are experiencing as compared to their ability to adapt to that stress. The existing literature on teacher stress, self-efficacy, burnout and subsequent intent to leave all support an examination of teachers through these two related frameworks.

\section{Transactional Model of Stress}

Lazarus and Folkman (1984) developed a model called the transactional model of stress. They state that the person-environment relationship is mediated by two processes: cognitive appraisal and coping (Lazarus \& Folkman, 1987). Lazarus and Folkman (1984) define stress as "a particular transaction between the individual and the environment in which the situation is evaluated as exceeding his resources or threatening his well-being” (p. 19), and coping as "all of the cognitive and behavioral efforts, constantly changing, expended (by one person) to manage the internal and/or external demands perceived as consuming or exceeding his resources" ( $\mathrm{p}$. 141). As earlier described, coping can be a range of strategies that induce both productive outcomes and negative outcomes. One study found that teachers coped with stress using four main strategies: need to communicate, coping centered on the problem, avoidance coping, and 
adopting a traditional style of teaching (Laugaa, Rascle, \& Bruchon-Schweitzer, 2008). The two former strategies led to positive outcomes, while the latter two strategies led to negative outcomes for both the teacher and students.

According to this model, life demands are filtered through two distinct cognitive processes (Figure 2) in which the demand is appraised and then coped with (Lazarus \& Folkman, 1987). To begin, the individual will appraise the event, which consists of two phases. The first phase, primary appraisal, is concerned with whether the event is motivationally relevant (Lazarus \& Folkman, 1987). This appraisal is a determination of whether the event is something that influences a person's well-being (harm, threats, challenges, benefits, etc.). This primary appraisal is, of course, dependent on the individual making the appraisal because of varied motivation, goals, and personality traits (Lazarus \& Folkman, 1987). If the primary appraisal determines that the event is motivationally relevant, then a person will enter the secondary appraisal. Secondary appraisal consists of determining whether any actions can be taken that will help improve or resolve the motivating event (Lazarus \& Folkman, 1987). Essentially, secondary appraisal is a determination of whether one believes he or she can exert control over the outcome of the event. This determination depends on whether a person believes they have sufficient coping power or resources to mitigate the demand of the event. Once this determination has been made, a person will then begin to employ the coping methods (either emotion-focused, problem-focused, or both) they believe will best suit the situation (Lazarus \& Folkman, 1987). Again, those coping methods could result in either positive or negative outcomes depending on the purpose of the coping method and the specific situation. 
Figure 2. Lazarus and Folkman (1984) Transactional Model of Stress.

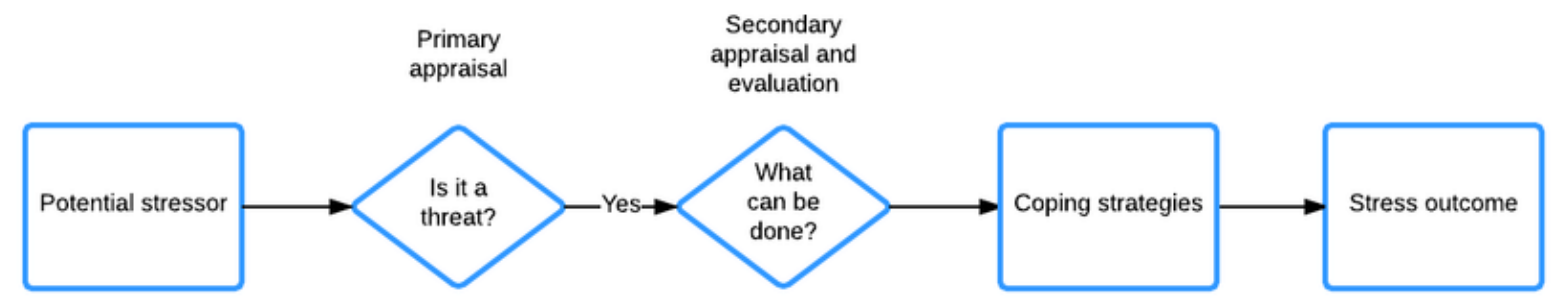

Even though this theory offers an explanation of how every person processes a potentially stressful event, it is important to note that not every person will reach the same determination or utilize the same coping methods in response to the same or similar events. The overall appraisal of the event, and thus the reaction to the event, is dependent on generalized beliefs about one's own competence to handle situations. These generalized beliefs could include things like self-confidence, mastery of the material required, self-esteem, trust, or an internal locus of control (Lazarus \& Folkman, 1987). Even these generalized beliefs could be trumped by situational appraisals that are depend upon the context of the event that override the more generalized beliefs (Lazarus \& Folkman, 1987). Thus any appraisal process and the subsequent coping with that process is certainly dependent upon the individual involved, and the amount of stress encountered as a result of any event is dependent on the specific individual.

\section{Margin in Life}

In 1963, McClusky proposed his Theory of Margin, consisting of two basic components: power and load. Load consists of the aspects of one's life that would be considered stressors, either physical, mental or emotional. Power consists of the resources an individual can utilize to deal with their load, such as money, time, or family (Hanpachern, Morgan, \& Griego, 1998). Load and power are used to determine an individual's Margin in Life (MIL) according to the formula: Margin = 1-Load/(Load + Power $)($ Hanpachern, Morgan, \& Griego, 1998). Hanpachern 
et al. (1998) explained that when an individual's load exceeds their power they are forced to focus on maintaining themselves, but when an individual's power exceeds their load they will feel a greater sense of satisfaction and believe they have more freedom of choice over what they do with their life. McClusky (1963) described how MIL relates to daily life:

Having a margin is essential to the mental hygiene of adulthood. An adult is a responsible person and since he has far less than perfect control over the situations in which he must exercise responsibility, he must at all times be prepared to meet unpredictable crises which make unusual demands on his ability to respond. (p. 17)

Hanpachern et al. (1998) found that for workers in a manufacturing company, MIL had a significant positive relationship with readiness for change, indicating that as a person's MIL increases, so does readiness for change. A later study confirmed this finding across a wide swath of workers in both for-profit and not-for-profit organizations that varied in industry, products, and services (Madsen, John, Miller, \& Warren, 2003). Similar to Hanpachern et al. (1998), some have described the Theory of Margin as a theory of adult potential (Madsen, et al., 2003; Hanpachern, Morgan, \& Griego, 1998). McClusky (1963) described MIL in a similar manner:

One who has margin has the power of choice over a range of relevant alternatives. Margin, then, would be a function of power of choice on the one hand, and the number of alternatives on the other. A person has margin when he has a broad field of life space, and is able to move autonomously within it. By contrast, a person lacks margin who has few or no alternatives, and lacks the power to exploit those he has. He is trapped with little space in which to move. (pp. 17-18) 
This connection between MIL and the potential for change is an important one in this study. A teacher with low MIL may feel "trapped" as McClusky described and have little opportunity to combat that feeling. As discussed above, teacher stress levels are high compared to many professions (Johnson et al., 2005). Additionally, stress begets burnout, and both of these are tied to a lower sense of self-efficacy and decreased likelihood to remain in a teaching position (Chambers Mack et al., 2019, Herman, et al., 2018; Avanzi et al., 2017; Lauermann \& Konig, 2016; Skaalvik \& Skaalvik, 2015; Hultell, Melin, \& Gustavsson, 2013; Schwarzer \& Hallum, 2008; Skaalvik \& Skaalvik, 2010). Teacher self-efficacy is closely tied to both teacher success and student academic and behavioral success (Herman et al., 2018). Clearly, low MIL could be an indicator of a teacher's job satisfaction because it is a measure of an individual's stress threshold which can lead to burnout and decreased job satisfaction. In addition, MIL supports the design of this study in its attempt to quantify both load and power, similar to how this study will quantify stress and coping.

\section{Summary}

The extant literature regarding teacher stress and coping makes it clear that this is a highstakes and high-cost issue confronting schools across the country. Teachers continue to face increasing stress loads, and while some are able to cope with that stress in adequate and positive ways, many are not and this is leading to a decrease in job satisfaction and teacher retention and can lead to increases in burnout symptoms. Schools would do well to be able to gain an accurate understanding of how their staffs are handling the ever-present stressors associated with teaching so that they can begin to intervene before job satisfaction and retention are negatively influenced. 
SECTION FOUR:

CONTRIBUTION TO PRACTICE 


\section{Plan for Dissemination of Practitioner Contribution}

After the defense of this dissertation, I plan to submit an article to The Missouri

Elementary Principal, which is a publication of the Missouri Association of Elementary School Principals.

\section{Type of Document}

The following article is written with the practitioner (elementary principals) in mind, and is written in a less technical manner while still conveying the rationale for the study and the results and their meaning.

\section{Rationale for this Contribution Type}

One of my goals for this research is to inform principals of the important relationships between stress, coping, and job satisfaction and how they influence these constructs among their staff in a way that aligns with research. This magazine article will reach a large target audience that has the power to make positive change in their buildings.

\section{Outline of Proposed Contents}

The article will start with a short review of literature regarding teacher retention, job satisfaction, stress, and coping and how those constructs are related to one another based on prior research. The review of literature will also make the case for the use of single-item measures of these constructs. Then, I will review the results of the study, why they are important, and what principals can do with the findings. 
Stress, Coping, \& Job

Satisfaction for

Teachers: How They

Work and How to

Measure Them

Efficiently?

By Seth Woods

\section{Keeping Teachers in the Profession}

It is no secret in the education community that teacher attrition is a serious problem of practice. Many studies suggest that between 25 and $50 \%$ of teachers do not continue to teach beyond their first 3 years of teaching (Blatt, 2016; Boe, Cook, \& Sunderland, 2008; Inman \& Marlow, 2004). These figures not only represent a problem of maintaining continuity within school staff, but they also represent a significant financial burden for school systems. Borman and Dowling (2006) estimated that recruitment, hiring, and training new teachers is costing $\$ 2.2$ billion annually. The Missouri Department of Elementary and Secondary Education reports that 3-year and 5-year teacher retention rates are $63.4 \%$ (in 20152016) and 34.6\% (in 2014-2015), respectively (Missouri Department of Elementary and Secondary Education, 2018), meaning this problem exists right here in our own districts and schools.

Many studies suggest that between 25 and $50 \%$ of teachers do not continue to teach beyond their first 3 years of teaching.

\section{Job Satisfaction, Stress, \& Coping}

Teachers' job satisfaction has been directly connected to teacher retention (Skaalvik \& Skaalvik, 2011), and it has also been tied to teachers' decisions about whether or not to stay in the teaching profession at all (Klassen \& Chiu, 2011; McCarthy, Lambert, Crowe, \& McCarthy, 2010). Job satisfaction also influences other aspects of teachers' work. It has been shown to have a positive effect on overall job performance (Wolomasi, Asaloei, \& Werang, 2019), effective use of classroom management (Kaya \& Selvitupo, 2019), teacher subjective well-being (Judge \& Watanabe, 1993), and teacher self-concept (Skaalvik \& Skaalvik, 2017).

One important influencer of job satisfaction is stress. Teachers with greater work-related stress have lower job satisfaction (Jepson \& Forrest, 2006; McCarthy, Lambert, Crowe, \& McCarthy, 2010). Skaalvik and Skaalvik (2015) explained that factors such as supportive school environments, positive relationships with colleagues and administration, and teacher autonomy are all positively related to job satisfaction, but all those factors can also be sources of stress when environments are not supportive, relationships are not positive, and autonomy is diminished as explained earlier in the sources of stress section.

So how are teachers to deal with their stress? The answer is coping. Coping is defined as "all of the cognitive and behavioral efforts, constantly changing, expended (by one person) to manage the internal and/or external demands perceived as consuming or exceeding his resources" (Lazarus \& 
Folkman, 1984, p. 141). As school leaders, we have seen the way our staffs have processed a host of stressors, particularly during the COVID-19 pandemic. We also have all seen that some individuals may not be bothered at all by a particular stressor, while others may truly struggle with that same stressor. The reason for this is that one teacher may have high stress, but also high coping strength, while another teacher may also have high stress but inadequate coping strength. These two teachers will likely experience very different outcomes because of the differences in their coping capacity (Herman, Hickman Rosa, \& Reinke, 2018). The Herman et al. (2018) study developed four classes of teachers within their sample based upon their stress and coping levels (High stress/low coping, high stress/medium coping, high stress/high coping, and low stress/high coping). They then examined various student outcomes (concentration, disruptive behavior, prosocial behavior, and achievement) for each class of teachers, but job satisfaction was not included as an outcome in this study. As you would probably expect, the teachers in the study were overall very stressed, with $93 \%$ of them in one of the high stress categories. Those teachers in the high stress/low coping group saw the highest rates of behavior problems and the lowest academic achievement. Studies like this make it clear that being mindful of teacher stress alone is not sufficient and that coping must also be considered.

\section{Stress \& Coping Theory}

Amy Benjamin, a teacher who contributes to Education Week, stated in a November 9, 2013 blog post, "It is said that stress equals the distance between what you have control over and what you are responsible for. Using that definition, teaching is a stressful job." (https://blogs.edweek.org/teachers/classroo m_qa_with_larry_ferlazzo/2013/11/response _using_selfcompassion_to_recover_from_a_bad_day.ht $\mathrm{ml}$ ) I'm not sure if Ms. Benjamin spent time researching the theoretical underpinnings of stress, but she has captured what is perhaps the fundamental process of the stress response among all people, according to the transactional model of stress from Lazarus and Folkman (1987). The transactional model of stress indicates that any time an individual encounters a life demand, a cognitive process is begun in which the individual weighs the demands of the task against his or her perceived ability to cope with the demand. If the demands of the tasks are perceived to be greater than the ability to

Studies like this make it clear that being mindful of teacher stress alone is not sufficient and that coping must also be considered.

deal with the demand, the stress response is triggered. If the individual believes his or her ability to deal with the event will resolve the issue at hand, then stress is absent or lessened (Lazarus \& Folkman, 1987). The research discussed earlier and this theoretical framework provide a compelling case for examining how stress and coping impact job satisfaction.

\section{Efficient Measurement}

One aspect of this research that makes it particularly useful for school leaders is that it collected data in a very efficient way. This study measured stress, coping, and job satisfaction among its participants using one 
question for each construct. It's no secret that it is difficult to get people to take surveys. Because many districts already do climate surveys for their staff members, it would be easy to add three simple questions. The survey items in this study were, "How stressful is your job?" "How are you coping with the stress of your job?" and "Overall, how satisfied are you with your job at this school?" The stress and coping items were measured with a 10-point Likert scale and the job satisfaction item was measured with a 6-point Likert scale. Research supports that shortening surveys can improve response rates (Rogelberg \& Stanton, 2007; Stanton, Sinar, Balzer, \& Smith, 2002), making these single-item measures particularly advantageous.

\section{Stress and Job Satisfaction Moderated} by Coping

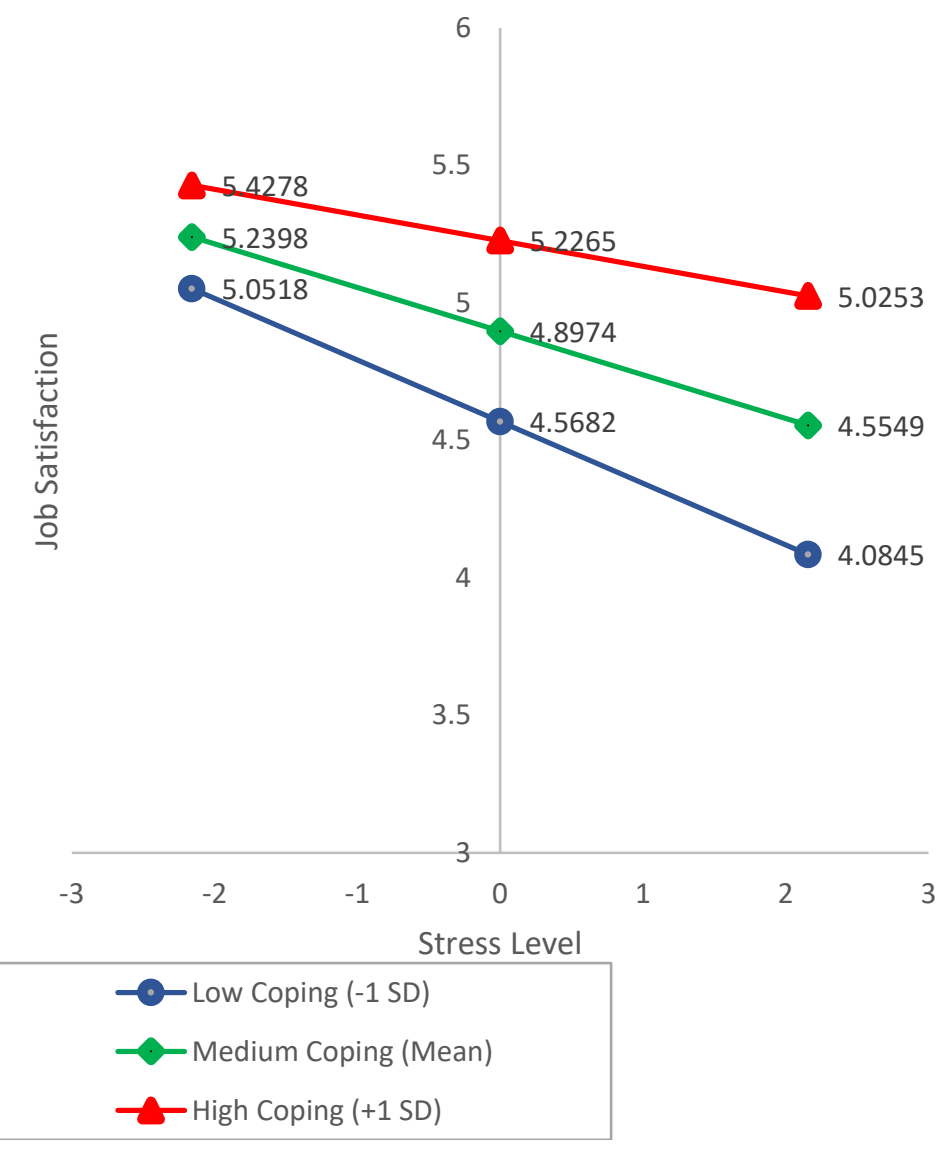

\section{What Did the Study Find?}

The primary finding of this study is that coping moderates the effect of stress on teachers' job satisfaction in a positive way. Generally, when a teacher's stress level increases, their job satisfaction ratings also

\section{DATA AND METHODS}

Purpose: To determine whether coping moderates the relationship between stress and job satisfaction among teachers.

Setting: A combination of elementary, middle, and high schools in the Kansas City area and in Oklahoma.

Number of participants: The moderation analysis consisted of 1,510 teachers at grade levels PK-12.

\section{Data Collection Tools: Single-item} measures of stress, coping, and job satisfaction that were part of surveys conducted as a part of the START and SCSL studies conducted by Dr. Keith Herman and the Missouri Prevention Science Institute

Research Method: Multiple regression moderation analysis 
decrease. As discussed earlier, increased stress and decreased job satisfaction can lead to many negative outcomes for teachers, students, and schools. However, coping has a buffering effect on the effect stress has on job satisfaction. Teachers who cope well tend to see smaller decreases in job satisfaction as stress increases, while those who cope at an average or below average level experience larger decreases in job satisfaction as stress increases, with those with the lowest coping ratings experiencing the largest decrease in satisfaction.

\section{What Do We Do with These Results?}

Of course, we can't control so many of the stressors our teachers face, but we can actively attempt to find out the overall stress levels, coping health, and job satisfaction levels of our teachers. If nothing else, this will provide school leaders with a snapshot of how their teachers are doing and it will also allow us to determine whether some sort of intervention is needed.

\section{Single Item Measures of Stress, Coping, and Job Satisfaction}

1. How stressful is your job? (Rating from 1 to 10)

2. How are you coping with the stress of your job? (Rating from 1 to 10)

3. Overall, how satisfied are you with your job at this school? (Rating from 1 to 6)

\section{Why Do These Findings Matter?}

The most important reason these findings are valuable for school leaders is that the study gives an efficient, proven way to measure the stress, coping, and job satisfaction ratings among our staff and it gives a clear understanding of how those ratings could be influencing our teachers and their performance in the classroom.

Measuring these factors and understanding the impact they are having on our teachers is an area that, at least in my experience, has not been a priority in the past. This study makes it clear that it is time to pay attention to these because the consequences are too important to ignore.
Investment in professional development addressing coping strategies for teachers could become a difference-maker for the job satisfaction of all teachers. This could be particularly true for those teachers who have the lowest coping ratings, as the results demonstrated that increases in stress negatively affect their job satisfaction more significantly than those teachers who are coping at an average or better level. There are several research-proven coping interventions that have paid positive dividends for teachers. One approach to intervention is utilization of a program such as Cultivating Awareness and Resilience in Education (CARE). CARE is a mindfulnessbased program that is designed to help teachers reduce stress and improve their classroom outcomes (Jennings, Frank, Snowberg, Coccia, \& Greenberg, 2013). In a randomized control trial, those teachers that 
were in the CARE group saw improvements in well-being, self-efficacy, stress, and mindfulness. In addition, the teachers themselves believed the CARE program was effective (Jennings et al., 2013). Another randomized control trial study showed that, over time, teachers who received the CARE intervention showed significantly lowered levels of psychological distress and increased capacity for emotion regulation when compared to the control group (Jennings et al., 2019).

Ansley et al. (2021) found that the use of an online stress intervention (consisting of eight modules to be completed over 4 weeks) resulted in increased use of coping strategies, increased teacher efficacy, and decreased emotional exhaustion and depersonalization (two main components of burnout) after just four weeks. Ansley et al. (2021)'s modules consisted of work related to mindfulness, relaxation, cognitive restructuring, social support, and physical exercise. Another option would be interventions targeted at teaching teachers to activate their relaxation response. Kaspereen (2012) found that a group of high school teachers who used a facilitator-guided visualization technique with a musical accompaniment reported lower levels of stress and greater levels of life satisfaction. Anderson, Levinson, Barker, and Kiewra (1999) studied the effects of a meditation
EDDY ET AL. (2019) ALREADY FOUND THAT IMPROVING COPING BY ITSELF MAY IMPROVE OUTCOMES FOR TEACHERSAND STUDENTS WHETHER STRESS LEVELS ARE IMPROVED OR NOT.

program on primary and secondary teachers. The participants in that program reported decreases in stress, burnout, and anxiety.

This research shows there are promising interventions available to increase the coping skills of teachers. Eddy et al. (2019) already found that improving coping by itself may improve outcomes for teachers and students whether stress levels are improved or not. School leaders need to take note and enact some of these programs, particularly given the body of research, including the present study, that emphasize the importance of coping in dealing with the growing number of stressors that teachers are facing and the potential negative effects of those stressors for both the teacher and for students. Particularly in the midst of still dealing with the effects of a global pandemic and the fallout from it, taking time to efficiently measure stress, coping, and job satisfaction among our teachers and then allotting time to devote to assist teachers with positive coping techniques is more important than ever. 
SECTION FIVE:

CONTRIBUTION TO SCHOLARSHIP 


\section{Section Five: Contribution to Scholarship \\ Target Journal}

After defending the dissertation in practice, I plan to submit the following journal-ready article to the journal Education Administration Quarterly (EAQ). The present study is relevant to education administrators and researchers, and EAQ is one of the top journals in that field. EAQ is focused on publishing articles that are important to leadership and/or policy issues for education organizations. EAQ is published by SAGE Publishing.

\section{Rationale for this Target}

The present study is germane to the practice of education leadership across all levels of PK-12 education. The journal publishes articles that are rigorous and relevant and of actual utility to educational organizations. The present study suits the mission of this journal.

\section{Plan for Submission}

The researcher will partner with the Missouri Prevention Science Institute, Dr. Keith Herman, and Dr. James Sebastian to prepare the article for publication. All will have the opportunity to review the article and make or suggest edits prior to submission. 
The Relationship Between Teacher Stress and Job Satisfaction as Moderated by Coping

\title{
Seth Woods
}

\author{
University of Missouri-Columbia
}




\section{Introduction}

Teacher retention is a significant problem in K-12 education (Goldring, Taie, \& Riddles, 2014; Inman \& Marlow, 2004; Dunn, 2018; Chambers Mack, Johnson, Jones-Rincon, Tsatenawa, \& Howard, 2019). Many studies suggest that between 25 and 50\% of teachers do not continue to teach beyond their first 3 years of teaching (Blatt, 2016; Boe, Cook, \& Sunderland, 2008; Inman \& Marlow, 2004). These figures not only represent a problem of maintaining continuity within school staff, but they also represent a significant financial burden for school systems. Borman and Dowling (2006) estimated that recruitment, hiring, and training new teachers is costing $\$ 2.2$ billion annually. In addition to the financial repercussions, schools that experience high levels of teacher turnover will also see this manifest in decreased student progress and achievement (Dolton \& Newson, 2003). Clearly teacher retention has become a significant problem of practice for principals, teachers, and state-level education officials.

One important influencer of teacher retention is job satisfaction. Because of its importance, much research has been devoted to examining teacher job satisfaction, its causes, and its effects on teachers. Teachers' job satisfaction has been directly connected to teacher retention (Skaalvik \& Skaalvik, 2011), and it has also been tied to teachers' decisions about whether or not to stay in the teaching profession at all (Klassen \& Chiu, 2011; McCarthy, Lambert, Crowe, \& McCarthy, 2010). Job satisfaction also influences other aspects of teachers' work. It has been shown to have a positive effect on overall job performance (Wolomasi, Asaloei, \& Werang, 2019), effective use of classroom management (Kaya \& Selvitupo, 2019), teacher subjective well-being (Judge \& Watanabe, 1993), and teacher self-concept (Skaalvik \& Skaalvik, 2017). This research makes it clear that job satisfaction is an integral part of not only retaining teachers, but also in helping teachers be successful. 
It is still imperative that practitioners understand the factors that influence job satisfaction among their teachers because of the potential negative ramifications for teachers who are not satisfied. One important influencer of job satisfaction is stress. In Herzberg's (1966) work regarding job satisfaction, he identified stress as an influencer of lower job satisfaction. There were specific factors that prevent dissatisfaction, such as peer relationships, salary, organizational policies, and supervision. Herzberg's (1966) prevention factors, unfortunately, are also closely aligned with known stressors for teachers. Those stressors include classroom management difficulties, time pressure and workload concerns, adjusting to change, teacher evaluation, peer relationships, self-esteem and status, working with administration, role conflict/ambiguity, and poor working conditions (Kyriacou, 2001; Travers \& Cooper, 1996). Many of these sources of stress are also on the list of factors that could prevent dissatisfaction (Herzberg, 1966).

The stress levels experienced by teachers are similar to those levels experienced by ambulance workers, police, and prison officers (Johnson et al., 2005). Stress and burnout among teachers are negatively related to job satisfaction (Avanzi et al., 2017; Ingersoll, 2001; Liu \& Ramsey, 2008; Richards, 2012; Watson, Harper, Ratliff, and Singleton, 2010) and teacher turnover intention (Hultell, Melin, \& Gustavsson, 2013; Kyriacou, 2001; Skaalvik \& Skaalvik, 2015; Skaalvik \& Skaalvik, 2010). Stress for teachers can come from a multitude of sources. Demands on time, increasing class sizes, student behavior problems, conflicts with other staff, and inadequate resources (both materials and buildings) can all be contributors to teacher stress (Wiley, 2000). Other potential stressors for teachers, such as working conditions, staff collegiality, and administrative support, all can have a significant effect on job satisfaction (or dissatisfaction) (Shen, Leslie, Spybrook, \& Ma, 2012). These sources of stress closely align with 
Herzberg's (1966) list of factors that are influencers of job dissatisfaction and with hindrance stressors. If these factors are in poor condition, then Herzberg (1966) contends that job dissatisfaction will increase.

The question, then, is what do teachers do about stress? The way teachers manage their stress is called coping. Coping is defined as "all of the cognitive and behavioral efforts, constantly changing, expended (by one person) to manage the internal and/or external demands perceived as consuming or exceeding his resources" (Lazarus \& Folkman, 1984, p. 141). One teacher may have high stress, but also high coping strength, while another teacher may also have high stress but inadequate coping strength. These two teachers will likely experience very different outcomes because of the differences in their coping capacity (Herman, Hickman Rosa, \& Reinke, 2018; Richards, 2012). Many studies have examined the combined effects of teacher stress and coping and generally conclude that stress is part of every teacher's job. They also contend that stress influences a variety of outcomes and that coping can play a role in how stress influences those outcomes. For example, outcomes that were specifically examined were student achievement, student behavior issues (Herman et al., 2018), burnout (Antoniou, Ploumpi, \& Ntalla; 2013), job satisfaction and intention to leave the profession (Klassen \& Chiu, 2011), and physical symptoms (Skaalvik \& Skaalvik, 2015). These outcomes can be influenced by the teacher's coping capacity or style (Antoniou, Ploumpi, \& Ntalla, 2013; Herman, et al., 2018; Laugaa, Rascale, Bruchon-Schweitzer, 2008). However, few studies have examined all three of stress, coping, and job satisfaction among teachers. Among the studies that have, McCarthy, Lambert, and Reiser (2014) and McCarthy, Lambert, Crowe, and McCarthy (2010) utilized a measurement scale called the Classroom Appraisal of Demands and Resources (CARD) as a way to measure demands and resources. The authors described the CARD as "a measure of teacher 
stress that is grounded in transactional models of stress and coping in that it measures teacher's perceptions of both classroom resources and demands." (McCarthy et al., 2010, p. 311) The CARD measured teacher perceptions of their demands and resources to classify the teachers into three groups (demands equal to resources, demands exceeding resources, and demands less than resources). Those in the under-resourced group experienced more burnout symptoms and statistically significantly lower job satisfaction scores than those teachers in the other two groups. While these measures of demands and resources in the CARD could be similar to stress and coping, they represent a finite list of potential demands/stressors and resources/coping resources instead of a more wholistic measure of overall stress and coping, and therefore may be unintentionally leaving out relevant stressors or coping resources (Scarpello \& Campbell, 1983). While coping has been utilized as a factor in many studies involving teacher stress, it has been used in various ways. Using coping as a moderator when examining the impact of stress on other outcomes has been supported by studies for outcomes such as stress and low coping among teachers leading to decreased academic achievement and increased disruptive behaviors (Herman, et al., 2018) and increases in teacher burnout (Antoniou, Ploumpi, \& Ntalla, 2013; Laugaa, Rascale, Bruchon-Schweitzer, 2008). Moderation analysis is used to determine if a third variable influences the direction or strength of the relationship between an independent and dependent variable (Field, 2018). Essentially, a moderator is like the dimmer switch for lighting in your home. As you turn the dimmer (or change the moderator), the level of light in your home changes. For this study, coping would be the moderator. Using coping as a moderator has theoretical support, as it is seen as a moderator in the transactional model of stress put forth by Lazarus and Folkman (1984), though the theory does not employ coping as a moderator to specifically examine job satisfaction. The McCarthy, Lambert, \& Reiser (2014) study concluded 
that the CARD score (which they called the appraisal index) and job satisfaction were significantly and positively correlated. The McCarthy et al. (2010) study found that increased resources were positively associated with job satisfaction and increased demands were negatively associated with job satisfaction, but it did not specifically measure overall stress and utilize overall coping as a moderator. In addition, the CARD has been described by McCarthy et al. (2015) as an appraisal of whether a teacher will experience stress based upon the demands the teacher experiences and the resources they can use to deal with those demands. Although there is support in literature and theoretical support for coping moderating the effects of stress, there are few empirical studies that examine the effect of coping on the relationship between stress and job satisfaction.

Some studies have examined the relationship between stress and job satisfaction, but do not include coping at all such as Klassen and Chiu (2010) who found that teachers with $10 \%$ greater teaching stress had approximately $2 \%$ lower job satisfaction. Further, several studies have examined the relationship between stress and coping in influencing other outcomes (not job satisfaction). One such study focused on outcomes for students, such as low academic achievement or increased discipline issues among high stress and low coping teachers (Herman et al., 2018). The Herman et al. (2018) study also found that high stress, low coping teacher group had increased burnout and lower self-efficacy (Herman et al., 2018; Klassen \& Chiu, 2009; Skaalvik \& Skaalvik, 2015). Other studies found stress was associated with negative physical symptoms such as headaches, back pain, and sleeping problems (Skaalvik \& Skaalvik, 2015), or an increased intent to leave their current position or leave the profession (McCarthy, Lambert, \& Reiser, 2014; McCarthy et al., 2010). Thus, there is a gap in the literature regarding the relationship between teacher stress and job satisfaction and how coping influences this 
relationship. The present study represents a critical gap in research considering the importance of job satisfaction for teacher retention and the close relationship between stress and coping.

\section{Single Item Measures of Stress and Coping}

Studies that have examined the relationship between stress, coping, and job satisfaction (McCarthy, Lambert, \& Reiser, 2014; McCarthy et al., 2010) have utilized a variety of measurement tools to measure stress, coping, and job satisfaction. Their research designs required participants to complete surveys consisting of dozens of items in total. For example, the data collection tools from the McCarthy et al. (2010) study included the CARD (64 items), the Preventive Resources Inventory Self-Acceptance Scale (14 items), the Job Satisfaction Scale (14 items), and the Plans to Leave Current Job Scale (13 items), making a 95 item survey. The present study utilizes ingle-item measures for measuring stress, satisfaction, and coping. Multiple studies have shown that perceived survey burden can cause lower response rates (Crawford, Couper, \& Lamias, 2001; Woods \& Hampton, 2005). On the other hand, shortening surveys can improve response rates and minimize non-response bias (Rogelberg \& Stanton, 2007; Stanton, Sinar, Balzer, \& Smith, 2002), making single-item measures particularly advantageous. In addition, Scarpello and Campbell (1983) explained that the use of multi-item scales may not be ideal because they can either include items that are not relevant to the construct being measured or they could omit items that are relevant. This means single-item measures may be more inclusive than scales (Scarpello \& Campbell, 1983). In the life of a practitioner, getting staff to complete a survey with many dozens of items is exceptionally challenging. Even though more robust scales are likely to give more complete data, the use of single-item measures should improve response rates and those measures can still give valuable information. 
There is precedent for utilizing single-item measures of stress, coping, and job satisfaction. Many studies have used a single item measure of stress, such as "I find teaching to be stressful” (Boyle, Borg, Falzon, \& Baglioni, 1995; Chaplain, 2008; Klassen, Usher, \& Bong, 2010; Kyriacou, 2001; Manthei, Gilmore, Tuck, \& Adair, 1996). Eddy, Herman, and Reinke (2019) conducted a study to test the concurrent and predictive validity and sensitivity to change of single-item teacher stress and coping measures. This study explains that single-item measures can give a more global account of factors related to stress or coping than multi-item measures that are limited to just the specific stressors or coping strategies that were asked about in the survey. In addition, Eddy, Herman, and Reinke (2019) found that the single-item stress measure was positively associated with emotional exhaustion and negatively associated with personal accomplishment while the single-item coping measure was negatively associated with emotional exhaustion, negatively associated with depersonalization, and positively associated with personal accomplishment. The coping item was also a significant predictor of end of the year emotional exhaustion and positively associated with self-efficacy (Eddy, Herman, \& Reinke, 2019). The Eddy, Herman, and Reinke (2019) study demonstrated the single-item measures of stress, coping, and job satisfaction all had demonstrable predictive validity. Wanous, Reichers, and Hudy (1997) explored the reliability of single-item measures of job satisfaction and found that the minimum estimated reliability of such measures to be close to .70 . These single-item measures of stress, coping, and job satisfaction could be powerful, expeditious, and reliable in helping teachers and school leaders get a clear picture of whether staff members are on the path to negative outcomes. Thus, the present study will also add to the research base examining the utility of single-item measures.

\section{Purpose of the Study}


The present study furthers the line of research examining teacher well-being by including coping as a moderator between stress and job satisfaction. Even though there are studies that examine different combinations of the relationships between stress, coping, and/or job satisfaction, few prior studies have empirically examined how coping moderates the relationship between stress and job satisfaction. Skaalvik and Skaalvik (2015) did a qualitative study related to stress, coping, and job satisfaction, but they stopped short of saying coping was moderating the relationship between stress and satisfaction. Instead, they focused on teachers at different stages of their careers and how they recovered from the stress of their jobs, such as taking vacations, using sick leave, reduction in work time, leaving the profession, or taking a disability pension. The present study can also be considered a replication study examining the relationship between stress and satisfaction, like the McCarthy, Lambert, and Reiser study (2014). Replication studies have long been considered an integral part of research design (Fisher, 1935). Polio and Gass (1997) identified two types of replication studies: exact and conceptual. Exact replication is intended to exactly duplicate every detail of a prior study to test that original study's findings. Conceptual replication, though, may have methodological variations from the original study, but still can test the generalizability of the original study's hypothesis (Polio \& Gass, 1997). The present study would be considered somewhat of a conceptual replication study of the work of McCarthy, Lambert, and Rieser (2014) and McCarthy et al. (2010) because of differences in methodology and measurement. Both those studies included stress, coping, and satisfaction, but and they did not include a true moderation analysis.

The use of single-item measures to examine these relationships is another component that makes the present study unique. Prior research that has measured stress, coping, and job satisfaction utilized scales with multiple items (Antoniou, Ploumpi, \& Ntalla, 2013; Foley \& 
Murphy, 2015; Laugaa, Rascle, \& Bruchon-Schweitzer, 2008; McCarthy, Lambert, \& Reiser, 2014; McCarthy, Lambert, Crowe, \& McCarthy, 2010; Salkovsky, Romi, \& Lewis, 2015; Smetackova et al., 2019). No study to date has utilized single item measures to examine the moderating effect of coping on stress using job satisfaction as an outcome. The use of single item measures makes surveying teachers significantly more expeditious and would provide schools a way to quickly measure the stress, coping, and job satisfaction levels of their teachers. The present study will further the line of research utilizing single-item measures of stress, coping, and job satisfaction by using them to test for a relationship between stress and job satisfaction using coping as a moderator. These plans make this study more than a just a replication study, although there are aspects of conceptual replication.

\section{Theoretical Frameworks}

The primary frameworks that support this study are the transactional model of stress (Lazarus \& Folkman, 1984) and McClusky's (1963) Theory of Margin. Both frameworks center their attention on the amount of stress individuals are experiencing as compared to their ability to adapt to that stress. Lazarus and Folkman (1984) put forth a theory of stress called the transactional model. The transactional model of stress indicates that any time an individual encounters a life demand, a cognitive process is begun in which the individual weighs the demands of the task against his or her perceived ability to cope with the demand. This demand is appraised in two phases, primary and secondary. The primary appraisal consists of a determination of whether the individual believes the event affects his or her well-being (Lazarus \& Folkman, 1987). The secondary appraisal is when the individual decides whether or not they have sufficient coping resources to deal with the event (Lazarus \& Folkman, 1987). If the demands of the tasks are perceived to be greater than the ability to deal with the demand, the 
stress response is triggered. If the individual believes his or her ability to deal with the event will resolve the issue at hand, then stress is absent or lessened (Lazarus \& Folkman, 1987).

In addition to the transactional model of stress, McClusky's (1963) Theory of Margin (Power-Load-Margin Theory) provides another theory that could help explain why teachers may experience lower job satisfaction. Margin in Life is a ratio of a person's load and power and it measures an adult's potential or readiness to learn or change (Hanpachern, et al., 1998). Load consists of those aspects of a person's life that are considered stressors when someone engages with them either mentally, emotionally, or physically. Power is made up of the resources (such as family support, money, employer support, etc.) that help an individual deal with their load (Hanpachern, et al., 1998; Merriam \& Bierema, 2014). Power can also come from a teacher's own personal coping capacity. Coping are those behaviors or thoughts a person uses to manage the demands of their load (Herman, Hickmon-Rosa, \& Reinke, 2018). Margin in Life supports the structure of this study in that it accounts for more than just stress in gauging an individual's outcomes.

Based upon these theoretical models, it is reasonable to expect that coping can moderate the relationship between stress and job satisfaction. Teachers with higher coping levels would have weaker relationships between stress and job satisfaction and teachers with lower coping levels would have stronger relationships between stress and job satisfaction. Therefore, for teachers with higher coping levels, the relationship between stress and job satisfaction will be relatively weak, whereas among teachers with lower coping levels, the relationship between stress and job satisfaction will be stronger. The formal research questions for the present study are:

Research Question 1: Is there a relationship between teacher stress and job satisfaction? 
Research Question 2: Is there a relationship between teacher coping and job satisfaction?

Research Question 3: Does coping moderate the relationship between teacher stress and job satisfaction?

\section{Study Context}

The data for this study was pulled from two larger studies conducted the Missouri Prevention Science Institute (Herman et al., 2010). One study is the Safe and Civil Schools Leadership (SCSL), which is a grant-funded randomized control trial funded by the Institute of Education Sciences (IES). The program focuses on training school principals to use data-driven decision-making tools to promote school safety and climate. The main goals of the SCSL study are to implement the Safe and Civil Schools training with principals and determine the training's effects on leadership skills, safety, school climate, and student achievement using a randomized control design (Missouri Prevention Science Institute, n.d.). For the SCSL study, cohort 1 included a total of 21 elementary, middle and high schools from four school districts in the Kansas City, Missouri area. Cohort 2 consisted of 16 elementary, middle, and high schools from three school districts in the same area.

The other study is also a randomized control trial called START, which utilized the START on Time program for school principals to teach them skills to foster a safe and positive learning environment for students (Missouri Prevention Science Institute, n.d.). This study also incorporates training in SCSL and is funded by a grant from the National Institute of Justice (NIJ) and is a randomized control design. START is the Principal and School Climate project and is funded by the National Institute of Justice in schools in Oklahoma. This study also incorporates training in Safe and Civil Schools and is a randomized control design. For the START study, cohort 1 included 10 middle schools and high schools from nine school districts 
in Oklahoma. Cohort 2 consisted of 4 middle and high schools from 4 school districts and Cohort 3 consisted of 9 middle and high schools from 6 school districts, also in Oklahoma. Both the SCSL and START studies consist of multiple cohorts spaced two years apart. Both studies are still ongoing and so far there are four cohorts in each study. Each cohort was surveyed 3 times per year.

\section{Setting}

For the SCSL study, cohort 1 included a total of 21 elementary, middle and high schools from four school districts in the Kansas City, Missouri area. Cohort 2 consisted of 16 elementary, middle, and high schools from three school districts in the same area. For the START study, cohort 1 included 10 middle schools and high schools from nine school districts in Oklahoma. Cohort 2 consisted of 4 middle and high schools from 4 school districts and Cohort 3 consisted of 9 middle and high schools from 6 school districts, also in Oklahoma.

\section{Data Used for the Present Study and Design of the Study}

\section{Participants}

The participants for this study are teachers who were part of cohorts 1 and 2 of the SCSL study and teachers in cohorts 1 through 3 in the START study, for a grand total of 1,777 teachers from 59 schools. Because of recoding of some of the survey data response categories, between the first and second round of data collection in cohort 1 of the START study, the present study will only focus on data collected during Time 2 in each cohort of each study. For the SCSL study, the Time 2 data was collected in May 2018 for cohort 1 and for cohort 2 in May 2019.

For the START study, the Time 2 data was collected from cohort 1 in November and December 2017, from cohort 2 in November and December 2018, and from cohort 3 in November and December 2019. In the SCSL study, the response rate for cohort 1 at time 2 was $71 \%$ (628 out of 
887 eligible teachers). For cohort 2, the response rate at time 2 was $84 \%$ (512 out of 609 eligible teachers). In the START study, the response rate for cohort 1 at time 2 was $80 \%$ (370 out of 463 eligible teachers). For cohort 2, the response rate at time 2 was $93 \%$ (65 out of 70 eligible teachers). For cohort 3, the response rate at time 2 was $85 \%$ (192 out of 226 eligible teachers).

\section{Data Collection Tools}

The study used surveys to collect data from participants. These surveys utilized single item measures of stress, coping, and job satisfaction. The single item for stress read, "How stressful is your job?" and participants responded on a 10-point Likert scale with a rating of 1 meaning "Not Stressful" and a rating of 10 meaning "Very stressful." The single item for coping read, "How well are you coping with the stress of your job?" and participants responded on a 10point Likert scale. The single item for job satisfaction reads "Overall, how satisfied with your job at this school?" This question utilized a 6-point Likert scale with 1 representing "Very Dissatisfied," and 6 representing "Very Satisfied." Responses 2 through 5 represented a continuum of satisfaction, with these descriptors (in order from 2 to 5): Dissatisfied, Slightly Dissatisfied, Slightly Satisfied, and Satisfied.

\section{Data Analysis}

To begin, a correlational analysis between stress levels and job satisfaction levels was conducted. This was done to determine whether there is a significant relationship between stress and job satisfaction for the data set, as prior research has indicated (McCarthy, Lambert, \& Reiser, 2014; McCarthy et al., 2010). To answer research question one, both a simple and multiple regressions were conducted using stress as the independent variable and job satisfaction as the dependent variable. The simple regression included no covariates and then there were three multiple regressions conducted, introducing a few covariates at a time until all were 
included (see the section below for information regarding covariates). To answer research question 2, the same process was followed using coping as the independent variable and job satisfaction as the dependent variable.

Because the existing literature base and theoretical models indicate that coping has a moderating effect on the relationship between stress and job satisfaction, a moderation analysis was then conducted in order to answer research question three. Moderation analysis is designed to determine whether a moderating variable (coping in this study) affects the strength and/or direction of the relationship between an independent variable (stress) and dependent variable (job satisfaction) (Field, 2018).

This moderation analysis was conducted using the procedure set forth by Baron and Kenny (1986) and used regression that included several participant-level covariates with school fixed-effects. This approach controls for non-observed school level characteristics using dummy variables for each school included in the studies. All outcome variables were treated as continuous for this process. Johnson \& Creech (1983) showed the treatment of this Likert-style data as continuous is supported when scales contains greater than five response categories. Norman (2010), Sullivan and Artino (2013), and Zumbo and Zimmerman (1993) have all reached similar conclusions about it being acceptable to utilize parametric tests (such as regression) with Likert-style variable when they contain at least five response categories. Prior to performing the moderation regression, the predictor variables (stress and coping) were centered. Centering is necessary in moderation analysis because it ensures that the slopes for stress and coping in this particular analysis represent the effect of each when the other predictor is at its mean value (which is zero because of the centering), and the intercept would then 
represent the job satisfaction rating when both stress and coping are at their means (Field, 2018). The following regression equation will be used for the moderation analysis:

$Y_{i}=\beta_{0}+\beta_{1}($ Stress_Centered $)+\beta_{2}($ Coping_Centered $)+\beta_{3}($ Stress*Coping $)+b_{x} \mathbf{X}_{i}+r_{i j}$

In formula (3), $Y_{i}$ denotes the job satisfaction outcome variable for teacher $i$. The slope $\beta_{1}$ represents the average expected change in job satisfaction when the stress score increases by one unit and coping is at its average value. The slope $\beta_{2}$ represents the average expected change in job satisfaction when the coping score is increased by one unit and stress is at its average value. The variable Stress*Coping is the interaction term. The slope $\beta_{3}$ represents the expected change in job satisfaction when the moderator score is increased by one unit. If the regression from (3) shows the effect of stress and coping as insignificant while the effect of the interaction term (Stress*Coping) is significant, then this would be considered complete moderation (Baron \& Kenny, 1986). It is also possible that one or both of stress and coping will show significance in addition to the interaction term, which would indicate that those terms still have a significant effect on job satisfaction even when considering the interaction term (Baron \& Kenny, 1986). $\mathbf{X} \boldsymbol{i j}$ represents a vector of the teacher level covariates which include experience, gender, grade level taught, White or non-White race, treatment condition, and school identification number. The PROCESS plugin for SPSS by Andrew F. Hayes was will be utilized to conduct the moderation analysis. The PROCESS plugin quickly conducts the moderation analysis and displays results that provide the needed regression data and simple slopes data to better aid with visual representations of the results of the moderation analysis.

\section{Control Variables}

Some studies suggest that stress varies across different points in a teacher's career (Harmsen, Helms-Lorenz, Maulana, \& van Veen, 2019; Hubermann, 1993; Ingersoll, 2001; 
Lauermann \& Konig, 2016; Prillentensky, Neff, and Bessell, 2016). Some research has shown that stress levels vary by grade levels the teacher teaches (Antoniou, Ploumpi, \& Ntalla, 2013), so this will be included as a covariate, as well. In addition, Antoniou, Polychroni, and Vlachakis (2006) found that females experience more occupational stress than their male counterparts. Therefore the following variables were included as covariates in the study: years of teaching experience, grade level taught, gender, and White or non-White race. Any school-level factors are controlled for by using the School ID as a covariate. Grade level taught spanned Pre-K through $12^{\text {th }}$ grade, with each category being its own variable that was dummy coded. Similarly, years of teaching experience was dummy coded into four categories, with categories for 1 to 2 years of experience, 3 to 5 years, 6 to 10 years, and greater than 10 years. Race was dummy coded into a single variable in which each participant was identified as either White or nonWhite. While the survey collected race data for many races, the number of responses in each of the race categories was so small that they were not having a significant influence on the model results. This study utilized listwise deletion of any responses that did not contain all the needed data, so any teacher who did not respond to all the questions of interest (stress, coping, job satisfaction, and all covariates) was not included in the analysis.

\section{Results}

\section{Descriptive statistics}

The present study focused on three variables (stress, coping, and job satisfaction) to answer the question of whether coping moderates the effect of stress on job satisfaction. In addition, there are several covariates that were included in the analysis: gender, whether the participant is White or non-White, years of teaching experience, grade level taught, and school identification code. 
In total, there were 338 male participants and 1,181 female participants, with another 258 who did not provide an answer to the gender question. The majority of the participants were White (1,405), and 107 participants identified as non-White, with 22 American Indian or Alaska Native, 3 Asian, 22 Black or African American, and 60 that identified as two or more races (265 participants did not select an answer to this question). A total of 1,516 teachers responded to the question about the number of years of experience they have working as a teacher. Of those, 130 had 1-2 years of experience, 249 had 3 to 5 years of experience, 264 had 6 to 10 years of experience, and 873 had more than 10 years of experience. More descriptive statistics can be found in Table 3.

Many teachers rated themselves as experiencing high levels of stress. Of the 1,539 teachers who responded to the single-item measure of stress, $1,129(73.4 \%$ of those who responded) rated their stress level at a 6 or higher on the 10-point scale. A histogram of teacher responses to the single-item measure of stress can be seen in Figure 3. Of the 1,539 teachers who responded to the single-item measure of coping, the data indicates that most teachers feel they are coping at least reasonably well, with 1,173 (76.2\% of those who responded) rating their coping level at a 6 or higher on the 10-point scale. A histogram of teacher responses to the single-item measure of coping can be seen in Figure 4. Despite high levels of stress, teachers in this study have high ratings of job satisfaction, with 1,351 of the 1,539 who responded rating themselves as either slightly satisfied, satisfied, or very satisfied (see Figure 5). Of the respondents to the job satisfaction rating item, 407 rated themselves as "Very Satisfied," which is $26.4 \%$ of those that responded, which is lower than the $39 \%$ of teachers found to be very satisfied in the 2012 Met Life survey discussed in the introduction (Metlife, 2012). 
Table 3. Descriptive statistics

\begin{tabular}{|c|c|c|c|c|c|}
\hline Variable & $\mathrm{N}$ & Mean & SD & Min & $\operatorname{Max}$ \\
\hline Stress rating & 1539 & 6.575 & 2.155 & 1 & 10 \\
\hline Coping rating & 1539 & 7.120 & 2.106 & 1 & 10 \\
\hline Job Satisfaction rating & 1539 & 4.821 & 1.105 & 1 & 10 \\
\hline Teaches PK & 1777 & .0011 & & 0 & 1 \\
\hline Teaches K & 1777 & .088 & & 0 & 1 \\
\hline Teaches 1st grade & 1777 & .088 & & 0 & 1 \\
\hline Teaches 2nd grade & 1777 & .093 & & 0 & 1 \\
\hline Teaches 3rd grade & 1777 & .095 & & 0 & 1 \\
\hline Teaches 4th grade & 1777 & .101 & & 0 & 1 \\
\hline Teaches 5th grade & 1777 & .156 & & 0 & 1 \\
\hline Teaches 6th grade & 1777 & .253 & & 0 & 1 \\
\hline Teaches 7th grade & 1777 & .231 & & 0 & 1 \\
\hline Teaches 8th grade & 1777 & .210 & & 0 & 1 \\
\hline Teaches $9^{\text {th }}$ grade & 1777 & .207 & & 0 & 1 \\
\hline Teaches $10^{\text {th }}$ grade & 1777 & .232 & & 0 & 1 \\
\hline Teaches $11^{\text {th }}$ grade & 1777 & .234 & & 0 & 1 \\
\hline Teaches $12^{\text {th }}$ grade & 1777 & .218 & & 0 & 1 \\
\hline Teaches other & 1777 & .021 & & 0 & 1 \\
\hline Gender $($ Male $=0$, Female $=1)$ & 1519 & .778 & .416 & 0 & 1 \\
\hline Race $($ White $=0$, non-White $=1)$ & 1512 & 0.071 & .257 & 0 & 1 \\
\hline $\begin{array}{l}\text { Years of experience }(1-2 \text { years }=1 \text {, } \\
3-5 \text { years }=2,6-10 \text { years }=3 \text {, More } \\
\text { than } 10 \text { years }=4)\end{array}$ & 1516 & 3.240 & 1.013 & 1 & 4 \\
\hline
\end{tabular}


Figure 3. Teacher Ratings of Stress Using Single-Item Measure. N=1,539

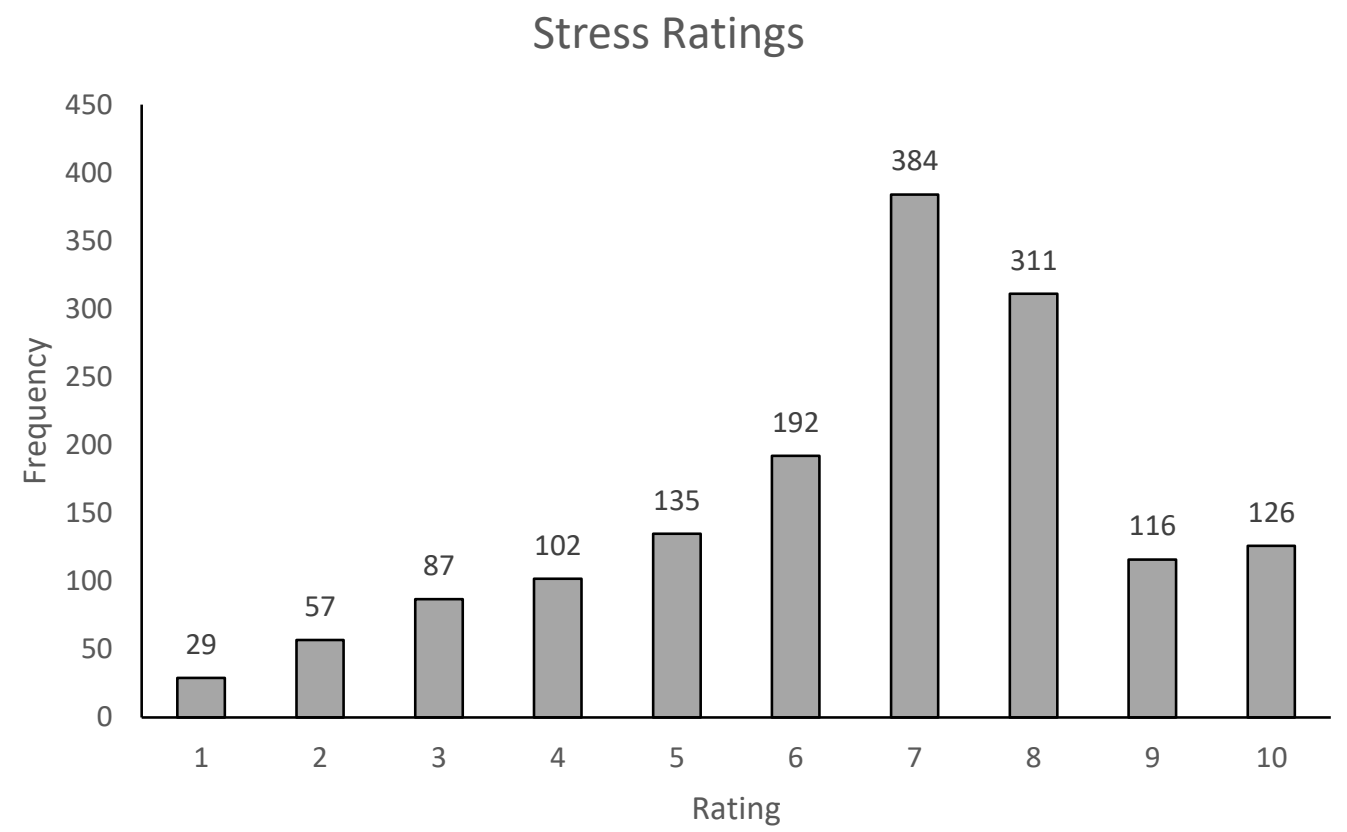

Figure 4. Teacher Ratings of Coping Using Single-Item Measure. N=1,539

Coping Ratings

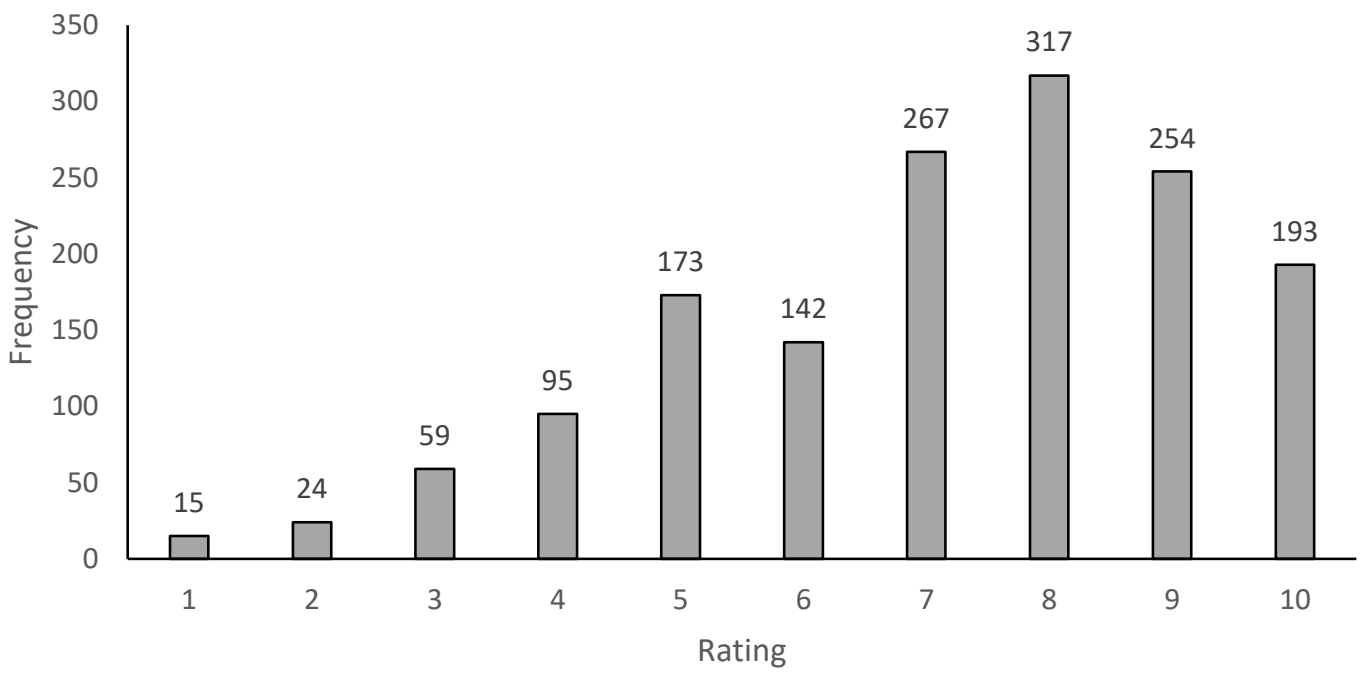


Figure 5. Teacher Ratings of Job Satisfaction Using Single-Item Measure. N=1,539

\section{Job Satisfaction Ratings}

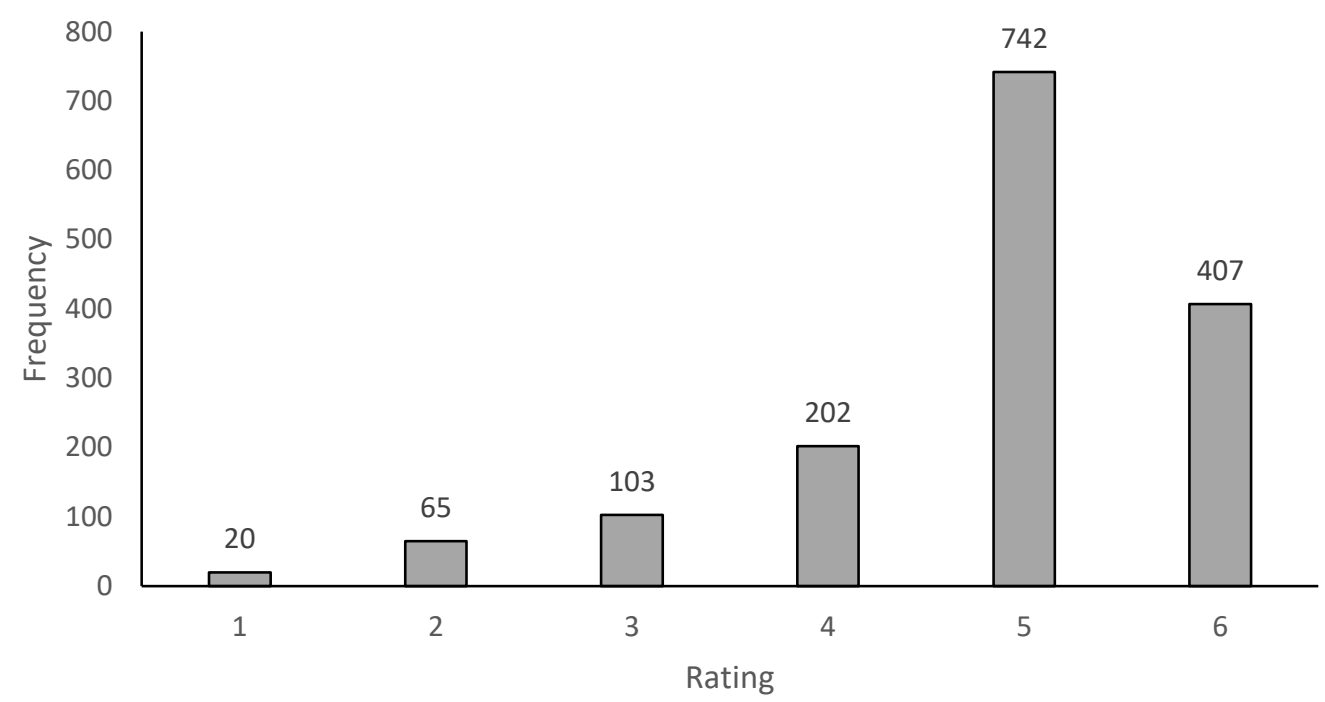

\section{Correlations}

Correlations were investigated using Pearson correlation between each pair of variables (stress, coping, and job satisfaction) using SPSS. Table 4 summarizes the results of those calculations. A significant $(p<.01)$ positive correlation of .495 was found between coping and job satisfaction. This correlation represents a medium effect size (Cohen, 1988). A Significant $(p<.01)$ negative correlation of -.435 was found between stress and job satisfaction. This correlation represents a medium effect (Cohen, 1988). There was also a significant $(p<$ $.01)$, negative, medium effect correlation of -.515 between stress and coping (Cohen, 1998). Table 4. Correlational Analysis

\begin{tabular}{|c|c|c|c|}
\hline Variable & 1 & 2 & 3 \\
\hline 1 Stress & 1 & $-.515^{* *}$ & $-.435 * *$ \\
\hline 2 Coping & $-.515^{* *}$ & 1 & $.495^{* *}$ \\
\hline 3 Job Satisfaction & $-.435^{* *}$ & $.495 * *$ & 1 \\
\hline
\end{tabular}

Note. $* * p<.01$ 


\section{Regression results}

The full regression models (including all main-focus variables and all covariates) included a total of 1,510 complete responses. In addition, regression analyses were conducted to examine the relationship between just stress and job satisfaction, just coping and job satisfaction, and also the actual moderation analysis. The results from these regression analyses are described below:

\section{Stress and Job Satisfaction Regression Analysis}

Table 5 displays the data for several regression models of the relationship between stress and job satisfaction. This analysis clearly answered research question one and there is a statistically significant relationship between stress and job satisfaction, in which stress is a negative influencer of job satisfaction. Model 1 represents a simple regression with stress as the predictor and job satisfaction as the outcome. Model 2 is a multiple regression that has stress as the predictor and job satisfaction as the outcome, and it also includes gender and race as (White or non-White) as covariates. Model 3 contains all of Model 2, but adds grade level taught and years of teaching experiences as additional covariates. Model 4 represents a multiple regression in which stress is the predictor and job satisfaction is the outcome. In Model 4, though, grade level taught, gender, race (White or non-White), years of experience, and school identification numbers are added as covariates. Grade level taught was dummy coded into 14 variables for grades PK through 12 and included an "other" category, as well. For this analysis, all categories were included except grade PK. Gender ( 0 for male, 1 for female) and race ( 0 for white, 1 for non-White) were dummy coded covariates. In addition, years of experience had dummy coded variables for each category (1-2 years, 3-5 years, 6-10 years, and more than 10 years) as did school identification numbers (one for each school for a total of 73 dummy variables). The 
school identification number variables also control for treatment status because that is a schoollevel factor. For these analyses, the 1-2 years of experience variable, those who teach PK, and School 20 variable were left out of Models 3 and 4, as appropriate.

In Model 1, the slope result for stress indicates that for an increase of one unit on teacher's stress rating, job satisfaction would decrease by .223 units (Table 5). The y-intercept of 6.287 represents a teacher's job satisfaction rating if their stress rating is zero (a teacher who has no stress). Of course, a stress rating of zero was not an option in the survey, so this intercept represents an extrapolation of the data if zero were an option. For Model 2, the slope for stress is -.231 , which means that a one unit increase in stress rating would result in a decrease of .231 job satisfaction units. The y-intercept of 6.190 represents the job satisfaction rating for a White male teacher. Again, this rating is not actually possible with this survey. For Model 3, the slope for stress is -.229 , which means that a one unit increase in stress rating would result in a .229 unit decrease in job satisfaction. The y-intercept of 6.432 represents the job satisfaction rating for a White, male, PK teacher with 1 or 2 years of experience. For Model 4, the slope for stress indicates that an increase of one on a teacher's stress rating would result in a decrease of .221 units for job satisfaction. The y-intercept of 6.440 (again, this is an extrapolation of the data to values that were not choices on the survey) represents the job satisfaction level when all predictors are held at zero. This would be a teacher who is White, male, a School 20 staff member, a Pre-K teacher with 1 to 2 years of teaching experience and if their stress rating were a zero. The addition of the covariates also increased the percentage of the variance explained from Model 1 to Model 4 by 8.3\%, with Model 4 explaining 27.2\% of the variance. 
Table 5. Simple and Multiple Regression Analyses of the Relationship Between Stress and Job Satisfaction

\begin{tabular}{|c|c|c|c|c|c|c|c|c|}
\hline \multirow[b]{2}{*}{ Parameter } & \multicolumn{2}{|c|}{ Model 1} & \multicolumn{2}{|c|}{ Model 2} & \multicolumn{2}{|c|}{ Model 3} & \multicolumn{2}{|c|}{ Model 4} \\
\hline & Coefficient & S.E. & Coefficient & S.E. & Coefficient & S.E. & Coefficient & S.E. \\
\hline Intercept & 6.287 & .081 & 6.190 & .088 & 6.432 & .128 & 6.440 & .265 \\
\hline Stress & $-.223 * * *$ & .012 & $-.231 * * *$ & .012 & $-.229 * * *$ & .012 & $-.221 * * *$ & .012 \\
\hline$R^{2}$ & .189 & & .194 & & .206 & & .272 & \\
\hline Gender & & & $.195 * *$ & .063 & $.158 *$ & .067 & .124 & .068 \\
\hline Race & & & -.031 & .099 & -.008 & .100 & -.044 & .102 \\
\hline Teach Grade K & & & & & -.030 & .107 & -.040 & .108 \\
\hline Teach Grade 1 & & & & & .017 & .110 & .060 & .113 \\
\hline Teach Grade 2 & & & & & .107 & .108 & .127 & .110 \\
\hline Teach Grade 3 & & & & & .072 & .101 & .053 & .105 \\
\hline Teach Grade 4 & & & & & -.048 & .096 & -.082 & .104 \\
\hline Teach Grade 5 & & & & & .041 & .074 & -.038 & .086 \\
\hline Teach Grade 6 & & & & & .029 & .066 & .028 & .073 \\
\hline Teach Grade 7 & & & & & -.012 & .078 & .058 & .087 \\
\hline Teach Grade 8 & & & & & .012 & .078 & -.023 & .087 \\
\hline Teach Grade 9 & & & & & -.090 & .114 & -.042 & .115 \\
\hline Teach Grade 10 & & & & & .119 & .147 & .271 & .152 \\
\hline Teach Grade 11 & & & & & .038 & .182 & .204 & .188 \\
\hline Teach Grade 12 & & & & & -.125 & .178 & -.164 & .177 \\
\hline Teach Other & & & & & .251 & .184 & .214 & .198 \\
\hline 3-5 years exp. & & & & & $-.359 * *$ & .108 & $-.341 * *$ & .107 \\
\hline 6-10 years exp. & & & & & $-.319 * *$ & .107 & $-.298 *$ & .107 \\
\hline > 10 years exp. & & & & & $-.237 *$ & .094 & -.175 & .095 \\
\hline $\begin{array}{l}\text { School Fixed } \\
\text { Effects }\end{array}$ & & & & & & & - & - \\
\hline
\end{tabular}




\section{Coping and Job Satisfaction}

Table 6 displays the data for several regression models of the relationship between stress and job satisfaction. This analysis clearly answered research question two and there is a statistically significant relationship between coping and job satisfaction, in which coping is a positive influencer of job satisfaction. Model 1 represents a simple regression with coping as the predictor and job satisfaction as the outcome. Model 2 is a multiple regression that has coping as the predictor and job satisfaction as the outcome, and it also includes gender and race as (White or non-White) as covariates. Model 3 contains all of Model 2, but adds grade level taught and years of teaching experiences as additional covariates. Model 4 represents a multiple regression in which coping is the predictor and grade level taught, gender, race (White or non-White), years of experience, and school identification numbers are added as covariates. Grade level taught was dummy coded into 14 variables for grades PK through 12 and included an "other" category, as well. Gender ( 0 for male, 1 for female) and race ( 0 for white, 1 for non-White) were dummy coded covariates. In addition, years of experience had dummy coded variables for each category (1-2 years, 3-5 years, 6-10 years, and more than 10 years) as did school identification numbers (one for each school). The school identification number variables also control for treatment status because treatment status is a school-level factor. For these analyses, the 1-2 years of experience variable, those who teach PK, and School 20 variable were left out of Models 3 and 4, as appropriate.

In Model 1, the slope for coping of .260 indicates that an increase of one coping unit would increase job satisfaction by .260 units (Table 6). The y-intercept of 2.973 represents the job satisfaction rating for a teacher with a coping rating of zero. For Model 2, the slope for coping of .262 means that an increase of one unit in coping rating would result in an increase of 
Table 6. Fixed Effects Regression Analysis of the Relationship Between Coping and Job Satisfaction

\begin{tabular}{|c|c|c|c|c|c|c|c|c|}
\hline \multirow[b]{2}{*}{ Parameter } & \multicolumn{2}{|c|}{ Model 1} & \multicolumn{2}{|c|}{ Model 2} & \multicolumn{2}{|c|}{ Model 3} & \multicolumn{2}{|c|}{ Model 4} \\
\hline & Coefficient & S.E. & Coefficient & S.E. & Coefficient & S.E. & Coefficient & S.E. \\
\hline Intercept & 2.973 & .086 & 2.858 & .106 & 3.165 & .139 & 3.499 & .267 \\
\hline Coping & $.260 * * *$ & .012 & $.262 * * *$ & .012 & $.261 * * *$ & .012 & $.248 * * *$ & .012 \\
\hline$R^{2}$ & .245 & & .246 & & .259 & & .318 & \\
\hline Gender & & & .123 & .060 & .111 & .064 & .084 & .065 \\
\hline Race & & & $.043 *$ & .096 & .046 & .097 & .024 & .099 \\
\hline Teach Grade K & & & & & .014 & .104 & .005 & .104 \\
\hline Teach Grade 1 & & & & & -.019 & .106 & .035 & .109 \\
\hline Teach Grade 2 & & & & & .026 & .104 & .062 & .107 \\
\hline Teach Grade 3 & & & & & .042 & .097 & .018 & .102 \\
\hline Teach Grade 4 & & & & & -.003 & .093 & -.029 & .101 \\
\hline Teach Grade 5 & & & & & .125 & .072 & .102 & .084 \\
\hline Teach Grade 6 & & & & & .073 & .063 & .058 & .071 \\
\hline Teach Grade 7 & & & & & .018 & .076 & .047 & .084 \\
\hline Teach Grade 8 & & & & & .026 & .075 & -.070 & .084 \\
\hline Teach Grade 9 & & & & & -.148 & .110 & -.115 & .111 \\
\hline Teach Grade 10 & & & & & -.009 & .142 & .099 & .147 \\
\hline Teach Grade 11 & & & & & .084 & .176 & .233 & .182 \\
\hline Teach Grade 12 & & & & & .042 & .172 & .005 & .171 \\
\hline Teach Other & & & & & .177 & .178 & .148 & .192 \\
\hline 3-5 years exp. & & & & & $-.401 * * *$ & .104 & $-.383 * * *$ & .104 \\
\hline 6-10 years exp. & & & & & $-.408 * * *$ & .103 & $-.383 * * *$ & .104 \\
\hline >10 years exp. & & & & & $-.360 * * *$ & .091 & $-.298 * *$ & .092 \\
\hline School ID & & & & & & & $X$ & $\mathrm{X}$ \\
\hline
\end{tabular}

Note. ${ }^{* * *} p<.001,{ }^{* *} p<.01,{ }^{*} p<.05 N=1510$ 
.262 units in job satisfaction. The y-intercept of 2.858 represents the job satisfaction level of a White male teacher with a coping rating of zero. For Model 3, the coping slope of .261 means that an increase of one coping unit would result in a .261 unit increase in job satisfaction. The yintercept of 3.165 represents the job satisfaction rating for a White male PK teacher with 1 or two years of experience whose coping rating is zero. In Model 4, the slope for coping of .248 indicates that an increase of one in coping rating would increase job satisfaction by 248 units. The y-intercept of 3.499 represents the job satisfaction rating when coping and all covariates are held at zero. This would be a teacher who is White, male, a School 20 staff member, a Pre-K teacher with 1 or 2 years of experience whose coping rating is zero. As with the stress models, the $y$-intercept in these models represents the job satisfaction level at a coping level of zero, which was not a choice on the survey, so this is an extrapolation of the data. The addition of the covariates also increased the percentage of the variance explained by $7.3 \%$ from Model 1 to Model 4, with Model 2 explaining 31.8\% of the variance.

\section{Moderation Analysis}

Table 7 displays the data for several moderation models of the relationship between stress, coping, and job satisfaction with stress as the independent variable, job satisfaction as the dependent variable, and coping as a moderator. Model 1 represents a simple moderation analysis regression with the centered versions of stress and coping as the predictor, the product of those variables as the moderator, and job satisfaction as the outcome.

Model 2 is a multiple regression that has stress and coping as the predictor, the product of stress and coping as the moderator, and job satisfaction as the outcome, and it also includes gender and race as (White or non-White) as covariates. Model 3 contains all of Model 2 but adds grade level taught and years of teaching experiences as additional covariates. Model 4 represents a multiple 
regression moderation analysis in which centered versions of stress and coping are the predictor, the product of those variables is the moderator, and job satisfaction is the outcome. In addition, Model 4 includes grade level taught, gender, race (White or non-White), years of experience, and school identification numbers as covariates.

For Model 1, all predictors are statistically significant at the $p<.001$ level. The slope for stress is -.1608 , which represents the effect of a one unit increase in stress on job satisfaction when coping is at its mean value. The slope for coping is .162, which represents the effect a one unit increase in coping has on job satisfaction when stress is at its mean value. The moderator term also has a significant slope of .034 , which means that coping does moderate the relationship between stress and job satisfaction. Model 2 finds similar results in that all the predictors are statistically significant. The slope for stress is -.167 , which means when coping is at its mean, a one unit increase in stress will result in a .167 unit decrease in job satisfaction. The slope for coping is .1636 , which means when stress is at its mean, a one unit increase in coping will increase the job satisfaction rating by .164 units. Again, the moderation term is significant, confirming that coping does moderate the relationship between stress and job satisfaction. Model 3 also finds similar results in that all the predictors are statistically significant. The slope for stress is -.164, which means when coping is at its mean, a one unit increase in stress will result in a .164 unit decrease in job satisfaction. The slope for coping is .164, which means when stress is at its mean, a one unit increase in coping will increase the job satisfaction rating by .164 units. Again, the moderation term is significant, confirming that coping does moderate the relationship between stress and job satisfaction. 
Table 7. Fixed Effects Moderation Regression Analysis of the Relationship Between Stress, Coping and Job Satisfaction

\begin{tabular}{|c|c|c|c|c|c|c|c|c|}
\hline \multirow[b]{2}{*}{ Parameter } & \multicolumn{2}{|c|}{ Model 1} & \multicolumn{2}{|c|}{ Model 2} & \multicolumn{2}{|c|}{ Model 3} & \multicolumn{2}{|c|}{ Model 4} \\
\hline & Coefficient & S.E. & Coefficient & S.E. & Coefficient & S.E. & Coefficient & S.E. \\
\hline Intercept & 4.900 & .026 & 4.722 & .054 & 4.977 & .102 & 5.102 & .242 \\
\hline Stress & $-.161 * * *$ & .014 & $-.167 * * *$ & .014 & $-.164 * * *$ & .014 & $-.159 * * *$ & .015 \\
\hline Coping & $.162 * * *$ & .014 & $.164 * * *$ & .014 & $.164 * * *$ & .014 & $.156^{* * * *}$ & .014 \\
\hline Moderator & $.034 * * *$ & .005 & $.032 * * *$ & .005 & $.032 * * *$ & .005 & $.031 * * *$ & .005 \\
\hline$R^{2}$ & .308 & & .312 & & .322 & & .372 & \\
\hline Gender & & & $.223 * * *$ & .059 & $.196 * *$ & .062 & $.171 * *$ & .063 \\
\hline Race & & & .023 & .092 & .039 & .093 & .005 & .056 \\
\hline Teach Grade K & & & & & .007 & .099 & -.021 & .100 \\
\hline Teach Grade 1 & & & & & .025 & .102 & .050 & .105 \\
\hline Teach Grade 2 & & & & & .017 & .100 & .028 & .103 \\
\hline Teach Grade 3 & & & & & .031 & .093 & -.002 & .098 \\
\hline Teach Grade 4 & & & & & -.037 & .089 & -.057 & .097 \\
\hline Teach Grade 5 & & & & & .103 & .069 & .093 & .081 \\
\hline Teach Grade 6 & & & & & .040 & .061 & .045 & .068 \\
\hline Teach Grade 7 & & & & & .005 & .073 & .044 & .081 \\
\hline Teach Grade 8 & & & & & .023 & .072 & -.041 & .081 \\
\hline Teach Grade 9 & & & & & -.141 & .106 & -.108 & .107 \\
\hline Teach Grade 10 & & & & & .037 & .136 & .160 & .141 \\
\hline Teach Grade 11 & & & & & .102 & .168 & .236 & .174 \\
\hline Teach Grade 12 & & & & & -.064 & .165 & -.098 & .165 \\
\hline Teach Other & & & & & .164 & .170 & .110 & .185 \\
\hline 3-5 years exp. & & & & & $-.334 * * *$ & .100 & $-.315 * *$ & .100 \\
\hline 6-10 years exp. & & & & & $-.328 * * *$ & .099 & $-.307 * *$ & .100 \\
\hline >10 years exp. & & & & & $-.264 * *$ & .087 & $-.201 *$ & .089 \\
\hline School ID & & & & & & & $X$ & \\
\hline
\end{tabular}

Note. ${ }^{* * *} p<.001, * * p<.01,{ }^{*} p<.05 N=1510$ 
Model 4 includes all the covariates as described above. Model 4 explains $6.44 \%$ more of the variance than Model 1 (Model 4 explains 37.22\% of the variance), and all its predictors are statistically significant. The slope for stress is -.159 , which represents the effect of a one unit increase in stress on job satisfaction when coping is at its mean value. The slope for coping is .156 , which represents the effect a one unit increase in coping has on job satisfaction when stress is at its mean value. The moderator term also has a significant slope of .031, which further confirms that coping moderates the effect of stress on job satisfaction, even when accounting for multiple covariates.

PROCESS provides additional output that is useful to visualize the moderating effect of coping in this relationship between stress and job satisfaction. Table 8 summarizes the outputs for Model 2 for job satisfaction at stress levels that are one standard deviation below the mean, at the mean, and one standard deviation above the mean for each level of coping (one standard deviation below the mean, at the mean, and one standard deviation above the mean). These simple slope outputs are also depicted by the graph in Figure 6. Both Table 8 and Figure 6 make clear the importance of coping for teachers as they deal with stress. Those teachers with low coping skills (one standard deviation below the mean) have lower job satisfaction ratings across all the levels of stress, seeming to indicate that even low levels of stress can be a problem for those teachers with low coping ratings. The drop in job satisfaction rating from the lowest level of stress to the highest level of stress is greater for those with low coping (a drop of nearly one entire unit) than either of the other two coping levels. The high coping teachers see the smallest decline as stress goes from low to high, losing approximately 0.4 job satisfaction units, while the medium coping teachers see a loss of approximately 0.7 job satisfaction units. This data shows that coping level has an important influence on outcomes for job satisfaction across stress levels. 
Table 8. Simple Slopes Outputs of the Relationship Between Stress, Coping and Job Satisfaction

\begin{tabular}{ccc}
\hline Stress & Coping & Job Satisfaction \\
\hline-2.158 & -2.108 & 5.052 \\
0 & -2.108 & 4.568 \\
2.158 & -2.108 & 4.085 \\
-2.158 & 0 & 5.240 \\
0 & 0 & 4.897 \\
2.158 & 0 & 4.555 \\
-2.158 & 2.108 & 5.428 \\
0 & 2.108 & 5.227 \\
2.158 & 2.108 & 5.025 \\
\hline
\end{tabular}

Note. The variables Stress and Coping were centered for this analysis.

Figure 6. Simple Slopes Graphs of the Relationship Between Stress, Coping and Job Satisfaction

Simple Slopes Stress and Job Satisfaction Moderated by

Coping (Model 4)

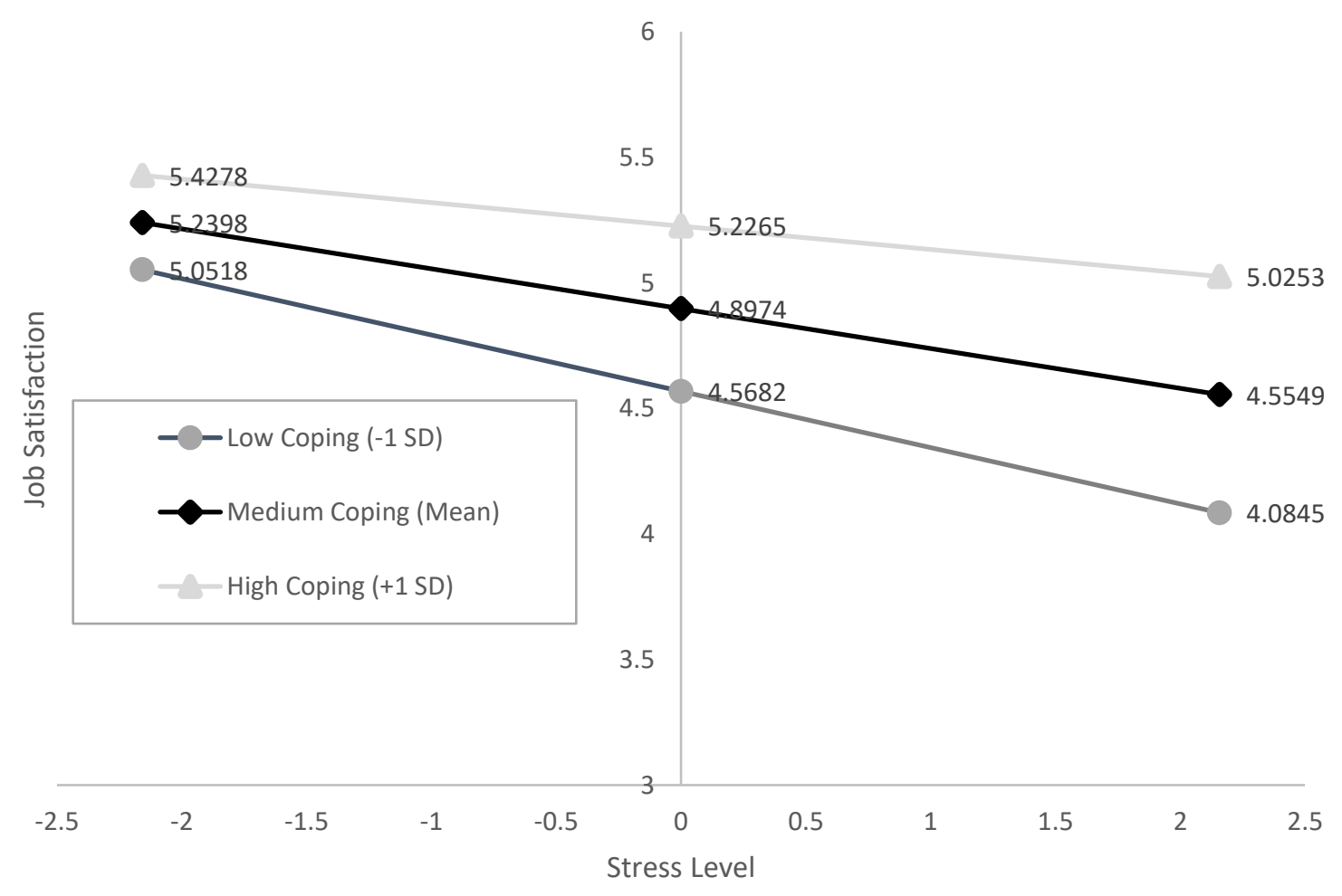




\section{Discussion}

\section{Implications for Scholarship}

One of the research questions the present study aimed to answer was: Does coping moderate the relationship between teacher stress and job satisfaction? The results section clearly demonstrated coping has a statistically significant moderating effect on the relationship between teacher stress and job satisfaction. Many studies conclude that stress and coping are part of every teacher's job and that the two constructs are linked together in determining a host of outcomes (Herman et al., 2018; McCarthy, Lambert, \& Reiser, 2014; Kyriacou, 2001). Prior studies have examined the outcomes of teacher stress and coping such as potential negative effects on student achievement and behavior (Herman et al., 2018), teachers leaving the profession (Kyriacou, 2001; Hubermann, 1993), and teacher burnout (Roger \& Hudson, 1995; Antoniou, Ploumpi, \& Ntalla, 2013; Van Dick \& Wagner, 2001). The present study adds to this literature base by showing that coping has a statistically significant moderating effect on stress as it relates to job satisfaction. In addition, this study adds to the evidence base of using single-item measures to measure stress, coping, and job satisfaction, making surveying teachers very expeditious for practitioners who may want to utilize these findings.

The participants for this study were somewhat similar to those involved in prior research into stress and job satisfaction levels of teachers. Approximately $88 \%$ of the participants rated themselves as at least slightly satisfied with their jobs, which is near the $90 \%$ that the 2018 OECD study found (Schleicher, 2018). The 2012 Met Life survey, though, found that 39\% of teachers rated themselves as very satisfied, but the present study found just $26.4 \%$ of the participants felt that way. The present study is limited to areas around Kansas City and in Oklahoma, so it would be difficult to say that overall satisfaction continues to decline nationwide 
(because we cannot make claims about the generalizability of this study due to its limited geographic coverage), but it is worth noting that, while the proportion of teachers saying they are satisfied aligns with prior research, there were a lower proportion of participants that are very satisfied with their career. This could be attributable to the increasing amount of stress that teachers are facing (von der Embse, Ryan, Gibbs, \& Mankin, 2019) and that could be eroding teacher job satisfaction based on the stress and job satisfaction regression results of the present study.

The results of the present study provide support for the transactional model of stress. The transactional model says that events are first filtered through a primary appraisal that determines whether the event is something that will influence the individual's well-being. If that event is deemed to be something that influences the individual's well-being, it is then put through a secondary appraisal of how much the individual believes he or she can control the outcome of the event, which is dependent upon the coping resources that person can muster (Lazarus \& Folkman, 1987). The significant moderating effect of coping in the stress and job satisfaction relationship fits nicely with the transactional model. Further, the results of this study show that weak coping disproportionately affects outcomes for teachers who do not cope well. Teachers with strong coping saw smaller decreases in job satisfaction as stress levels increased when compared to teacher with medium or low coping. This result further supports studies such as Herman et al. (2018) and Richards (2012) who found teachers displaying differences in outcomes of well-being depending upon differences in their coping capacities. In particular, the results of the study show that those teachers with low coping see lower levels of job satisfaction that the other coping groups, which is consistent with the findings of Herman et al. (2018). The present study also aligns with the work of McCarthy, Lambert, and Reiser (2014) who used the 
CARD as a measure of demands and resources and used that tool to examine job satisfaction scores among teachers. They found that teachers who had demands exceeding their resources reported statistically significant lower job satisfaction ratings than those who were neutral on demands and resources or those whose resources exceeded their demands.

Herman, Reinke, and Eddy (2020) posited a theory for teacher stress and coping called the Coping-Competence-Context Theory (3C) of Teacher Stress. The 3C Theory says that coping, competence, and context make up three interconnected pathways of teacher stress development and intervention. The Competence pathway explains how stress and classroom practices (particularly classroom management skills) are related. The Context pathway explains that school and educational system policies and practices contribute to teacher stress. The present study supports the Coping pathway of this theory. The Coping pathway consists of those individual characteristics of a teacher, such as mindset, interpersonal qualities, and coping, that directly influence stress responses (Herman, Reinke, \& Eddy, 2020). Specifically, this study supports the Coping pathway in that it further supports the part of this pathway that includes teachers' coping skills and the effects they have on teacher outcomes (which would be job satisfaction in the case of the present study).

While the present study reinforces previous work regarding stress and coping among teachers, it is worth noting that, in some ways, the present study expands that work because of its measurement of stress, coping, and job satisfaction differs from many of those other studies. The majority of previous studies that examined these constructs did so with surveys that utilized a scale of multiple questions (sometimes many dozens) to measure stress, coping, and/or job satisfaction. The use of single-item measures reduces survey burden and improve response rates (Rogelberg \& Stanton, 2007; Stanton, Sinar, Balzer, \& Smith, 2002), which makes this 
methodology more practical for practitioners. The present study furthers the literature utilizing single-item measures of stress, coping, and job satisfaction, yielding statistically significant results and has given further support for utilizing such items.

\section{Implications for Practice}

Perhaps the most important implication of the present study for practitioners is that coping levels are moderating the effect of stress on job satisfaction in a way that is favorable to reducing the negative influence of stress on satisfaction. This would imply that school leaders should find ways to support the development of effective coping skills among their teachers. With job satisfaction being directly connected to teacher retention (Skaalvik \& Skaalvik, 2015) and whether teachers stay in the profession (Klassen \& Chiu, 2011; McCarthy, Lambert, Crowe, \& McCarthy, 2010), investment in professional development addressing coping strategies for teachers could become a difference-maker for the job satisfaction of all teachers. This could be particularly true for those teachers who have the lowest coping ratings, as the results demonstrated that increases in stress negatively affect their job satisfaction more significantly than those teachers who are coping at an average or better level.

Because of the importance of coping, practitioners should consider effective methods for growing the coping skills of teachers. One approach to doing so is utilization of programs such as Cultivating Awareness and Resilience in Education (CARE). CARE is a mindfulness-based program that is designed to help teachers reduce stress and improve their classroom outcomes (Jennings, Frank, Snowberg, Coccia, \& Greenberg, 2013). In a randomized control trial, those teachers that were in the CARE group saw improvements in well-being, self-efficacy, stress, and mindfulness. In addition, the teachers themselves believed the CARE program was effective (Jennings et al., 2013). Another randomized control trial study showed that, over time, teachers 
who received the CARE intervention showed significantly lowered levels of psychological distress and increased capacity for emotion regulation when compared to the control group (Jennings et al., 2019).

Ansley et al. (2021) found that the use of an online stress intervention (consisting of eight modules to be completed over 4 weeks) resulted in increased use of coping strategies, increased teacher efficacy, and decreased emotional exhaustion and depersonalization (two main components of burnout) after just four weeks. Ansley et al. (2021)'s modules consisted of work related to mindfulness, relaxation, cognitive restructuring, social support, and physical exercise. Another option would be interventions targeted at teaching teachers to activate their relaxation response. Kaspereen (2012) found that a group of high school teachers who used a facilitatorguided visualization technique with a musical accompaniment reported lower levels of stress and greater levels of life satisfaction. Anderson, Levinson, Barker, and Kiewra (1999) studied the effects of a meditation program on primary and secondary teachers. The participants in that program reported decreases in stress, burnout, and anxiety. This research shows there are promising interventions available to increase the coping skills of teachers. Eddy et al. (2019) already found that improving coping by itself may improve outcomes for teachers and students whether stress levels are improved or not. School leaders need to take note and enact some of these programs, particularly given the body of research, including the present study, that emphasize the importance of coping in dealing with the growing number of stressors that teachers are facing and the potential negative effects of those stressors for both the teacher and for students. Pre-service teacher preparation programs should also be examining how to prepare their future teachers to cope with the inevitable stressors of the teaching profession. It is clear that there are a number of viable options that can improve teachers' coping skills and the 
outcomes they experience, and school leaders should investigate these opportunities because of the benefit it would have for their staff, students, and districts.

In addition to the importance of taking action to build coping capacity among teachers, school leaders should be actively monitoring the stress, coping, and satisfaction levels of their staff. The work of Eddy et al. (2019) established the validity and reliability of single-item measures of both stress and coping. Wanous, Reichers, and Hudy (1997) have established the reliability of single-item measures of job satisfaction. The utility and ease of use of these singleitem measures should make it easy for school leaders to survey their staffs with high response rates, particularly given the low survey burden (Rogelberg \& Stanton, 2007; Stanton, Sinar, Balzer, \& Smith, 2002). Depending upon the demographic data collected, school leaders could gain valuable information about whether their staff as a whole or certain sub-segments of their staff could benefit from professional development around coping strategies.

It is important to note here that coping is NOT the only important component of the teacher stress equation. The 3C Theory (Herman, Reinke, \& Eddy, 2020) also includes competence and context as fundamental aspects of teacher stress responses. The competence pathway of this theory explains the link between stress and classroom practices and emphasizes the importance of classroom management in teacher stress levels. The context pathway focuses on school and system policies and practices that can also influence teacher stress levels. So, while coping is an important component of the teacher stress problem, it is not the only important component. Focusing on interventions for coping and measurement of stress, coping, and job satisfaction can be meaningful practices and should positively influence teacher job satisfaction, but school leaders still need to attend to the other two pathways described by the $3 \mathrm{C}$ Theory. 


\section{Limitations}

The present study has several limitations. The first of these limitations is that the data was cross-sectional. Field (2018) explains that cross-sectional research can only explain what is occurring in the moment the data was collected. Because the present study is not a longitudinal design, claims about causality are not warranted (Field, 2018). In the present study, longitudinal data at the teacher level was not available, as there was no data identifying particular teachers to track their responses across time. However, neither the SCSL nor START studies set out to test the question posed by the present study, nor was the intervention utilized in those studies directly tailored to stress, coping, or job satisfaction. A cross sectional design made sense for the present study because it is exploratory in nature and because it is testing for a relationship (stress and job satisfaction as moderated by coping) that has not been thoroughly explored in previous studies (Spector, 2019).

Another limitation of this study is that it does not explore a course of course of action for building coping capacity among teachers nor does it test to see if such actions improve job satisfaction. Research regarding coping has shown that it is negatively associated with stress and burnout (Eddy et al., 2019; Kyriacou, 2001). Coping is also part of the 3C theoretical framework put forth by Herman, Reinke, and Eddy (2020) and they point out that teacher training in coping can help avert teacher burnout and attrition. Programs such as the CARE program (Jennings et al., 2013), online stress intervention (Ansley et al., 2021), visualization techniques (Kaspereen, 2012), and meditation programs (Anderson et al., 1999) all showed promising results in helping teachers increase their coping strategy use, lower stress, increase satisfaction, or some combination of those. While job satisfaction was not measured in these interventions, further 
research into whether they increase job satisfaction could be worthwhile given their positive influence on stress and coping and several other teacher outcomes.

A third limitation of this study is that it does not specify what types of coping the teachers surveyed are using. Kyriacou (2001) explained that coping techniques are either direct action or palliative. Direct action techniques are those that directly address the problem (by learning a new teaching technique or speaking directly to the person who is a source of stress, for example), while palliative techniques are those that a teacher may use to lessen the feeling of stress without resolving the source of the stress (Kyriacou, 2001). Multiple studies have demonstrated that the use of negative or ineffective coping strategies only serve to increase teacher burnout levels (Austin, Shah, \& Muncer, 2005; Marroquin et al., 2010; Shin et al., 2014), Austin, Shah, and Muncer (2005) showed that teachers that use problem centered coping strategies experience lower levels of burnout. Because of the cross-sectional nature of this study and the lack of individual teacher identifiers in the data, it is not possible to know how those who say they are coping well fare over time (particularly if they are using ineffective techniques to cope). The survey item read, "How well are you coping with the stress of your job?" but did not ask for further explanation, so we do not have a way to know whether teachers are employing positive coping techniques or negative techniques. This information could be particularly useful to practitioners to help guide any potential interventions.

Another limitation of the present study has to do with the limited geographic regions covered by the sample. All the participating schools were in either the Kansas City area or in Oklahoma. This provides limited teacher perspectives and there may also be stressors or coping mechanisms in other locales that are not present in these two locations. It is possible that other 
regions of the United States or the world would report similar results, but the present study cannot claim that the results are generalizable to any location. 
SECTION SIX:

SCHOLARLY PRACTITIONER REFLECTION 


\section{Introduction}

To say my experience in the Ed.D. in Education Leadership and Policy Analysis program has been limited to impacts in just my life as a leader and a scholar would not capture the entire picture. When I began this program a little over four years ago, my children were eight years old and five years old, I was an elementary assistant principal at a new elementary school, and I had significantly less grey hair. Since then, I have become the principal of that same elementary school, we have endured the effects of a pandemic for over a year, and my children have a difficult time remembering a time that I wasn't taking classes or working on my dissertation. I realize that I am straying a bit here, but one of the biggest lessons this program has taught is one that I hope was impressed upon my children: We do not quit at something just because it is hard. In fact, persevering through those big challenges helps us grow as people, and that making it through those challenges make future obstacles easier to overcome. There were multiple times throughout my path in this program where I could have stopped, such as when my mother passed away right after summer two courses wrapped up or while trying to acclimate to being a new principal in the middle of a pandemic that required all of us to re-invent the way we teach school. It was important to me, though, to persist and finish this degree because I found it valuable to me as a leader and a scholar AND because I wanted my children to learn that they can also push through hard challenges and come out better on the other side.

\section{The Influence of the Dissertation as an Educational Leader}

For me, the dissertation process stretches back to the beginning of coursework. When I began this program, I had no idea at all what I wanted to study. I saw the Ed.D. program as an opportunity to learn more about leadership and, if I am being completely truthful, an opportunity to potentially advance my career. That first summer, we spent a lot of time reading about and 
practicing with framing issues using the work of Bolman and Deal (2013). While I thought I was beginning to get my arms around leading an educational organization, the opportunity to learn about and refine the use of multiple frames in processing decisions was a significant paradigm shift for my practice as a school administrator. The structural frame has to do with the way an organization defines its roles and responsibilities to maximize performance. The human resource frame focuses on what organizations and people do for each other. The political frame deals with the decision making and resource allocation (with the assumption that resources are scarce and there are potentially opposing interests in those resources). The symbolic frame focuses on how people make meaning of the world around them and the symbols we attach to them. I had seen my efforts succeed and fail in a variety of endeavors prior to learning about framing, but after framing I can more clearly see why things were or were not successful. I still employ the frames, particularly while trying to lead in a pandemic. Every frame was important when trying to make decisions about processes for delivering instruction in a way we had never utilized while also attending to the stress levels and mental health ramifications for our staff, students, and families. I believe the ability to filter the dilemmas we faced, such as how to set priorities for instruction with our teachers, through multiple frames helped me to make decisions that, while not always well like by everyone, had accounted for as many possible perspectives as I could.

The pandemic has been present for more than half of my principal career and it is definitely a wicked problem, and what I learned about framing decisions in this program has been a big part of my leadership during this time. The structural frame, the human resource frame, the symbolic frame, and the political frame played an important role in nearly every decision we made, whether we were determining how to maintain stable groups through class roster design (structural), how to deliver lessons electronically (structural), how to help take 
some of the workload off of our teachers' plates (human resource), how to pay hourly staff when we were virtual (structural and human resource), how to hold virtual graduations (structural and symbolic), or when to open and how to handle masking requirements (political...unfortunately). Many of these decisions had to be made quickly and evaluated as we implemented them, but having the knowledge of how to frame them was extraordinarily helpful in aiding me in making the best decisions that I could.

\section{Guiding leadership theories}

My work as a leader has been guided primarily by two theories, Emotional Intelligence (EI) and servant leadership. The five skills included as part of EI are self-awareness, selfregulation, motivation, empathy, and social skill. EI fits under the larger umbrella of trait leadership because it is a specific trait of the leader and it does not depend upon characteristics of the followers (Northouse, 2016). In addition to EI, I also have come to value servant leadership as an aspect of my own leadership. Northouse (2016) described a servant leader as someone who places the good of followers over their own and someone who seeks to develop their followers. Greenleaf (1970) explained that servant leaders are motivated by a desire to serve others over the desire to lead others. This leadership theory is something I have closely identified with because it has always been my view that a leader's role is to serve their followers in order to make them more successful.

In addition to coursework helping guide my leadership during the pandemic, my choice of dissertation topic has turned out to be particularly useful, though I selected that topic prior to the onset of COVID. While the goal of my study was to find out if coping moderated the relationship between stress and job satisfaction, I was also able to gain a deep understanding of the effects stress has on teachers. I can think of no time in my education career when stress has 
been more of a problem than in the past 15 months or so. Schools were asked to reinvent the way we deliver instruction and the way we deliver all sorts of social, emotional, and physical supports all while trying to keep ourselves, our students, and their families safe. I saw the teachers in my own building push themselves far beyond their normal limits in order to continue to meet the needs of theirs students, and I also saw the toll it was taking on them. Many of my most talented teachers (and most of the others) were having difficulty keeping up with the demands this new instructional paradigm was imposing on them, and many felt they were working more than twice as hard for less than half of the normal results. The stress in the lives of these educators was obvious.

Initially, I set out to study stress and coping among teachers because I had seen so many of my colleagues (and myself) through the years experiencing struggles with the stressors of teaching with no real way to manage it. It seemed to me that teachers were either able to effectively cope or they would burn out and leave the profession or their present position. The results of my study confirmed some of what I had noticed observationally. Teachers can experience the same event and whether they experience a stress response or not depends greatly on their individual ability to cope (Lazarus \& Folkman, 1987). Those teachers that could cope tended to continue to thrive, while those that could not slipped further away from being able to remain in their position. I also found promising research that shows there are effective coping interventions for teachers that yield positive results (Jennings et al., 2013; Ansley et al., 2021; Kaspereen, 2012; Anderson et al., 1999; Eddy et al., 2019). It is my hope to employ some of these coping interventions on a targeted basis in hopes of improving outcomes for both those teachers that need it and their students. One important key to me to consider before employing these coping interventions, though, is how to do so without making teachers feel as though I am 
creating more stress for them. I genuinely want to do good for them, but it could be difficult for the teachers to receive that message if they feel stressed out about getting the coping support.

I think the research I have done connected with stress and coping has heightened the importance to me of utilizing my Emotional Intelligence (EI). I believe that utilizing the skills that make up EI help me to be a better leader for my staff. If I am unable to utilize empathy, for example, I would be blind to the feelings and worries of my staff even though I should be taking those into account when making decisions. Put simply, my EI is clearly tied to the job satisfaction of my teachers (Singh, 2013), so it is imperative to me that I am mindful of the five skills that make up EI. The importance of EI and empathy has never been more apparent to me than over the last 15 months while trying to help our staff navigate educating children in a pandemic while also still attending to the needs of themselves and their own families.

I believe one way in which I can be a servant leader to my teachers is to help them grow their coping skills. My dissertation has made it clear that coping has an important moderating role between stress and job satisfaction, and I want my teachers to be satisfied with their jobs. I can use the knowledge I have gained through this study to implement research-based coping interventions for my staff that help positively influence their coping and also their job satisfaction (Jennings et al., 2013; Ansley et al., 2021; Kaspereen, 2012; Anderson et al., 1999; Eddy et al., 2019). Adult learning theory explains that adult learners need immediate application of what they learned (Merriam \& Bierema, 2014). I believe my dissertation research has led to outcomes that I can share with my staff and that the coping interventions will be exactly the type of learning that our teachers can implement right away.

The Influence of the Dissertation as a Scholar 
When I entered the Ed.D. program, I had only a mild interest in being a scholar or academic. I was interested enough to go through the program, though, because I believed it would enhance my leadership skills knowledge of how to effectively lead. Scholarship and research, however, were secondary benefits of the program and ones that I did not necessarily believe were important to me or my future. However, the coursework in this program and the dissertation process have had a significant influence on my beliefs about the role of scholars as practitioners and about my potential for a future as a researcher. Adult learning theory assumes a number of things about adults, but of particular import to me are just a few. First, as adults mature, their self-concept moves toward being a self-directed individual. Also, adults want their learning to be immediately applicable. Finally, adults need to know the reason for learning the topic at hand (Merriam \& Bierema, 2014). Knowing these assumptions has helped frame my own learning as a scholar in this program and also how I can approach learning among my staff.

As a result of my experiences as a scholar in this program, I have become very interested in how I can use those skills to help better my own organization. In my career, I have seen schools jump at different programs or initiatives, hoping they will provide the "magic bullet" effect that will solve whatever problem is at hand, such as increasing achievement in reading or math or decreasing student discipline problems. What I have not seen much of in those situations is valid research that supports such programs. The dissertation process has helped me become a more discerning consumer of any program we are considering that could help our students, which is a direct connection to the assumptions of adult learning because I (and my staff) need for the programs we are learning to be immediately applicable and for it to be clear why the program addresses the need we have (Merriam \& Bierema, 2014). The opportunity to hone my research skills through the dissertation process has helped me be able to inform myself about 
whether a particular program aligns with research-based best practices prior to purchasing or implementing. Curricular programs, for example, are extremely costly and require a great deal of training and work to implement effectively. I owe it to our staff, students, and school district to be relatively confident that a program will pay dividends prior to committing funds and effort to it. This ability to research and justify the reasoning for utilizing a particular program or process also makes it more likely to suit the needs of my adult learners (the staff). Additionally, the gap between research and practice is something that continues to persist in education (Farley-Ripple, May, Karpyn, Tilley, \& McDonough, 2018; McIntyre, 2005; Nelson \& Campbell, 2017). In the past couple of years, our district has invested a large amount of resources and time in implementation of interventions for struggling readers at the elementary level. Because of the research skills that I have been able to develop as part of my dissertation process and through the program in general, I was able to learn more about the research base and rationale supporting these interventions. These interventions were largely based on what is being called the "science of reading," (Petscher et al., 2020) and many among my staff were not trained using such methodology. However, my experience as a researcher helped me understand the rationale behind the science of reading is that it is based on years of studies and data regarding how students learn to read and what types of interventions are most effective. As a researcher, that kind of information makes the science of reading far more credible than just some company trying to sell their program. This background knowledge in research methods truly helped me in explaining the interventions to my staff and helping to create buy in for this program even though educators are sometimes skeptical about new initiatives (an understandable reaction). I believe my training in research can make me a more effective principal because I can use those skills to determine what is working about the programs we implement for our students 
and what is not. However, a system the size of CPS, should also be engaged in institutional research. The Association for Institutional Research (AIR) clearly lays out the functions of such a department (which can be found at https://www.airweb.org/docs/default-source/documents-forpages/air-duties-and-functions-of_ire96e442e8924495cb1f954be7c9012ca.pdf). While institutional research departments typically exist in higher education, I believe such departments in large school systems could be immensely useful. Decisions or programs implemented at a building level are clearly important and can be instructive for others, but effective systems of support for students and staff that can help raise outcomes district wide require the assistance of a dedicated department that can properly vet the data and results to decide whether these singular successes could be system-wide successes. With the knowledge I gained through coursework (such as program evaluation, organizational analysis, policy, qualitative and quantitative methods) and my own research (actual application of the coursework and the study of stress and coping among teachers), I believe the work I have done through this program has made me wellsuited to a role something like institutional research. At CPS, such a department already exists (we call it Assessment, Intervention, and Data) and they are actively interrogating the data we get from new instructional, intervention, and discipline programs to determine their effectiveness and to help the district set and measure appropriate goals and priorities. Work such as this still supports our adult learners (and myself!) because I would be providing compelling reasons for why we continue to maintain the status quo or for why new learning is needed within our organization.

In addition to the potential for institutional research at the K-12 level, I believe this program has prepared me to take on (at some point) a role among university faculty as either a researcher or instructor of practitioner-oriented courses (or both). When I have been able to 
devote my full attention to the dissertation, I have truly enjoyed the work and learning more about my chosen area. There are several other areas I am also interested in, such as student executive function skills and how those skills interplay with math achievement and principal characteristics or practices that make for increased student achievement. I think I could find a niche as an education researcher and truly enjoy the work. Because of my background as a practitioner (that I hope to continue to expand) and my recent work as a scholar, I believe I could also be a valuable resource for aspiring teachers or administrators. I would definitely be interested in helping work in teacher or administrator preparation courses, whether that be a full time or adjunct faculty role.

\section{Summary}

The dissertation process has changed me as both a leader and scholar. I have learned so much about the effects of stress on teachers that I am constantly using that knowledge as a filter when making decisions about how to lead our school. In addition, I want to explore a targeted coping training program for those that need it (and those that may just want to participate). Too much has been put on the plates of teachers for so long, and, while I may not be able to remove much from the teachers' plates (though I'll try to do so when I can), I can do something to help them learn how to effectively cope with the stressors they are facing. I also feel as though my work as a scholar has helped me to be better at researching a problem and using that research to develop an informed plan for how to proceed, rather than relying just on feelings or anecdotal evidence. I believe in using evidence-based approaches to addressing areas of need, and I feel I am a much more competent researcher and consumer of information when it comes to vetting resources or implementing initiatives. 


\section{References}

Abouserie, R. (1996). Stress, coping strategies, and job satisfaction in university academic staff. Educational Psychology, 16(1), 49-56.

Anderson, V. L., Levinson, E. M., Barker, W., \& Kiewra, K. R. (1999). The effects of meditation on teacher perceived occupational stress, state and trait anxiety, and burnout. School Psychology Quarterly, 14(1), 3-25.

Ansley, B. M., Houchins, D. E., Varjas, K., Roach, A., Patterson, D., \& Hendrick, R. (2021). The impact of an online stress intervention on burnout and teacher efficacy. Teaching and Teacher Education, 98, 1-11.

Antoniou, A. S., Ploumpi, A., \& Ntalla, M. (2013). Occupational stress and professional burnout in teacher of primary and secondary education: The role of coping strategies. Psychology, $4(3), 349-355$.

Antoniou, A. S., Polychroni, F., \& Vlachakis, A. N. (2006). Gender and age differences in occupational stress and professional burnout between primary and high school teachers in Greece. Journal of Managerial Psychology, 21, 682-689.

Austin, E. J., Saklofske, D. H., \& Egan, V. (2005). Personality, well-being and health correlates of trait emotional intelligence. Personality and Individual Differences, 38, 547-558.

Austin, V., Shah, S., \& Muncer, S. (2005). Teacher stress and coping strategies used to reduce stress. Occupational Therapy International, 12, 63-80.

Avanzi, L., Fraccaroli, F., Castelli, L., Marcionetti, J., Crescentini, A., Balducci, C., \& van Dick, R. (2018). How to mobilize social support against workload and burnout: The role of organizational identification. Teaching and Teacher Education, 69, 154-167. 
Bakker, A. B., \& Demerouti, E. (2007). The job demands-resources model: State of the art. Journal of Managerial Psychology, 22, 309-328.

Bandura, A. (1997). Self-efficacy: The exercise of control. New York, NY: Macmillan.

Baron, R. M., \& Kenny, D. A. (1986). The moderator-mediator variable distinction in social psychological research: Conceptual, strategic, and statistical considerations. Journal of Personality and Social Psychology, 51(6), 1173-1182.

Beck, C. D. (2014). Antecedents of servant leadership: A mixed methods study. Journal of Leadership \& Organizational Studies, 21(3), 299-314.

Benson, G. (1997). Informal training takes off. Training and Development, 51(5), 93-94.

Belcastro, P. A., \& Gold, R. S. (1983). Teacher stress and burnout: Implications for school health personnel. Journal of School Health, 53, 7404-7407.

Berry, R. A. (2010). Preservice and early career teachers' attitudes toward inclusion, instructional accommodations, and fairness: Three profiles. Teacher Educator, 45(2), 7595.

Betoret, F. D. (2006). Stressors, self-efficacy, coping resources, and burnout among secondary school teachers in Spain. Educational Psychology, 26(4), 519-539.

Blatt, D. (2016, January 13). Prosperity policy: Teacher shortage a growing problem. The Journal Record. http://journalrecord.com/2016/01/13/prosperity-policy-teacher-shortagea-growing-problemopinion/

Boe, E. E., Cook, L. H., \& Sunderland, R. J. (2008). Teacher turnover: Examining exit attrition, teaching area transfer, and school migration. Exceptional Children, 75(1), 7-31.

Borman, G. D., \& Dowling, N. M. (2006). Teacher attrition and retention: A meta-analytic and narrative review of the research. Review of Educational Research, 78(3), 367-409. 
Boyle, G. J., Borg, M. G., Falzon, J. M., \& Baglioni, A. J. (1995). A structural model of the dimensions of teacher stress. British Journal of Educational Psychology, 65, 49-67.

Butler, S., \& Constantine, M. (2005). Collective self-esteem and burnout in professional school counselors. Professional School Counseling, 9(1), 55-62.

Caprara, G.V., Barbaranelli, C., Borgogni, L. \& Steca, P. (2003), Efficacy beliefs as determinants of teachers' job satisfaction. Journal of Educational Psychology, 95(4), 821-832.

Cavanaugh, M. A., Boswell, W. R., Roehling, M. V., \& Boudreau, J. W. (2000). An Empirical Examination of Self-Reported Work Stress Among U.S. Managers. Journal of Applied Psychology, 85(1), 65-74.

Chambers Mack, J., Johnson, A., Jones-Rincon, A., Tsatenawa, V., \& Howard, K. (2019). Why do teachers leave? A comprehensive occupational health study evaluating intent-to-quit in public school teachers. Journal of Applied Biobehavioral Research, 24(1), 1-13.

Chaplain, R. P. (2008). Stress and psychological distress among trainee secondary teachers in England. Educational Psychology, 28, 195-209.

Chen, C. K., Lin, C., Wang, S. H., \& Hou, T. H. (2009). A study of job stress, stress coping strategies, and job satisfaction for nurses working in middle-level hospital operating rooms. Journal of Nursing Research, 17(3), 199-211.

Cohen, J. (1988) Statistical power analysis for the behavioral sciences. (2nd ed.). Hillsdale, NJ: Erlbaum.

Crawford, S. D., Couper, M. P., \& Lamias, M. J. (2001). Web surveys: Perception of burden. Social Science Computer Review, 19, 146 -162. 
Cronbach, L. J., \& Meehl, P. E. (1955). Construct validity in psychological tests. Psychological Bulletin, 52, 281-302.

Darling-Hammond, L. (2000). Teacher quality and student achievement. Education - Policy Analysis Archives, 8, 1-45.

Decker, P. J., \& Borgen, F. H. (1993). Dimensions of work appraisal: Stress, strain, coping, job satisfaction, and negative affectivity. Journal of Counseling Psychology, 40(4), 470-478.

Dolton, P., \& Newson, D. (2003). The relationship between teacher turnover and school performance. London Review of Education, 1(2), 131-140.

Dunn, A. H. (2018). Leaving a profession after it's left you: Teachers' public resignation letters as resistance amidst neoliberalism. Teachers College Record, 120(9), 1-34.

Eddy, C. L., Herman, K. C., \& Reinke, W. M. (2019). Single-item teacher stress and coping measures: Concurrent and predictive validity and sensitivity to change. Journal of School Psychology, 76(2019), 17-32.

Farley-Ripple, E., May, H., Karpyn, A., Tilley, K., \& McDonough, K. (2018). Rethinking connections between research and practice in education: A conceptual framework. Educational Researcher, 47, 235-245.

Field, A. (2018). Discovering statistics using IBM SPSS statistics. Thousand Oaks, CA: Sage.

Fink, A. (2017). How to conduct surveys: A step-by-step guide. (6th ed.). Thousand Oaks, CA: Sage.

Fisher, G. G., Matthews, R. A., \& Gibbons, M. A. (2016). Developing and investigating the use of single-item measures in organizational research. Journal of Occupational Health Psychology, 21(1), 3-23.

Fisher, R. A. (1935). The design of experiments. Edinburgh, United Kingdom: Oliver \& Boyd. 
Fogarty, G. J., Anthony Machin, M., Albion, M. J., Sutherland, L. F., Lalor, G. I., \& Revitt, S. (1999). Predicting occupational strain and job satisfaction: The role of stress, coping, personality, and affectivity variables. Journal of Vocational Behavior, 54(3), 429-452.

Foley, C., \& Murphy, M. (2015). Burnout in Irish teachers: Investigating the role of individual differences, work environment and coping factors. Teaching and Teacher Education, 50, 46-55.

Fritzsche, B.A., \& Parrish, T.J. (2005). Theories and research on job satisfaction. In Brown, S.D. \& Lent, R.W. (Eds.), Career development and counselling: Putting theory and research to work (pp. 180-202). Hoboken, NJ: Wiley.

Gardner, L., \& Stough, C. (2002). Examining the relationship between leadership and emotional intelligence in senior level managers. Leadership \& Organisational Development Journal, 23(2): 68-78.

Goldring, R., Taie, S., and Riddles, M. (2014). Teacher attrition and mobility: Results from the 2012-13 teacher follow-up survey (NCES 2014-077). U.S. Department of Education. Washington, DC: National Center for Education Statistics.

Goleman, D. (1996). Emotional intelligence. London: Bloomsbury.

Goleman, D. (2011). What makes a leader? In HBR's 10 must reads: On leadership (pp. 1-22). Boston, MA: Harvard Business Review Press.

Greenleaf, R. K. (1970). The servant as leader. Indianapolis, IN: Greenleaf Center.

Hanpachern, C., Morgan, G. A., \& Griego, O. V. (1998). An extension of the theory of margin: A framework for assessing readiness for change. Human Resource Development Quarterly, 9(4), 339-350. 
Hargrove, M. B., Nelson, D. L., \& Cooper, C. L. (2013). Generating eustress by challenging employees: Helping people savor their work. Organizational Dynamics, 42(1), 61-69.

Harmsen, R., Helms-Lorenz, M., Maulana, R., \& van Veen, K. (2019). The longitudinal effects of induction on beginning teachers' stress. British Journal of Educational Psychology, $89,259-287$.

Harmsen, R., Helms-Lorenz, M., Maulana, R., \& van Veen, K. (2018). The relationship between beginning teachers' stress causes, stress responses, teaching behaviour and attrition. Teachers and Teaching, 24(6), 626-643.

Hastings, R. P., \& Bham, M. S. (2003). The relationships between student behavior problems and teacher burnout. School Psychology International, 24(1), 115-127.

Hastings, R. P., \& Brown, T. (2002). Coping strategies and the impact of challenging behaviors on special educators' burnout. Mental Retardation, 40, 148-156.

Helms-Lorenz, M., \& Maulana, R. (2015). Influencing the psychological well-being of beginning teachers across three years of teaching: Self-efficacy, stress causes, job tension and job discontent. Educational Psychology, 36(3), 569-594.

Helms-Lorenz, M., Slof, B., Vermue, C. E., \& Canrinus, E. T. (2012). Beginning teachers' selfefficacy and stress and the supposed effects of induction arrangements. Educational Studies, 38(2), 189-207.

Herman, K. C., Hickmon-Rosa, J., Reinke, W. M. (2018). Empirically derived profiles of teacher stress, burnout, self-efficacy, and coping and associated student outcomes. Journal of Positive Behavior Interventions, 20(2), 90-100. 
Herman, K. C., Reinke, W. M., \& Eddy, C. L. (2020). Advances in understanding and intervening in teacher stress and coping: The Coping-Competence-Context Theory. Journal of School Psychology, 78, 69-74.

Herman, K. C., Reinke, W. M., Stormont, M., Puri, R., \& Agarwal, G. (n.d.). Using prevention science to promote children's mental health: The founding of the Missouri Prevention Center. The Counseling Psychologist, 38(5), 652-690.

Herzberg, F. (1966). Work and the nature of man. Cleveland, OH: The World Publishing Company.

Hiemstra, R. (1993). Three underdeveloped models for adult learning. New Directions for Adult and Continuing Education, 57, 37-46.

Houdmont, J., Hopson, S., Nuttall, S., Pamia, S., Jachens, L., \& Randall, R. (2019). What does a single-item measure of job stressfulness assess? International Journal of Environmental Research and Public Health, 16(9), 1480-1495.

Hubermann, M. (1993). Burnout in teaching careers. European Education, 25(3), 47-69.

Hubermann, M. (1995). Professional careers and professional development: Some intersections. In T. Guskey, \& M. Hubermann (Eds.), Professional development in education: New paradigms and practices (pp. 193-224). New York, NY: Teachers College Press.

Hultell, D., Melin, B., \& Gustavsonn, J. P. (2013). Getting personal with teacher burnout: A longitudinal study on the development of burnout using a person-based approach. Teaching and Teacher Education, 32, 75-86.

Ingersoll, R. M. (2001). Teacher turnover and teacher shortages: An organizational analysis. American Educational Research Journal, 38(3), 499-534. 
Ingersoll, R. M., \& Smith, T. M. (2004). Do teacher induction and mentoring matter? NASSP Bulletin, 88(638), 28-40.

Inman, D., \& Marlow, L. (2004). Teacher retention: Why do beginning teachers remain in the profession? Education, 124(4), 605-614.

Jennings, P. A., Doyle, S., Oh, Y., Rasheed, D., Frank, J. L., \& Brown, J. L. (2019). Long-term impacts of the CARE program on teachers' self-reported social and emotional competence and well-being. Journal of School Psychology, 76, 186-202.

Jennings, P. A., Frank, J. L., Snowberg, K. E., Coccia, M. A., \& Greenberg, M. T. (2013). Improving classroom learning environments by Cultivating Awareness and Resilience in Education (CARE): Results of a randomized controlled trial. School Psychology Quarterly, 28(4), 374-390.

Jepson, E., \& Forrest, S. (2006). Individual contributory factors in teacher stress: The role of achievement striving and occupational commitment. British Journal of Educational Psychology, 76, 183-197.

Johnson, S., Cooper, C., Cartwright, S., Donald, I., Taylor, P., \& Millet, C. (2005). The experience of work-related stress across occupations. Journal of Managerial Psychology, 20, 178-187.

Johnson, D.R., \& Creech, J.C. (1983). Ordinal measures in multiple indicator models: A simulation study of categorization error. American Sociological Review, 48, 398-407.

Judge, T.A., Thoresen, C.J., Bono, J.E., \& Patton, G.K. (2001). The job satisfaction-job performance relationship: a qualitative and quantitative review. Psychological Bulletin, 127(3), 376-407. 
Judge, T. A., \& Watanabe, S. (1993). Another look at the job satisfaction-life satisfaction relationship. Journal of Applied Psychology, 78(6), 939-948.

Karabatak, S., \& Alanoglu, M. (2019). The mediator effect of stress on teachers' self-efficacy beliefs and job satisfaction. International Journal of Contemporary Educational Research, 6(2), 230-242.

Kaspereen, D. (2012). Relaxation intervention for stress reduction among teachers and staff. International Journal of Stress Management, 19(3), 238.

Kalynych, C. J. (2010). The application of margin in life theory in regard to attrition and remediation among emergency medicine residents. (Doctoral disseration). Retrieved from: https://digitalcommons.unf.edu/etd/238/

Kaya, M., \& Selvitopu, A. (2019). A meta-analysis of the effects of some factors on teachers' classroom management skills. International Journal of Contemporary Educational Research, 6(2), 409-425.

Klassen, R. M., \& Chiu, M. M. (2011). The occupational commitment and intention to quit of practicing and pre-service teachers: Influence of self-efficacy, job stress, and teaching context. Contemporary Educational Psychology, 36, 114-129.

Klassen, R. M., Bong, M., Usher, E. L., Chong, W. H., Huan, V. S., Wong, I. Y., et al. (2009). Exploring the validity of the teachers' self-efficacy scale in five countries. Contemporary Educational Psychology, 34, 67-76.

Kyriacou, C. (2001). Teacher stress: Directions for future research. Educational Review, 53(1), 27-35.

Lambert, R. G., Kusherman, J., O’Donnell, M., \& McCarthy, C. J. (2006). Teacher stress and classroom structural characteristics in preschool settings. In R. G. Lambert \& C. J. 
McCarthy (Eds.), Understanding teacher stress in an era of accountability (Vol. 3, pp. 105-120). Greenwich, CT: Information Age.

Lambert, R. G., McCarthy, C. J., O’Donnell, M., \& Melendres, L. (2007). Teacher stress and classroom structural characteristics in elementary settings. In G. Gates, M. Wolverton, \& W. Gmelch (Eds.), Emerging thought and research on student, teacher, and administrator stress and coping (pp. 109-131). Charlotte, NC: Information Age.

Lauermann, F., \& Konig, J. (2016). Teachers' professional competence and wellbeing: Understanding the links between general pedagogical knowledge, self-efficacy and burnout. Learning and Instruction, 45, 9-19.

Laugaa, D., Rascle, N., \& Bruchon-Schweitzer, M. (2008). Stress and burnout among French elementary school teachers: A transactional approach. Revue europeenne de physchologie appliquee, 58, 241-251.

Lazarus, R. S., \& Folkman, S. (1984). Stress, appraisal, and coping. New York, NY: Springer.

Lazarus, R. S., \& Folkman, S. (1987). Transactional theory and research on emotions and coping. European Journal of Personality, 1, 141-169.

Liu, X. S., \& Ramsey, J. (2008). Teachers' job satisfaction: Analyses of the teacher follow-up survey in the United States for 2000-2001. Teaching and Teacher Education, 24(5), 1173-1184.

Lohman, M. C. (2005). A survey of factors influencing the engagement of two professional groups in informal workplace learning activities. Human Resource Development Quarterly, 16(4), 501-527. 
Madsen, S. R., John, C., Miller, D., \& Warren, E. (2003, March). The relationship between an individual's margin in life and readiness for change. Paper presented at the meeting of the Academy of Human Resource Development, Austin, TX.

Manthei, R., Gilmore, A., Tuck, B., \& Adair, V. (1996). Teacher stress in intermediate schools. Educational Research, 38, 3-19.

Mark, G., \& Smith, A.P. (2012). Effects of occupational stress, job characteristics, coping, and attributional style on the mental health and job satisfaction of university employees. Anxiety, Stress, \& Coping, 25(1), 63-78.

Marroquin, B. M., Fontes, M., Scilletta, A., \& Miranda, R. (2010). Ruminative subtypes and coping responses: active and passive pathways to depressive symptoms. Cognition and Emotion, 24(8), 1446-1455.

Maslow, A.H. (2005). A theory of human motivation. In Shafritz, Ott, \& Jang (Eds.), Classics of organization theory (6 ${ }^{\text {th }}$ ed., pp. 167-178). Belmont, CA: Wadsworth. (Reprinted from Psychological Review 50(4), pp. 370-396, 1943).

McCarthy, C. J., Lambert, R. G., Crowe, E. W., \& McCarthy, C. J. (2010). Coping, stress, and job satisfaction as predictors of advanced placement statistics teachers' intention to leave the field. NASSP Bulletin, 94(4), 306-324.

McCarthy, C., Lambert, R., Lineback, S., Fitchett, P., \& Baddouh, P. (2016). Assessing teacher appraisals and stress in the classroom: Review of the Classroom Appraisal of Resources and Demands. Educational Psychology Review, 28(3), 577-603.

McCarthy, C. J., Lambert, R. G., \& Reiser, J. (2014). Vocational concerns of elementary teachers: Stress, job satisfaction, and occupational commitment. Journal of Employment Counseling, 51, 59-74. 
McCarthy, C. J., Lambert, R. G., O’Donnell, M., \& Melendres, L. T. (2009). Relationship of elementary teachers' experience, perceived demands, and coping resources to burnout symptoms. Elementary School Journal, 109, 1-19.

McClusky, H. Y. (1970). An approach to a differential psychology of the adult potential. In S. M. Grabowski (Ed.)., Adult learning and instruction (pp. 82-83). Syracuse, NY: ERIC Clearinghouse of Adult Education.

McClusky, H. Y. (1963). The course of the adult life span. In C. Verner, \& G. S. Jensen (Eds)., Psychology of adults (pp. 10-19). Chicago, IL: Adult Education Association of the U.S.A.

McIntyre, D. (2005). Bridging the gap between research and practice. Cambridge Journal of Education, 35, 357-382.

Merriam, S. B., \& Bierema, L. L. (2014). Adult learning: Linking theory and practice. San Francisco, CA: Jossey-Bass.

MetLife. (2012). The MetLife survey of the American teacher: Teachers, parents and the economy. New York, NY: Author.

Missouri Department of Elementary and Secondary Education. (2018). Recruitment and retention of teachers in Missouri public schools. Retrieved from https://dese.mo.gov/sites/default/files/2018-RR-Report.pdf

Missouri Prevention Science Institute. (n.d.) Active projects. Retrieved from http://moprevention.org/active-projects/

Nelson, J., \& Campbell, C. (2017). Evidence-informed practice in education: Meanings and applications. Educational Research, 59, 127-135.

Norman, G. (2010). Likert scales, levels of measurement and the "laws" of statistics. Advances in Health Sciences Education, 15(5), pp. 625-632. 
Northouse, P. G. (2016). Leadership: Theory and practice (7th ed.). Thousand Oaks, CA: Sage.

Nunnally, J. C., \& Bernstein, I. H. (1978). Psychometric theory (2nd ed.). New York, NY: McGraw-Hill.

Petscher, Y., Cabell, S. Q., Catts, H. W., Compton, D. L., Foorman, B. R., Hart, S. A., Lonigan, C. J., Phillips, B. M., Schatschneider, C., Steacy, L. M., Terry, N. P., \& Wagner, R. K. (2020). How the science of reading informs 21 st-century education. Reading Research Quarterly, 55, 267-282.

Pogere, E. F., Lopez-Sangil, M. C., \& Garcia-Senoran, M. M. (2019). Teachers' job stressors and coping strategies: Their structural relationships with emotional exhaustion and autonomy support. Teaching and Teacher Education, 85, 269-280.

Polio, C., \& Gass, S. (1997). Replication and reporting: A commentary. Studies in Second Language Acquistion, 19(4), 499-508.

Prilleltensky, I., Neff, M., \& Bessell, A. (2016). Teacher stress: What is it, why is it important, how it can be alleviated. Theory Into Practice, 55, 104-111.

Reilly, E., Dhingra, K., \& Boduszek, D. (2014). Teachers' self-efficacy beliefs, self-esteem, and job stress as determinants of job satisfaction. The International Journal of Educational Management, 28(4), 365-378.

Rogelberg, S. G., \& Stanton, J. M. (2007). Introduction: Understanding and dealing with organizational survey nonresponse. Organizational Research Methods, 10, 195-209.

Richards, J. (2012). Teacher stress and coping strategies: A national snapshot. The Educational Forum, 76(3), 299-316. 
Ryan, S. V., von der Embse, N. P., Pendergast, L. L., Saeki, E., Segool, N, \& Schwing, S. (2017). Leaving the teaching profession: The role of teacher stress and educational accountability policies on turnover intent. Teaching and Teacher Education, 66, 1-11.

Salkovsky, M., Romi, S., \& Lewis, R. (2015). Teachers' coping styles and factors inhibiting teachers' preferred classroom management practice. Teaching and Teacher Education, $48,56-65$.

Sass, D. A., Seal, A. K., \& Martin, N. K. (2011). Predicting teacher stress and support variables. Journal of Educational Administration, 49(2), 200-215.

Scarpello, V., \& Campbell, J. P. (1983). Job satisfaction: Are all the parts there? Personnel Psychology, 36, 577-600.

Schleicher, A. (2018). TALIS 2018 insights and interpretations. Retrieved from http://www.oecd.org/education/talis/TALIS2018_insights_and_interpretations.pdf

Schriesheim, C. A., Hinkin, T. R., \& Podsakoff, P. M. (1991). Can ipsative and single-item measures produce erroneous results in field studies of French and Raven's (1959) five bases of power? An empirical investigation. Journal of Applied Psychology, 76, 106 -114.

Schwarzer, R., \& Hallum, S. (2008). Perceived teacher self-efficacy as a predictor of job stress and burnout: Mediation analyses. Applied Psychology: An International Review, 57, 152171.

Shen, J., Leslie, J. M., Spybrook, J. K., \& Ma, X. (2012). Are principal background and school processes related to teacher job satisfaction? A multilevel study using schools and staffing survey 2003-04. American Educational Research Journal, 49, 200 -230. 
Shin, H., Park, Y. M., Ying, J. Y., Kim, B., Noh, H., \& Lee, S. M. (2014). Relation between coping strategies and burnout symptoms: A meta-analytic approach. Professional Psychology: Research and Practice, 45, 44-56.

Singh, P. (2013). Influence of the leaders' emotionally intelligent behaviors on their employees' job satisfaction. International Business \& Economics Research Journal, 12(7): 799-814.

Skaalvik, E. M., \& Skaalvik, S. (2017). Still motivated to teach? A study of school context variables, stress and job satisfaction among 10 BioMed Research International teachers in senior high school. Social Psychology of Education, 20(1), 15-37.

Skaalvik, E. M., \& Skaalvik, S. (2015). Job satisfaction, stress, and coping strategies in the teaching profession - what do teachers say? International Education Studies, 8(3), 181192.

Skaalvik, E. M., \& Skaalvik, S. (2011). Teacher job satisfaction and motivation to leave the teaching profession: Relations with school context, feeling of belonging, and emotional exhaustion. Teaching and Teacher Education, 27, 1029-1038.

Skaalvik, E. M., \& Skaalvik, S. (2010). Teacher self-efficacy and teacher burnout: A study of relations. Teaching and Teacher Education, 26, 1059-1069.

Skaalvik, E. M., \& Skaalvik, S. (2009). Does school context matter? Relations with teacher burnout and job satisfaction. Teaching and Teacher Education, 25(3), 518-524.

Smetackova, I., Viktorova, I., Pavlas Martanova, V., Pachova, A., Francova, V., \& Stech, S. (2019). Teachers between job satisfaction and burnout syndrome: What makes difference in Czech elementary schools. Frontiers in Psychology, 10, 1-8.

Spector, P.E. (1997). Job satisfaction: Application, assessment, causes and consequences. Thousand Oaks, CA: Sage. 
Spector, P. E. (2019). Do not cross me: Optimizing the use of cross-sectional designs. Journal of Business and Psychology, 34(2), 125-137.

Srivastava, R. V., \& Tang, T. (2018). Coping intelligence theory: Coping strategies, satisfaction and sales commission. Journal of Business \& Industrial Marketing, 33(5), 610-624.

Stanton, J. M., Sinar, E. F., Balzer, W. K., \& Smith, P. C. (2002). Issues and strategies for reducing the length of self-report scales. Personnel Psychology, 55, 167-194.

Stein, S., \& Book, H. (2001). The EQ edge. Emotional intelligence and your success. Toronto: Stoddart.

Stoeber, J, \& Rennert, D. (2008). Perfectionism in school teachers: Relations with stress appraisals, coping styles, and burnout. Anxiety, Stress, and Coping, 21(1), 37-53.

Sullivan, G. \& Artino Jr., A. R. (2013). Analyzing and Interpreting Data From Likert-Type Scales. Journal of Graduate Medical Education. 5(4), pp. 541-542.

Travers, C. J., \& Cooper, C. L. (1996). Teachers under pressure: Stress in the teaching profession. New York, NY: Routledge.

United States Department of Education, Office of Postsecondary Education. (2105). Higher education act title II reporting system. Retrieved on 7 March, 2020 from: https://title2.ed.gov/Public/44077_Title_Issue_Brief_Enrollment_V4a.pdf.

Van Dick, V., \& Wagner, U. (2001). Stress and strain in teaching: A structural equation approach. British Journal of Educational Psychology, 71, 203-212.

Vinothkumar, M., Arathi, A., Joseph, M., Nayana, P., Joshy Jishma, E., \& Sahana, U. (2016). Coping, perceived stress, and job satisfaction among medical interns: The mediating effect of mindfulness. Industrial Psychiatry Journal, 25(2), 195-201. 
von der Embse, N. P., Kilgus, S. P., Solomon, H. J., Bowler, M., \& Curtiss, C. (2015). Initial development and factor structure of the Educator Test Stress Inventory. Journal of Psychoeducational Assessment, 33(3), 223-237.

von der Embse, N. P., Schoemann, A., Wicoff, M., Kilgus, S. P., \& Bowler, M. (2017). The influence of test-based accountability policies on teacher stress and teaching practices: A moderated mediation model. Educational Psychology, 37(3), 312-333.

von der Embse, N. P., Ryan, S. V., Gibbs, T., \& Mankin, A. (2019). Teacher stress interventions: A systematic review. Psychology in the Schools, 56(8), 1328-1343.

Watson, J. C., Harper, S., Ratliff, L., \& Singleton, S. (2010). Holistic wellness and perceived stress: Predicting job satisfaction among beginning teachers. Research in the Schools, 17, 30-38.

Wentzel, K. R. (2010). Students' relationships with teachers. In J. L. Meece \& J. S. Eccles (Eds.), Handbook of research on schools, schooling, and human development (pp. 7591). New York, NY: Routledge.

Wiley, C. (2000). A synthesis of the research on the causes, effects, and reduction strategies of teacher stress. Journal of Instructional Psychology, 27(2), 80-87.

Woods, S. A., \& Hampson, S. E. (2005). Measuring the big five with single items using a bipolar response scale. European Journal of Personality, 19, 373-390.

Wolomasi, A. K., Asaloei, S. I., \& Werang, B. R. (2019). Job satisfaction and performance of elementary teachers. International Journal of Evaluation and Research in Education, $8(4), 575-580$.

Wong, V. W., Ruble, L. A., Yu, Y., \& McGrew, J. H. (2017). Too stressed to teach? Teaching quality, student engagement, and IEP outcomes. Exceptional Children, 83(4), 412-427. 
Zumbo, B. D., \& Zimmerman, D. W. (1993). Is the selection of statistical methods governed by level of measurement? Canadian Psychology, 34, 390-400.

Zurlo, M. C., Pes, D., \& Capasso, R. (2016). Personality characteristics, job stressors, and job satisfaction: Main and interaction effects on psychological and physical health conditions of Italian schoolteachers. Psychological Reports, 119(1), 27-38. 


\section{VITA}

Seth Woods was raised in Hillsboro, Missouri. He earned a Bachelor of Science in Mathematics and a Master of Arts in Education from Truman State University in 2002 and 2004, respectively. For nine years, he taught high school mathematics in Centralia, Missouri. For the next four years, he was the Director of Curriculum and Instruction for Centralia R-6 Schools while also teaching part time. In January 2015, Seth began the Education Specialist in Education Leadership and Policy Analysis program at the University of Missouri-Columbia, completing that degree in August 2016. In July 2016, he became the assistant principal at Beulah Ralph Elementary School in Columbia, Missouri, which was set to open in August 2016. Seth was the assistant principal there for 3 school years before being hired as the building principal beginning with the 2019-2020 school year, a position he remains in presently. 